\title{
Gender Gaps in Time Use by Age Groups in Ten Industrialized Countries, 2005-2015
}

\author{
Joan García Román ${ }^{1}$; Pablo Gracia ${ }^{2}$ \\ ${ }^{1}$ Centre d'Estudis Demogràfics, Bellaterra, Spain \\ ${ }^{2}$ Trinity College Dublin, Dublin, Ireland
}

\begin{abstract}
This study uses largescale cross-national time-diary data from the Multinational Time Use Study (MTUS) $(\mathrm{N}=201,972)$ covering the period from 2005 to 2015 to examine gender differences in time use by age groups. The study compares ten industrialized countries across Asia, Europe, and North America. In all ten countries, gender differences in time use are smaller in personal care, sleeping and meals, followed by leisure time (including screen-based leisure and active leisure), and largest in housework, care work and paid work activities. Gender disparities in time use are higher in South Korea, Hungary, and Italy, followed closely by Spain, with moderate gender gaps in Western European countries like France and Netherlands, and lowest differences in Finland and Anglo-Saxon countries, including Canada, US, and the UK. Gender differences in housework and caring time increase from adolescence (10-17 years) to early adulthood (1829 years), showing strong gender gaps in early/middle adulthood (30-44 years), but narrow again during late adulthood (65 years or older). However, the age gradient in care work and housework is most pronounced in Italy and South Korea, being less prominent in Canada and Finland. Gender gaps in paid work are larger in early/middle adulthood (30-44) and middle/late adulthood (45-64), with strongest age gradients observed in the Netherlands and weaker gradients for the US. Gender differences in active leisure increase by age, especially in Southern European countries, while screen-based leisure shows more stable gender gaps by age groups across different countries. Overall, this study shows that age and gender intersect strongly in affecting time-use patterns, but also that the national context plays an important role in shaping gender-age interactions in time use allocation.
\end{abstract}

Keywords: Age; Cross-national; Gender; Life course; Time use

* Corresponding author: jgarcia@ced.uab.es; All authors contributed equally to this work. 


\section{INTRODUCTION}

The last decades have seen remarkable progress towards gender equality in how men and women spend time in multiple activities. Since the 1970s women have entered massively into the labor force, while men have significantly increased their participation in domestic tasks, especially in childcare activities [1]. However, research reveals that women remain more actively involved than men in housework and childcare, and less active in employment, leading to women's disadvantages in income, health, and stress levels $[2,3]$. Previous studies found that gender gaps in time spent on paid work and domestic chores augment during early adulthood and early/middle adulthood, which are life stages when partnership and parenthood transitions are most common [4-9]. While gender differences in time use across parenthood transitions have been well documented, the role of national contexts in shaping gender differences in daily activities across the whole life course (e.g., by age groups) remains poorly understood.

To our knowledge, only one study has systematically examined gender gaps in time use across age groups in cross-national perspective [10]. Using 1998-2004 time-diary data from individuals aged 18 or older in some selected Western European countries and the United States, Anxo et al. (2011) [10] found that countries with more active gender egalitarian policies and norms (i.e. Sweden) are more effective at reducing motherhood penalties in (un)paid work time during early and mid-adulthood, compared to countries with more gender traditional contexts (i.e., Italy). This study implies that national contexts can play a central role in shaping gender-age interactions associated with time-use patterns. While the mentioned study makes a relevant contribution, it only includes data from Western Europe and the US and uses surveys restricted to the late 1990 s and early 2000 s and excluding non-adults (i.e., children, teenagers) from the analyses. Also, the study by Anxo and colleagues [10] focuses only on three broad activities (employment, domestic work, and leisure in general), missing a rich variety of important activities to understand individuals' well-being, including not only a differentiation between housework and care work, but also other key activities for individuals' well-being and health like exercising, sleeping, eating or intellectual activities. These gaps motivate new research using more recent time-use data, adding previously excluded countries and regions, and focusing on multiple activities from childhood to late adulthood. 
Our study contributes to the literature with a new cross-national analysis of gender differences in time-use allocation across age groups. To do so, we examine high-quality harmonized time-diary data from 2005 to 2015 across ten industrialized countries encompassing Asia, Europe, and North America. Drawing on the gender regimes literature, we hold that countries with different cultural, ideological and policy characteristics create different conditions for the development of power relations between men and women $[11]^{1}$ We argue that countries with different gender regime types may differ in the relative opportunities that society offers to men and women to use their time across age groups. Countries with stronger gender egalitarian policies and norms exhibit high levels of gender symmetry in activities like paid work, domestic labor, and leisure [5, 13-18]. Additionally, gender differences in time use may be less subject to age-specific stages from early to late adulthood in more gender egalitarian countries (i.e. Nordic countries like Finland; Anglo-Saxon countries like Canada), where family policies and gender norms provide support to both men and women to engage in similar time-use arrangements in those ages with high family and caring demands, namely early/middle adulthood, when parenthood transitions are more extended [15-16]. By contrast, industrialized regions that are more gender unequal in their polices and norms, such as Southern Europe (i.e., Italy), East-Central Europe (i.e. Hungary) and East Asia (i.e., South Korea), may show particularly pervasive gender disparities in paid work, leisure or domestic work during early/middle adulthood, as these countries often have weaker institutions and social support to promote gender equal time-use arrangements targeting this demographic group.

Our cross-national study bridges the sociological and demographic literatures on time-use and lifecourse by analyzing gender differences in individuals' time use across age groups that range from childhood to late adulthood. Drawing on the life course perspective, which emphasizes the importance of time, context, process and meaning in individuals' development over the years [19], we analyze gender disparities in time use across five relevant age groups that capture distinct life-course stages in individuals' biographies which have been similarly applied in the human development and demographic literatures [20, 21]: (1)

\footnotetext{
${ }^{1}$ For a more recent critical discussion about gender regimes see [12].
} 
adolescence (ages 10-17); (2) early adulthood (ages 18-29); (3) early/middle adulthood (ages 30-44); (4) middle/late adulthood (ages 45-64); (5) late adulthood (aged 65 or older). Examining in what national contexts men and women adopt more (or less) similar time-use arrangement by ages helps to better understand the individual and societal dynamics of gender differences in lifestyles and daily routines across the life span. For reasons of space and focus, our study does not concentrate on other important indicators of the life course, such as being a parent versus being childless, living with parents versus having left home already and being partnered compared to being single. However, we conduct analyses that intersect age and gender which control for important markers of the life course, such as family structure and number of children. Age is a crucial life-course marker to study individuals' time-use allocation. Age is a measure that allows us to assess how a universally comparable biological marker relates to different gendered patterns in time use allocation, but also whether these gender-age interactions are more or less similar or stable depending on the national context.

Our study makes three main contributions to the international literature on gender differences in time use by considering both the absolute (total time) and relative (percentages) gender gaps across all countries of study. First, unlike previous studies, we use the most recent data available from the Multinational Time Use study (MTUS) between 2005 and 2015 for ten countries, encompassing regions that have been omitted in previous comparative literature, such as East-Central Europe (i.e., Hungary), and East Asia (i.e., South Korea), besides Western Europe, North America, and Southern Europe. Second, unlike previous studies, we examine time-use patterns from adolescence (10-17 years old) to old age (65 years old and older). Third, unlike previous studies, we not only study paid work, housework, care work and leisure in general, but also focus on other key markers of men's and women's health and well-being over their life course: sleeping, personal care, eating and studying. Previous research has found that lacking enough sleeping time is associated with poorer health outcomes and mental well-being (22-26). Studies also found that time spent in physical and active leisure helps to prevent pathologies and mental health problems, while more sedentary leisure - particularly high levels of screen-based leisure- has been found to be associated with physical and mental health problems, especially among the younger cohorts $(24,27$, 
28). Overall, our study adds to the scarce literature on gender gaps in time use across age groups by adding a cross-national approach on multiple activities with different well-being implications.

Globally, this study demonstrates the importance of national context in shaping age-gender interactions that define individuals' time-use patterns over the life course. Our study represents a clear example of how using precise time-diary data provides unique understandings of the role of societal contexts in shaping how age impacts the way men and women engage in activities that are essential to understand differences in health, well-being or income across countries. These time-use differences are crucial to inform debates on gender inequalities across policy and cultural contexts.

\section{DATA AND METHODS}

We use data from the Multinational Time Use Study (MTUS), the largest openly accessible nationally representative harmonized time diary survey database that provides data comparable across time and space [29]. Time-diary data are considered the most precise and robust statistical sources available to measure individuals' behavior [e.g., 30, 18]. Time-use diary surveys provide nationally representative samples of comprehensive, continuously-registered, records about the activities of daily life [31]. The data were obtained from the MTUS-X extract system (www.mtusdata.org), allowing us to personalize the selection of samples and surveys [32]. We obtained large diary data collected between 2005 and 2015 from ten industrialized countries representing different gender regimes $(\mathrm{N}=201,972)$. Appendix 1 shows a summary of our sample. The selection of countries is both strategic and practical. From a strategic point of view, we are interested in countries that have different social, cultural, and policy environments to explore the macrolevel determinants of gender differences in time use. From a practical point of view, we are limited by data access. Not all countries that carried out time use surveys are available in the MTUS and access to multiple surveys is either restricted or challenging in terms of data harmonization. Drawing on previous crossnational frameworks on gender attitudes and work-family policies [e.g., 13, 17, 18], our ten countries can be integrated into six clusters:

- Anglo-Saxon: Canada (2010), United Kingdom (2014), United States (2010)

- East Asia: South Korea (2009)

- East-Central Europe: Hungary (2009) 
- $\quad$ Nordic Europe: Finland (2009)

- Southern Europe: Spain (2009), Italy (2008)

- Western Europe: France (2009), Netherlands (2005)

We created twelve groups of activities across a random 24-hours day from the time diaries, adding the average number of daily minutes devoted to each activity. The aggregated variables are created according to the main activity reported in the diary. The list of activities and the main activities and codes considered in each group are as follows ${ }^{2}$ :

- $\quad$ Sleeping (codes 2-3): Sleeping, naps, imputed sleep.

- Personal care (codes 1 and 4): Washing up, dress, care for self, imputed personal.

- Meals (codes 5-6): Meals, snacks.

- Paid work (codes 7-9, 11-13): paid work at main or second job, travel as part of work, work breaks.

- Study (codes 15-17): regular schooling, homework, leisure or other education or training.

- Housework (codes 18-27): food preparation, cooking, setting the table, washing dishes, cleaning, laundry, ironing, clothing repairs, maintaining home or vehicle purchase goods, consuming personal care services, pet care.

- Care for others (codes 28-32): physical and medical childcare, teach and help child with homework, reading to, talking or playing with child, supervise, accompany a child, adult care. ${ }^{3}$

- Active leisure (codes 42-47): general sport or exercise, walking or cycling, other outside recreation, walking with pets.

- Screen-based leisure (codes 59-61): watch TV, video or dvd, computer games, e-mail, surfing the internet or computing.

- Other Leisure (codes 33-41 and 48-58) ${ }^{4}$ : voluntary activities, worship and religion, general out-ofhome leisure, attend sports events, cinema theatre, opera, concerts, other public events, restaurant, cafe, bar, pub, party, social event, gambling, , receive or visit friends, conversations, games, general indoor leisure, art or music, correspondence, knit, crafts or hobbies, relax, think, read, listen to music or radio,

- Travel (codes 62-68): travel to/from work, voluntary travel, child/adult care travel, other travel

- Other activities (code 10, 14, 69)

\footnotetext{
${ }^{2}$ We have excluded time in travel and other activities from the more detailed analyses of our study. There were not significant differences in these activities across countries throughout a full random day of 24 hours (1440 minutes).

${ }^{3}$ We include all types of activities of care for others within one category. We acknowledge that each type of care (e.g., care for adults versus care for children) has a different nature and implications for the person who does the activity. We decided to integrate all care as a single activity for reasons of space, but also because the average minutes allocated to caring for adults and the proportion of respondents who engaged in this activity is low.

${ }^{4}$ Other leisure includes social and cultural activities as well as those leisure activities that are not specified enough to be classified in the more detail leisure categories.
} 
Our analyses focus on five age groups that, as explained above, generally correspond to meaningful stages of the life course across industrialized countries, which have been previously associated with gendered lifecourse stages over the life course:

- $\quad$ Age: $10-17^{5}, 18-29,30-44,45-64,65$ and older

We present general average measures by age, gender and country ${ }^{6}$. First, we show the general average time (daily minutes) allocated to each activity over the day (1440 minutes). Second, we show the average time for each activity by country and age group. Third, we explore gender gaps in each activity of interest by using the following formula of time-use gender ratio (33-34):

Gender relative ratio $=\frac{\text { Men's Time }- \text { Women's Time }}{\text { Men's Time }+ \text { Women's Time }}$

The time-use gender ratio shows differences between men and women in time use. It goes from -1 (when women do all time in the specific activity) to 1 (when men do all time). Positive values mean that men spend more time in the activity, with negative values indicating that women spend more time in the activity. The value 0 indicates no gender differences in time use. Averages correspond to the average by week including weekends and weekdays. To compute averages, we have used the proposed weights (PROPWT) provided by the MTUS to rescale the population and day of the week. Applying weights is necessary in time use surveys when weekdays and weekend diaries are integrated within the same analyses. Weights correct for the overrepresentation of weekends respondents in some surveys and imbalances in the population's structure by age, gender and employment status. There are not missing values in the

\footnotetext{
${ }^{5}$ For Canada and the United States, the 10-17 age group includes the ages of 15-17, as there are no data available for younger individuals in these two countries. For the rest of countries, we add all ages from 10 to 17 years.

${ }^{6}$ In additional analyses (not shown) we have computed multivariate OLS models controlled for basic demographics (i.e. education, employment status). Results were generally in line with our main findings. We decided to take out these controls from the model, which partly condition our estimations. For example, countries differ in female employment policies, which affect gender differences in employment status, and this in turn contributes to explain the gender gap in time use).
} 
harmonized variables used in our analysis, although there might be some imputation in the procedures to create the harmonized files that the MTUS-X provides.

Finally, we conduct multivariate analyses to estimate gender differences in the time spent on each activity within country and age groups. Using Ordinary Least Squares (OLS) regression, we run 500 models (10 activities $* 10$ countries $* 5$ groups of age $=500$ regressions $)$ so that each coefficient (500 in total) presents the differences between men and women in estimating activity $\mathrm{X}$ within the same country and age group. We are not running Compositional Data Analysis, as we are not combining multiple activities within the same statistical model, but rather estimate each activity separately (35-39). Previous studies show that OLS regressions are robust estimation techniques for cross-sectional observational time-diary data and a better alternative than Tobit regressions (40). In these final analyses, we start by presenting the coefficient and significance test of gender on time use for each group and country, after controlling for day of the week. Subsequently, we reproduce the analyses of the effect of gender on time use, adjusting for socioeconomic and demographic factors in each model. We are limited by the harmonized variables in the original dataset, especially for the group 10-17, but we can use the following sociodemographic controls:

- Educational attainment: respondent is under18 or value is missing, less than secondary, completed secondary, above secondary

- Employment status: employed or not employed

- Couple status: in union or not

- Children status: respondent is under 18, without coresident children in the household, coresident children under 5 years old in the household, coresident children 5-17 household. ${ }^{7}$

Finally, we run several tests to check the necessary assumptions to conduct OLS regressions, including checks of homoscedasticity and multicollinearity in all OLS regressions. Analyses suggest that parameters to run OLS regressions are correct. For all models obtained, we run tests in Stata, using vif and imtest commands. Moreover, the number of observations in all regressions is large enough to assume normality in the data (see annex 1 to check our sample sizes).

\footnotetext{
${ }^{7}$ Note that we refer to coresident children who may not be the respondent's children.
} 


\section{RESULTS}

\section{Description of Gender Differences in Time Use in Ten Countries}

Figure 1 presents the average daily minutes in each activity by country, separately for men and women. The total time is 1440 minutes, that is 24 hours. Estimates correspond to the average time of the overall population in each country. We only report differences for our ten activities of study, without discussing differences in travelling and 'others.'

Figure 1 shows that men spent more time than women on paid work and also, even with smaller gender differences, on leisure activities, particularly in relation to active and screen-based leisure. Women allocated more time to housework, caring and -to a lesser extent- personal care. Patterns in sleeping time, study and meals were similar by gender. More important, the magnitude of gender gaps in time use differed remarkably across countries.

FIGURE 1 ABOUT HERE

TABLE 1 ABOUT HERE

TABLE 2 ABOUT HERE

In Figure 1, we observe small gender differences in sleeping time. Sleeping takes between 8 and 9 hours, with a maximum of 8 hours and 45 minutes for women in Italy (one minute more than Spanish men and US women) and a minimum of 7 hours and 54 minutes for both genders in South Korea. Time in personal care differed remarkably across countries, ranging from 79 minutes for Hungarian men (75 for women) to 33 minutes for Canadian men (46 for women). Gender differences in personal care seem slightly higher in Anglo-Saxon countries and Finland (women spend around 1.4 and 1.3 times more than men, respectively) than in the other countries. For meals, French, Spaniards, and Italians spent the highest amount of time (about 2 hours 15 minutes in France, 1 hours 45 minutes in Italy and 1 hour and 40 minutes in Spain), and Americans, Canadians, and the Dutch the least. However, gender differences in eating time were generally small in all countries. 
Figure 1 shows clear gender gaps in paid work time and domestic work across countries. For paid work, the most active men were South Koreans (253 minutes) and the least active ones were the Finnish (166 minutes). For women, Americans and Canadians were the most involved in paid work, with 165 and 161 minutes respectively, and Italians the least (95 minutes). Finland, France, Canada, and US had the lowest gender gaps in employment activities, and Italy, Spain and South Korea showed the largest paid work gender gaps.

As for housework, men in South Korea (31 minutes) were the least active and men in France (118 minutes) and Canada (115 minutes) the most active (see Figure 1). For women, the Italian spent the highest amount of time in housework (226 minutes) and South Koreans and Americans the lowest (155 minutes and 152 minutes, respectively). Gender differences in housework were largest in Southern Europe, Hungary, and South Korea and lowest in Anglo-Saxon countries and Finland. Regarding care time, American women showed the highest average time, whereas South Korean presented the lowest involvement in care work (10 minutes). Gender gaps in time allocated to caring activities were highest in South Korea and smallest in Finland.

For leisure activities, we observed the highest averages of time for screen-based activities and the lowest in active leisure. For screen-based leisure, the highest averages were observed among males in UK (199 minutes) followed closely by males in Finland, Hungary and the US (between 190 and 188 all). Among females, the US shows the highest average minutes allocated to screen-based activities (163 minutes). Time on screen-based leisure is lowest among the Dutch (128 minutes for males and 98 minutes for females) (see Figure 1). For active leisure we found the highest averages in Spain (69 minutes for males and 44 for females, respectively) and the lowest among Hungarians (21 minutes for males and 11 for females). While gender differences in screen-based time were largest in Finland, Netherlands and the UK (and lowest in South Korea and the US), gender gaps in active leisure were largest in the US (and smallest in Finland).

Study time showed values close to zero, as most adults did not engage in these activities. South Korea was by far where people spent more time of study ( 1 hour and 30 minutes for men; 1 hour and 21 
minutes for women). The lowest means of study time were found for France and the United States, with a minimum of 13 minutes for French men.

\section{Unadjusted Relative Gender Gaps in Time Use by Age Groups and Countries}

Figure 2 presents the average time spent by men and women in each activity by age groups across countries. While the direction of patterns by age groups were quite similar across all ten countries, the magnitude of these gendered gaps differed cross-nationally. In Table A2 we present the percentage of people who have participated in each activity by age, gender and country. There are some activities such as sleeping, personal care and meals for which the average time was generally flat by age and gender, even if time on meals tended to increase for the older demographic groups (i.e., 45-64; 65 or older). For studying, not surprisingly, the highest averages appeared in the 10-17 age group, followed by the 18-29 group, while afterward the average study time was almost zero for both men and women. Participation rate in studying activities in adult population was very low and, as a result, the average was low too, as visible in Table A2. As mentioned, South Korea was an outlier in study time, with very high average minutes among both boys and girls. Time in personal care differs between countries, as mentioned already, but we observe an interesting stability within countries when comparing personal care across age groups.

\section{FIGURE 2 \& TABLE 3 ABOUT HERE}

For housework, women spent more time than men at all ages. For men, housework time increased with age (see Figure 2). For women, housework augmented up to middle adulthood, and then the pattern differed cross-nationally. In Southern Europe and South Korea, with more gender traditional norms, women's housework increased until the ages of 45-64 and decreased for the elderly. In Anglo-Saxon and Western European countries, women's housework time moderately increased for the elderly. Hungary exhibited a certain stabilization of housework time in old age $(45-64 ; 65+)$.

For paid work, we found an increase of time until the age group 30-44, a slight decrease in the 4564 age group, and more pronounced declines among the group aged 65 and older (see Figure 2). For men, 
this pattern was common everywhere. Yet, in South Korea, a long-hours working regime, the average of paid work for the group of 65+ was above 2 hours, and in Hungary 1 hour and 20 minutes. In the US and Canada, where retirement is not strongly supported by the welfare state, men aged 65 or older spent 53 and 45 minutes in paid work, respectively. By contrast, in EU countries where people retire early, such as Spain, France and Finland, men in the eldest group spent less than 15 minutes in paid work. For women, we found important cross-national variations in women's paid work across age groups. In some countries, women's paid work for the 30-44 and 45-64 age groups were similar or even higher for the older group, as in South Korea, Finland and Anglo-Saxon countries. In the Netherlands, women aged 18-29 were the most active in paid work (186 minutes, one minute more than US women). However, Dutch women were the least active in paid work across all ten countries within the 30-44 age group (163 minutes). This pattern shows the institutionalization of short part-time employment among Dutch women in this age group.

For screen-based leisure, the age progression in time use showed a U-shape for both men and women, with a reduction of time for the 30-44 age group and largest amounts of time for the youngest and eldest groups (see Figure 2). The highest amounts of screen-based time were globally found in the group of age 65 and older, especially in the US. For active leisure, time-use patterns differed across countries. In the Mediterranean countries, averages were quite constant in both the youngest and middle-age groups and increased among older groups. In Anglo-Saxon countries, averages decreased for the adult age groups and went up among the late-adulthood groups, but not as much as in Mediterranean countries. South Korea shows the lowest averages for active leisure among the youngest groups, with a subsequent increase for the older groups, while Hungary shows the lowest averages across all age groups. Men spent more time than women in both active leisure and screen-based leisure in all countries and age groups.

Finally, regarding caring activities, the general pattern showed an inverted U-shape, but especially so among women (see Figure 2). The age group 30-44 was the most active in care activities in all countries. For the US, Women in the group 18-29 were very active in caring activities with an average of 80 minutes, rising to almost a hundred in the group 30-44. Men in Italy and South Korea remained little involved in care work, even during the 30-44 age groups, when care needs are highest. For the eldest group (65 or 
older), both Spanish men and women were the most active in care work, with men and women in AngloSaxon countries being the least involved in these activities (only 4 minutes for both genders).

\section{Unadjusted Relative Gender Gaps in Time Use by Age Groups}

Figure 3 shows the relative gender gaps in time use by activity and age across countries. We show a gender ratio indicator that ranges from -1 (women did all the time in the activity) to +1 (men did all the time in the activity). Relative gender gaps were strongest for domestic work, paid work and, to a lesser extent, leisure. For screen-based leisure, the gender gap indicator was almost flat across age groups, with men spending more time across the different groups of age. Gender gaps in active leisure were also positive and higher for children and the older population groups.

\section{FIGURE 3 \& TABLE 4 ABOUT HERE}

In the case of paid work, relative time-use gender gaps differed across ages and countries (see Figure 3). Gender gaps were largest and more different cross-nationally within the extreme age groups (1017 and 65 and older). Yet, these results need to be taken with caution, as very few people engaged in paid work at these opposite groups of age. Gender gaps in paid work time were flatter in the age groups between 18 and 64, except for Italy and the Netherlands where the indicator took higher values, with men engaging disproportionately in paid work (around +0.35 ).

For housework, changes across age groups were most evident in South Korea, Southern Europe (especially Italy) and Hungary (see Figure 3). In all groups, women did more housework, regardless of age. During early and middle adulthood (i.e. ages $30-44$ ) the indicator took values that got closer to -1 , that is women doing more housework, particularly in Italy and South Korea. Finland and Canada showed lower relative gender gaps in housework time. As for caring work, the higher gender gaps corresponded to South Korea across most age groups, with gaps ranging between -0.75 and -0.25 among adults. Gaps for the 1017 age group seemed sensitive to low participation rates, meaning that results for the youngest group need to be taken with caution. 
Finally, for personal care, women did more of it across countries and ages (negative values), with cross-country differences increasing at the age of 65 or older, showing gaps in favor of women in Canada and the US (around -0.1 ), but interestingly in favor of men in Hungary $(+0.08)$ (see Figure 3). Differences in study time were largest for the older groups, even if study time was rare for the elderly. Interestingly, for the 30-44 age group, the US presented the largest gender gaps in study time (women did more of it) and for the 65 or older group (but here men did more of it). Gender gaps in sleeping and meals remained around 0 in all ten countries.

\section{Regression Analyses}

Figure 4 presents the results of the regression analyses. In Panel A, we present the statistical association between gender and time use for our ten activities of study and with separated models for each group age and country, without adding demographic and socioeconomic controls, and only controlling for day of the week. In Panel B, we present the same analyses, adding also a control of day of the week, but in this case we control for multiple socioeconomic and demographic variables, including education, employment status, union status and number of children at home. Combinations in grey denote the coefficients that are not significant at $95 \%$ level of significance. All coefficients and levels of statistical significance are presented in Table A3 and Table A4.

\section{FIGURE 4 ABOUT HERE}

Figure 4 shows clear differences in the intersection of age, gender and country in predicting variations in time use. Panel A shows a very similar picture to the one presented in Figure 2, showing clear gendered patterns across age groups in housework, work and leisure, where the gender coefficients are statistically significant $(\mathrm{p}<0.05)$ in most countries and age groups, but with some exceptions where gender differences are not statistically significant, including the ages 10-17 for paid work (Canada, Finland, South Korea, Spain, UK, US) and for leisure the Netherlands (ages 45-64 and 65 and older) and France (ages 10-17). For housework, the gender gap is statistically significant $(\mathrm{p}<0.05)$ in all countries and age groups, but the gaps 
are stronger in Italy, South Korea and Spain for the age groups 30-44, 45-64 and 65 and older, with the most gender unequal division of housework being observed among Italians for the age group 45-64. Higher gender gaps in paid work are in population in the group of age 30-44, whereas Netherlands and South Korea present the higher coefficients. For screen-based leisure, we observe the highest gender gaps in the extreme age groups (10-17 and 65 and over), while the US was the country with larger gender gaps. For active leisure, the highest gender gaps were found in the group 65 and older, while Spain and Italy were the countries where these gaps were largest.

Panel B of Figure 4 shows that, when socioeconomic and demographic controls are added, the picture of gender differences in time use by age groups shows only some minor changes. The inclusion of controls increases the magnitude of the gender gap in housework, particularly for the population aged 45 and older. On the contrary, gender gaps in paid work generally decrease after adjusting for demographic factors, especially for the age group 30-44. The 30-44 age group includes a high proportion of population living in union with children, and so these demographic controls globally attenuate the relationship between gender and time spent in employment. Regarding leisure, the inclusion of controls leads to a certain increase in the strength of gender gaps in all ages for both active and screen-based leisure. However, we do not observe important changes in the level of significance for these coefficients. Largest changes are observed in screen-based leisure for the older group, with an increase of gender-gaps in all countries. In the case of active leisure, gender gaps in time use increased for the group 45-64 in all countries.

Overall, despite some minor differences between Panel A and Panel B in Figure 4, adding control variables does not generally alter the relation between gender and age in individuals' time use across countries.

\section{Additional Analyses}

We conducted additional analyses that control for retirement in the older groups of study. We did this by differentiating in the analyses between unemployed, employed, and retired people for our two older groups: ' 45 to 64 years old' and ' 65 years old or older'. First, Figure A1 adds the category retirement compared to unemployed within our multivariate statistical framework, controlling for all other variables of study, 
including being employed too. These analyses exclude Finland due to having no data on retirement status for this country. Results for the other nine countries reveal that, when differentiating between pensioners, employed and unemployed as controls, observed gender differences in time use remain unchanged.

Second, we conducted additional analyses to compare differences in time use between retired people and unemployed respondent, also adding a coefficient of being employed, controlling for various demographic factors, including age, gender, and country of study, again excluding Finland from the models. In Table A6 we observe some net differences between unemployed and retired people. For the age group of 45 to 64 years old we find that, compared to the retired, the unemployed spent 2 minutes less eating, 12 minutes more in housework, 21 minutes less on physical care, 16 minutes less on non-screen leisure, 1 minute less studying, and 26 minutes more in paid work $(p<0.05)$. Differences between retired and unemployed individuals for this age group were not statistically significant for care work, screen-based leisure, personal care, and sleeping. The observed differences between the unemployed and retired in paid work capture that retired people in the 45-64 age groups may have access to a pension. By contrast, the unemployed may eventually have to engage in casual paid work activities to make ends meet (typically through informal activities), particularly when unemployment benefits are limited or unavailable. However, we must stress that additional analyses (not shown) reveal that the proportion of unemployed people who spent some time in paid work in our sample is very low.

For the group of 65 years or older, differences between become statistically insignificant for meals, while we observe that the unemployed slept 8 daily minutes more than retired respondents $(p<0.05)$, net of all demographic controls. We interpret these results as a sign that retirement is associated with different life conditions compared to being a non-retired non-working person (e.g., unemployed people may have to engage more frequently in informal work activities than pensioners to make ends meet) or due to selection (e.g., unemployed people may have a more disadvantaged socioeconomic background than pensioners). Understanding these specific mechanisms goes beyond the scope of the present study.

Future studies should further address such interesting differences by carefully analyzing the interplay between gender, age, and country, considering existing variations in retirement and work policies 
related to gendered time-use patterns. Unfortunately, we cannot specifically focus on the phenomenon of retirement for reasons of focus, space, and incomplete data on retirement for some countries. However, and crucially, additional analyses reveal that, after controlling for retirement in our models, the observed country and gender differences in our main analyses remain the same. Therefore, the main results of this paper remain do not change irrespective of whether we control for being a pensioner or not.

\section{DISCUSSION}

This article provides an exhaustive large-scale study of gender differences in time-use across age groups, using recent high-quality data across ten industrialized countries spanning the regions of Asia, Europe and North America. We make three key contributions to the international cross-national time use and gender literatures by (i) examining detailed time-diary data from childhood to old age, (ii) studying eight activities with key well-being implications, and (iii) showing age-specific gender gaps at both absolute (minute gap) and relative levels (percentage gaps). Our results clearly indicate that gender differences in time use differ by activities and across age groups. Yet, the magnitude of these gender-age interaction differs remarkably across countries with different policy contexts and gender norms.

First, our study shows that gender gaps in time use are small in essential activities such as sleeping and meals, moderate in leisure time, and highest in paid work (with men doing more of it) and domestic work (with women doing more of it). Yet, these gender gaps were largest in South Korea, Hungary and Southern Europe (more in Italy than in Spain). Western Europe (i.e. France, Netherlands) showed intermediate gender gaps in time use. Anglo-Saxon countries (more in Canada than the US and UK) and Finland showed the lowest gender differences in time-use patterns. These cross-country findings add new relevant evidence on the most robust and recent available time-diary cross-country data on gendered time use patterns. Lower differences in more essential activities reveal that gender gaps increase in activities that are more gendered stereotypical (especially paid work and domestic work) and in activities that depend more on the remaining time after basic and mandatory activities are considered (leisure time).

Second, we found important cross-country gender variations in time use across age groups that represent key variations in lifestyles and life-course stages. Gender gaps in housework and care work were 
largest in the adult population over 29 and 44 years old, narrowing substantially among the elderly (from 65 years old onward). Italy, and especially South Korea, exhibited the largest gender gaps in domestic work, while Canada and Finland presented smaller gaps for these age groups in these activities. Furthermore, we found gender gaps in paid work to be largest during early/middle and middle/late adulthood (aged 30-44 and 45-64), and this was especially true for the Netherlands. Study time showed mixed patterns across countries and gender. Interestingly, both boys and girls in South Korea (ages 10-17) spent much more time studying than their counterparts in other countries, at the costs of their leisure time, showing an interesting finding to be explored in future literature.

Third, we conducted various statistical analyses to establish if findings are sensitive to demographic and socioeconomic factors. Our results generally remain stable when sociodemographic factors are considered, although factors such as the presence of children or being in a union moderate the association between gender and those activities where this association is stronger. Early/middle adulthood (ages 30-44) and middle/late adulthood (ages 45-64) are the ages where the gender gap in time use is most affected by the consideration of demographic and socioeconomic variables in the analyses, but the direction of this variation differs remarkably between activities and countries. Gender gaps in employment time decrease when controls are added, whereas they are larger in the case of housework. This fact indicates that gaps in housework work and paid work are strongly driven by family characteristics (e.g., parenthood transitions) [3], although we still observe persistent gender gaps in both domestic work and paid work across countries when such family characteristics are considered. By contrast, gender gaps in leisure activities increase after adjusting for sociodemographic factors, indicating that mechanisms of gender inequalities in leisure follow different patterns than those linked to paid work, care work and housework. This pattern is observed in all countries, although it is clearer in countries with overall higher gender inequalities, like Hungary, Italy, South Korea and Spain.

The findings of our study suggest that policy and cultural contexts can critically shape the opportunities that men and women encounter to engage in different activities with key well-being and health implications. We found some relevant cross-national differences in time use in activities such as sleeping 
and personal care, which are known to be associated with physical health and mental well-being [22-28], even if age-gender interactions for these activities did not differ cross-nationally. Yet, differences by country, age, and gender were significant when examining active leisure (a healthy activity to which women devote less time) and screen-based leisure (a potentially risky activity to which men devote more time) [2528]. These findings contribute to international debates on health and well-being.

Interestingly, personal care does not differ significantly by age in our analyses. It is important to clarify that all activities like washing up, dress up, care for oneself, but also doctor visits, are included as personal care. By contrast, being in the hospital to care for others, and related activities, would be care work. We cannot differentiate between time travelling to hospital and other traveling with our data. Thus, all types of traveling are included in the traveling category (see the methods section). We hope future studies will be able to further investigate these important questions with more detail.

In general, we show that the national context plays an important role in moderating existing timeuse gender gaps across the life course. We show that women in South Korean (an East Asian case), Italy (a Southern European case), followed by Hungary (an East-Central European case) and Spain (a Southern European case) are countries where women have higher constraints to spend time in non-domestic activities. Also, these gender gaps across countries are particularly strong in the ages associated with higher caring responsibilities (ages 30-44), with interesting patterns observed in specific countries. For example, Dutch women suffer the strongest paid work penalties of all countries from early adulthood (18-29 years old) to early/middle adulthood (30-44), capturing the institutionalization of female part-time employment in the country [41]. Contrary to less gender egalitarian countries in terms of gender politics and gender ideologies, Anglo-Saxon countries (and particularly Canada in our study) and Nordic European countries (i.e., Finland) reveal higher gender equality in time use than other countries, but especially regarding the most sensitive age groups with respect to gender inequalities (early/middle and middle/late adulthood). These results are important to situate public policy debates on the importance of targeting gender gaps in time use during early/middle adulthood, when risks of gender inequalities are highest, and particularly so in countries providing poorer support and resources to women in these age groups. 
Our study offers a new understanding of how gender and age intersect which contribute to recent cross-national studies on gender gaps in time use. Our results help to contextualize existing scholarship that indicates cross-country variations in life satisfaction and well-being by highlighting the importance of age in shaping these gender disparities in how men and women use their time every day [3]. Also, by bringing together a time-use and life-course approach, our study provides a picture that contributes to cross-national research that has often focused on very specific age groups separately, including childhood and adolescence [18], early adulthood [42] or late adulthood [43], while complementing exceptional older studies that adopted a similar approach to our study [10].

We should acknowledge four types of limitations in our study, despite our contribution to the gender, time use and cross-national literatures. First, this study only uses the age of individuals to follow the life course. Not all individuals are in the same conditions at a specific age and future research should add other transition factors (i.e., union status, parenthood, retirement) to capture better the differences in time use during the life course and explore the causes of gender inequalities across national contexts. Our study conducts multiple regression analyses controlling for several demographic variables on such lifecourse stages, with results remaining quite consistent after these adjustments are added. Age is an interesting variable because it is constant across the world, despite people aging differently across different regions of the globe. The fact that we find differences between countries when comparing the same age groups, but also some consistent patterns, does reflect the interest of examining age variations to understand gender differences in time use. Future studies should focus on other indicators related to the life course (not only age) and more closely inspect issues related to retirement and youth unemployment, which vary significantly across countries.

Second, this study is limited to cross-sectional data collected around 2010 and individuals in each group of age are not the same. The availability of longitudinal data would provide information of the same individuals at different moments of their life course and would improve the analysis of changes on time use throughout the life course. However, at this stage, high-quality longitudinal time-use data with rich 
measures from diary data are very scarce and limited to very few countries, which does not allow to conduct a large comparable cross-national analysis across various countries and regions.

Third, future related research should consider a 24-hour analytical framework by applying some alternative techniques that can more explicitly integrate all activities conducted over the day (Bauman et al 2019). Also, we must remember that activities are not fully comparable in terms of costs and benefits, which needs to be considered regarding the units of time. For example, the benefits of spending one hour exercising are not comparable to the benefits of spending one hour sleeping, as the latter is a much longer activity than the former. We hope future studies will ask similar questions than the ones we are asking in this study by adopting complementary methods that account for the nature of time-use tradeoffs that men and women face within a 24-hour context.

Fourth, this is an observational study that is subject to issues of selection and which does not have complete relevant information on demographic and socioeconomic variables. Our study presents multivariate analyses that adjust for employment status. This allows us to analytically disentangle the degree to which men and women differ in their time use after accounting for selection in employment. Yet, there may be other issues of selection that we cannot account for in our data (e.g. type of contract, specific occupation, employment trajectory) and that may still explain differences. This limits our ability to explain why gender differences in time use exist across age groups across the ten countries included in this study. Future studies should pay more attention to these issues by using surveys that, despite adding less countries and potentially poorer quality data on time use (e.g., some longitudinal surveys), do contain better data on employment trajectories and repeated observations to account for unobserved heterogeneity.

To conclude, and despite having some shortcomings that we acknowledge above, our study opens an important window to future studies and approaches on gender differences in time use. Future research should combine our approach with one that accounts for different periods to analyze the interaction between gender, age and time use, not only across countries, but also over recent decades by considering cohort and period effects $[18,44]$. For example, recent studies conducted during the COVID-19 pandemic lockdowns reveal persistent time use differences between women and men due to the new responsibilities derived from 
the COVID-19 emergency and temporary closure of schools $[45,46]$. Future studies will be able to cover these more recent years in relation to the age and gender interactions in time use allocation across countries. We hope scholars will further collect rich time-use data from new countries across policy and cultural contexts, especially from low- and middle-income countries. This way scholars will be able to offer new understandings of how national contexts shape gender differences in time use across age groups and to assert in which direction gender gaps in time use are moving to. 


\section{REFERENCES}

1. Goldscheider, F.; Bernhardt, E. \& Lappegard, T. (2015). "The gender revolution: A framework for understanding changing family and demographic behavior". Population and Development Review, 41 (2): 207-239.

2. Craig, L. (2006). Does father care mean fathers share? A comparison of how mothers and fathers in intact families spend time with children. Gender \& Society, 20(2), 259-281.

3. Gershuny, J. (2013). National utility: Measuring the enjoyment of activities. European Sociological Review, 29(5), 996-1009.

4. Baxter, J., Hewitt, B., \& Haynes, M. (2008). Life course transitions and housework: Marriage, parenthood, and time on housework. Journal of Marriage and Family, 70(2), 259-272.

5. Craig, L., \& Mullan, K. (2010). Parenthood, gender and work-family time in the United States, Australia, Italy, France, and Denmark. Journal of Marriage and Family, 72(5), 1344-1361.

6. Dribe, M., \& Stanfors, M. (2009). Does parenthood strengthen a traditional household division of labor? Evidence from Sweden. Journal of Marriage and Family, 71(1), 33-45.

7. Grunow, D., Schulz, F., \& Blossfeld, H. P. (2012). What determines change in the division of housework over the course of marriage?. International Sociology, 27(3), 289-307.

8. Gupta, S. (1999). The effects of transitions in marital status on men's performance of housework. Journal of Marriage and the Family, 700-711.

9. Sayer, L.C. (2010). "Trends in Housework" pages 19-38 in Dividing the Domestic: Men, Women, and Household Work in Cross-National Perspective, edited by Judith K. Treas and Sonja Drobnič, Stanford University Press: Stanford, CA.

10. Anxo, D., Mencarini, L., Pailhé, A., Solaz, A., Tanturri, M. L., \& Flood, L. (2011). Gender differences in time use over the life course in France, Italy, Sweden, and the US. Feminist Economics, 17(3), 159-195.

11. Orloff, A. S. (1993). Gender and the social rights of citizenship: The comparative analysis of gender relations and welfare states. American sociological review, 303-328.

12. Walby, S. (2020). Varieties of gender regimes. Social Politics: International Studies in Gender, State \& Society, 27(3), 414-431.

13. Craig, L., \& van Tienoven, T. P. (2020). Gendered Shares of the Family Rush Hour in Fulltime Dual Earner Families. A Cross National Comparison. Social Indicators Research, 1-21.

14. Esping-Andersen, G., Boertien, D., Bonke, J., \& Gracia, P. (2013). Couple specialization in multiple equilibria. European Sociological Review, 29 (6), 1280-1294.

15. Esping-Andersen, G., \& Billari, F. C. (2015). Re-theorizing family demographics. Population and development review, 41(1), 1-31.

16. Gracia, P., Garcia-Roman, J., Oinas, T., \& Anttila, T. (2021). Gender differences in child and adolescent daily activities: A cross-national time use study. Acta Sociologica, 00016993211008500 .

17. Hook, J. (2006). Men's unpaid work in 20 countries, 1965-2003. American Sociological Review, 71 (4), 639-660.

18. Kan, M. Y., Sullivan, O., \& Gershuny, J. (2011). Gender convergence in domestic work: Discerning the effects of interactional and institutional barriers from large-scale data. Sociology, 45(2), 234-251. 
19. Bengtson V.L., Allen K.R. (2009). The life course perspective applied to families over time. In: Boss P., Doherty W.J., LaRossa R., Schumm W.R., Steinmetz S.K. (eds) Sourcebook of Family Theories and Methods. Springer, Boston, MA.

20. Feldman, R. S. (2017). Development across the life span. Pearson Education, New Zealand. effects of social restrictions on COVID-19 behavioral infection risk. Plos one, 16(2), e0245551.

21. Medley, M. L. (1980). Life satisfaction across four stages of adult life. The International Journal of Aging and Human Development, 11(3), 193-209.

22. Kredlow, M. A., Capozzoli, M. C., Hearon, B. A., Calkins, A. W., \& Otto, M. W. (2015). The effects of physical activity on sleep: a meta-analytic review. Journal of behavioral medicine, 38(3), 427-449.

23. Foti, K. E., Eaton, D. K., Lowry, R., \& McKnight-Ely, L. R. (2011). Sufficient sleep, physical activity, and sedentary behaviors. American journal of preventive medicine, 41(6), 596-602.

24. Mochón-Benguigui S, Carneiro-Barrera A, Castillo MJ, Amaro-Gahete FJ. (2021) Role of physical activity and fitness on sleep in sedentary middle-aged adults: the FIT-AGEING study. Scientific Reports,11(1), 1-12.

25. Wahid, A. et al. (2016) Quantifying the association between physical activity and cardiovascular disease and diabetes: A systematic review and meta-analysis. Journal of the American Heart Association, 5(9), e002495.

26. Dumuid, D., et al. (2018). Compositional data analysis for physical activity, sedentary time and sleep research. Statistical methods in medical research, 27(12), 3726-3738.

27. Vizcaino, M., Buman, M., DesRoches, T., \& Wharton, C. (2020). From TVs to tablets: the relation between device-specific screen time and health-related behaviors and characteristics. BMC public health, 20(1), 1-10.

28. Bohnert, M., \& Gracia, P. (2021). Emerging Digital Generations? Impacts of Child Digital Use on Mental and Socioemotional Well-Being across Two Cohorts in Ireland, 2007-2018. Child Indicators Research, 14(2): 629-659.

29. Kolpashnikova, K., Flood, S., Sullivan, O., Sayer, L., Hertog, E., Zhou, M., \& Gershuny, J. (2021). Exploring daily time-use patterns: ATUS-X data extractor and online diary visualization tool. Plos one, 16(6): e0252843.

30. Gauthier, A. H., Smeeding, T. M., \& Furstenberg Jr, F. F. (2004). Are parents investing less time in children? Trends in selected industrialized countries. Population and Development review, 30(4), 647-672.

31. Gershuny, J., Sullivan, O., Sevilla, A., Vega-Rapun, M., Foliano, F., Lamote de Grignon, J., Harms, T. \& Walthery, P. (2021). A new perspective from time use research on the effects of social restrictions on COVID-19 behavioral infection risk. Plos one, 16(2), e0245551.

32. Fisher, K.; Gershuny, J.; Flood, S.; Backman, D. \& Hofferth, S. (2019) Multinational Time Use Study Extract System: Version 1.3 [dataset]. Minneapolis, MN: IPUMS. https://doi.org/10.18128/D062.V1.3.

33. Ajenjo, M.; García-Román, J. (2011) "El tiempo productivo, reproductivo y de ocio en las parejas de doble ingreso." Papers: revista de sociologia (2011): 985-1006. 
34. Gracia, P., Garcia-Roman, J., Oinas, T., \& Anttila, T. (2021). Gender differences in child and adolescent daily activities: A cross-national time use study. Acta Sociologica, 00016993211008500 .

35. Aitchison J (1982) The statistical analysis of compositional data. Journal of the Royal Statistical Society: Series B (1982), 44 (2): 139-177

36. Bauman, A., Bittman, M., \& Gershuny, J. (2019). A short history of time use research; implications for public health. BMC public health, 19(2), 1-7.

37. Dumuid, D., Pedišić, Ž., Palarea-Albaladejo, J., Martín-Fernández, J. A., Hron, K., \& Olds, T. (2020). Compositional data analysis in time-use epidemiology: what, why, how. International journal of environmental research and public health, 17(7), 2220.

38. Gupta, N., Mathiassen, S.E., Mateu-Figueras, G. et al. (2018). A comparison of standard and compositional data analysis in studies addressing group differences in sedentary behavior and physical activity. International Journal of Behavioral Nutrition and Physical Activity 15 (53):1-12.

39. Martín-Fernández, J.A., Daunis-i-Estadella, J. \& Mateu-Figueras, G. (2015). On the interpretation of differences between groups for compositional data". SORT-Statistics and Operations Research Transactions, [online], 39 (2): 231-252.

40. Stewart, J. (2013). Tobit or not Tobit?. Journal of economic and social measurement, 38(3), 263290.

41. Yerkes, M. (2009). Part-time work in the Dutch welfare state: the ideal combination of work and care?. Policy \& Politics, 37(4), 535-552.

42 Craig, L., Churchill, B., \& van Tienoven, T. P. (2019). Young people's daily activity in a globalized world: a cross-national comparison using time use data. Journal of Youth Studies, 1-22.

43. Sayer, L.C. \& Gornick, J. (2009). Cross-national variation in older adult's housework, active pursuits, and passive leisure. Social Indicators Research. 93: 215-218.

44. Fisher, K., Egerton, M., Gershuny, J. I., \& Robinson, J. P. (2007). Gender convergence in the American heritage time use study (AHTUS). Social Indicators Research, 82(1), 1-33.

45. Giurge, L., Whilans, A. \& Yemiscigil (2021) A multicountry perspective on gender differences in time use during COVID-19. Proceedings of the National Academy of Sciences, 118 (12) e2018494118; DOI: 10.1073/pnas.2018494118

46. Farré, L.; Fawaz, Y.; Gonzalez, L. \& Graves, J. (2020) How the COVID-19 Lockdown Affected Gender Inequality in Paid and Unpaid Work in Spain. IZA Discussion Papers, No. 13434, Institute of Labor Economics (IZA), Bonn. 


\section{TABLES AND FIGURES}

Figure 1 . Average time by activity. Men and Women by country

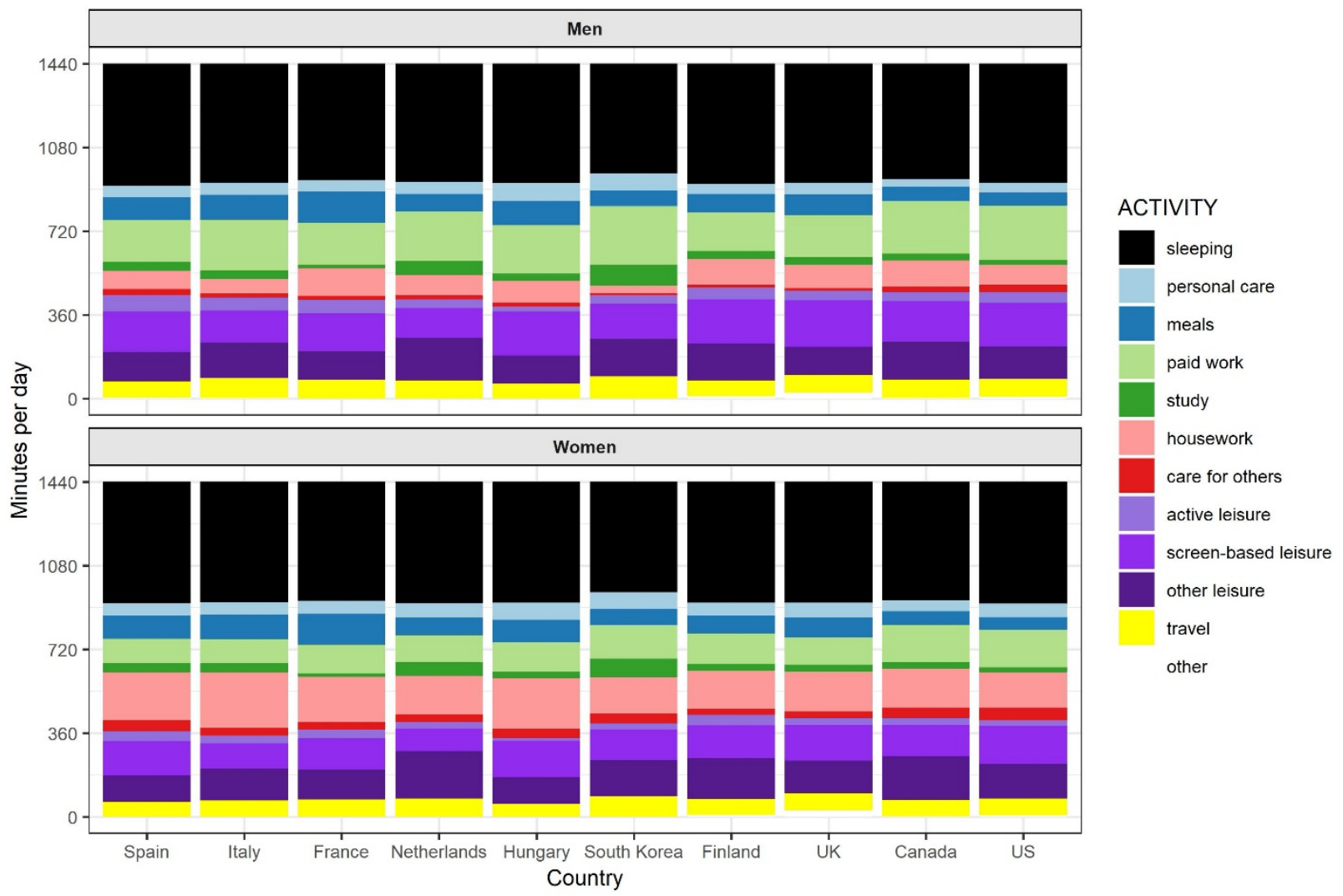

Source: Own calculations from the Multinational Time Use Study [32].

*Activities created from the variable Main activity: Sleeping (codes 2 and 3), personal care (1 and 4), meals (5 and 6), paid work ( 7 to 13, except 10), study (15 to 17), housework (18 to 27), care for others (28 to 32), active leisure (42-47), screen-based leisure (59 to 61), other leisure (33-41 and 48-58) (see methods section). Other two activities include: travel (codes 62 to 68), others (10, 14 and 69).

**Estimates of the figure available in Table 1. 
Figure 2 . Average time by activity and age. Men and women by country
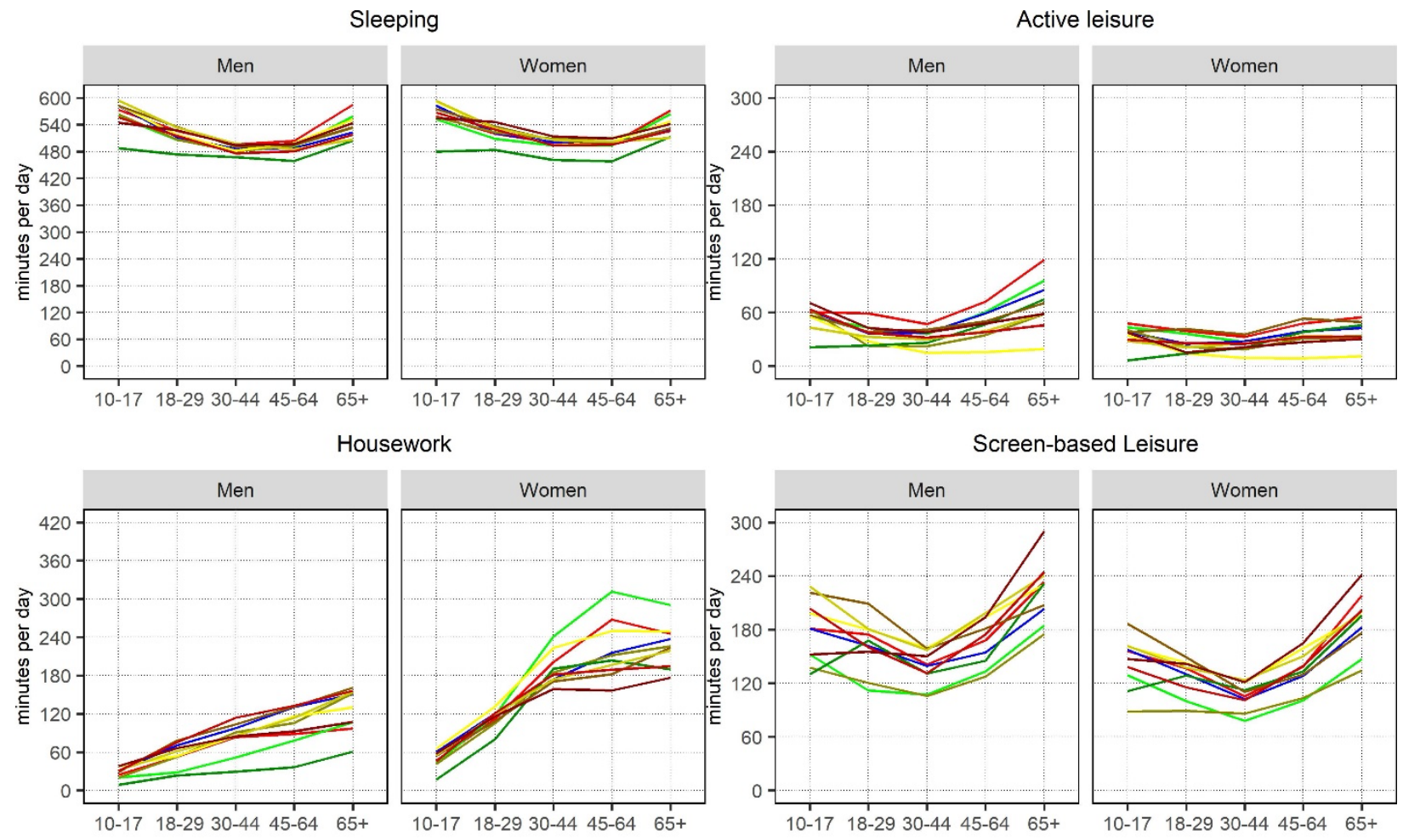

Paid Work
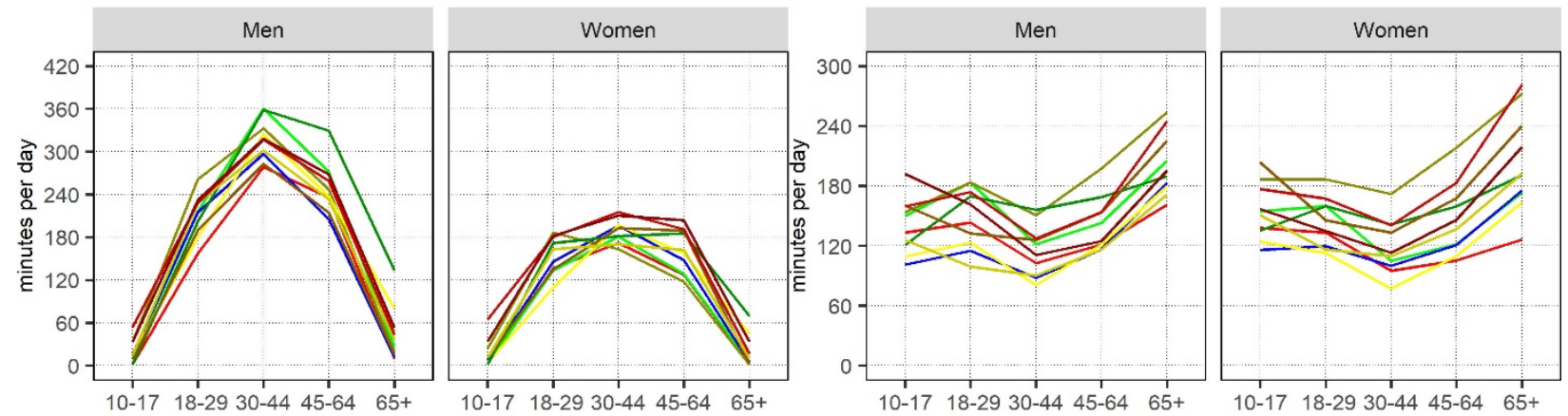

$$
\begin{aligned}
& \text { - Spain - France }- \text { Hungary - Finland - Canada } \\
& \text { - Italy - Netherlands - South Korea - UK - US }
\end{aligned}
$$

Source: Own calculations from the Multinational Time Use Study [32].

*Estimates of the figure available in Table 3. 
Figure 2. Average time by activity and age. Men and women by country (continuation)
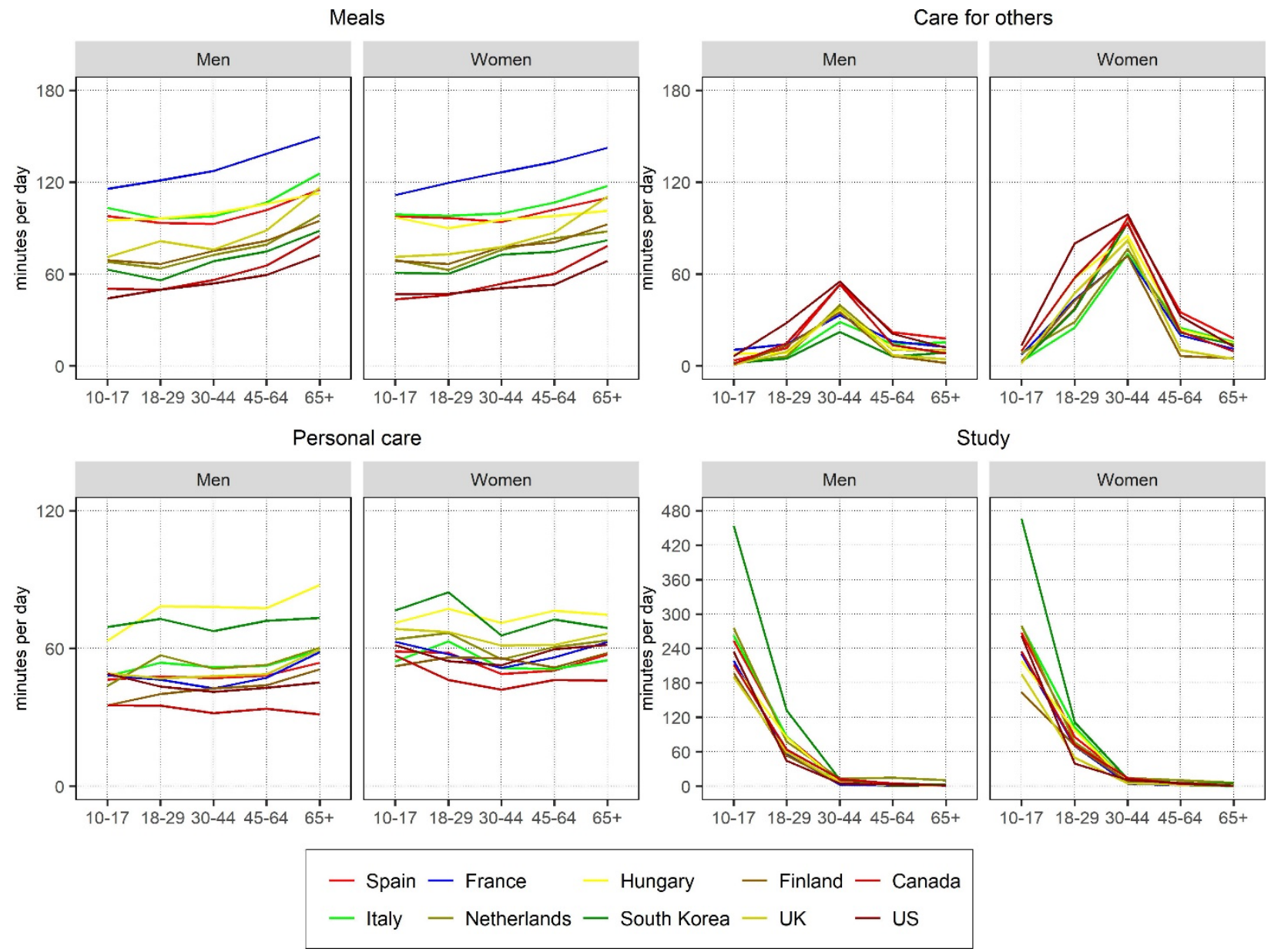

Study

Source: Own calculations from the Multinational Time Use Study [32].

*Estimates of the figure available in Table 3. 
Figure 3. Gender gaps in time use (Indicator from -1 to 1). Differences in activities by Age
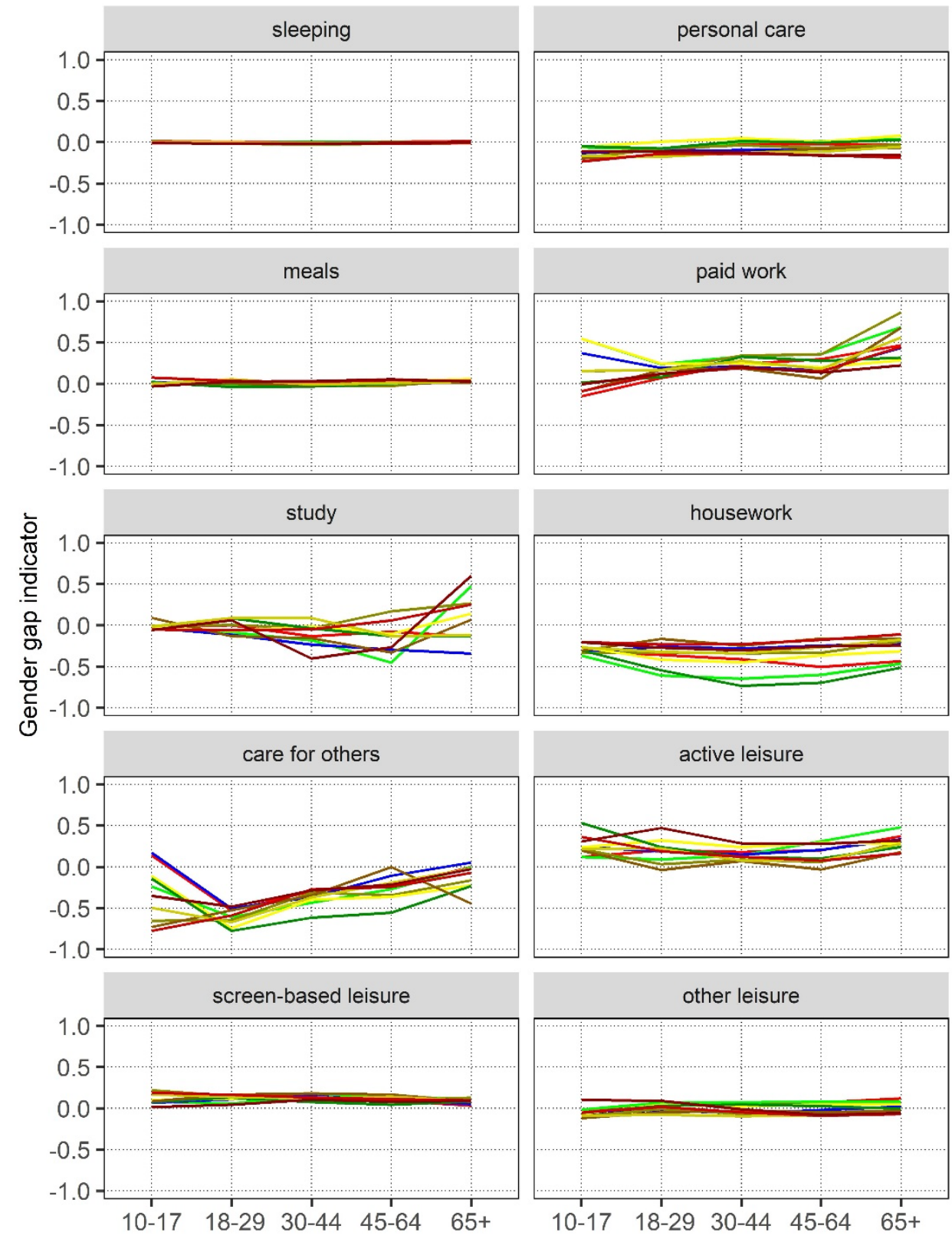

$$
\begin{aligned}
& \text { - Spain }- \text { France }- \text { Hungary }- \text { Finland }- \text { Canada } \\
& \text { - Italy }- \text { Netherlands }- \text { South Korea }- \text { UK }- \text { US }
\end{aligned}
$$

Source: Own calculations from the Multinational Time Use Study [32].

*Estimates of the figure available in Table 4. 
Figure 4. Gender Differences in Time Use.

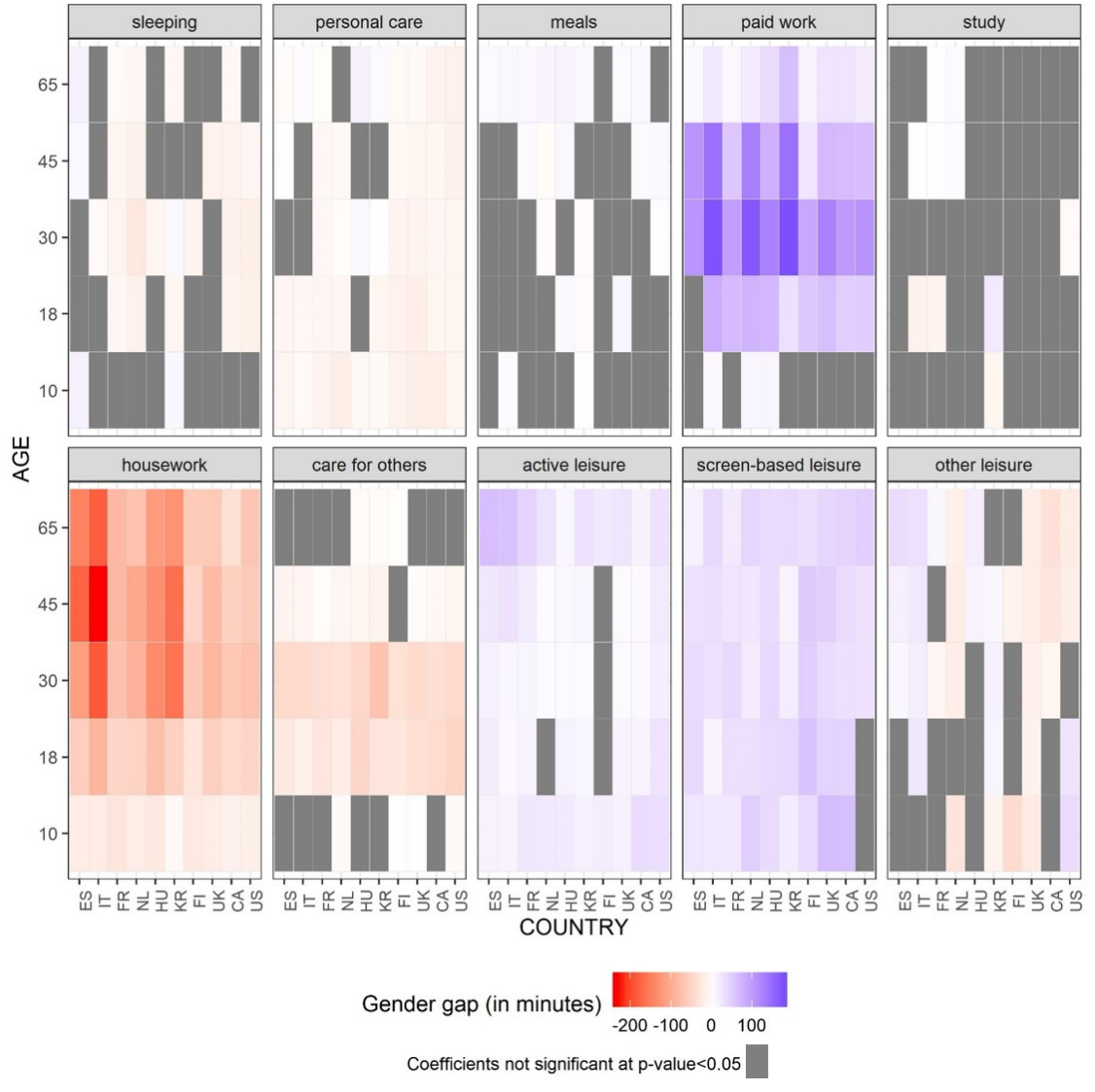

Panel A. Without Adjusting for Socioeconomic and Demographic Factors.

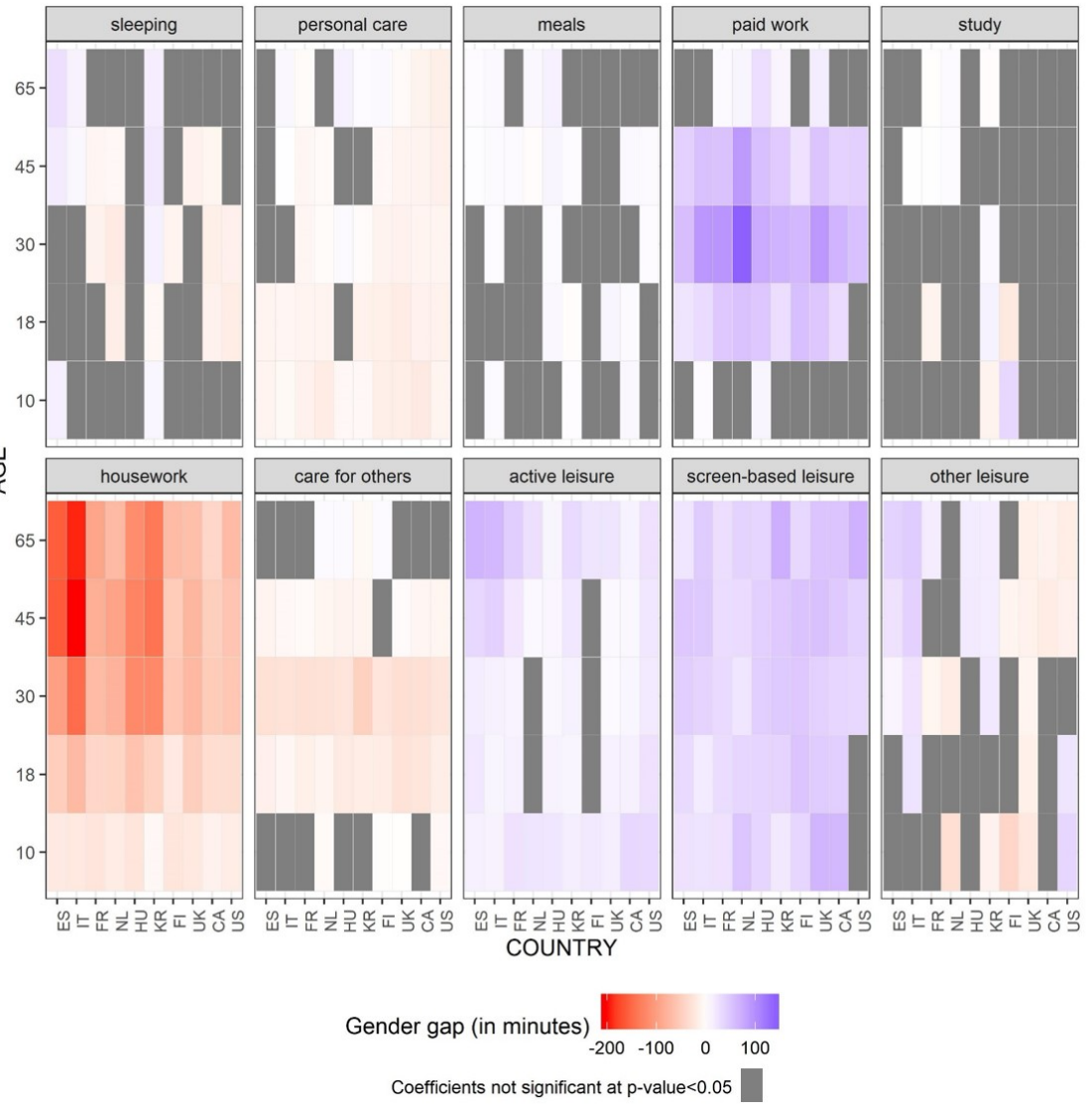

Panel B. Adjusting for Socioeconomic and Demographic Factors

Source: Own calculations from the Multinational Time Use Study [32].

Notes: Estimates for Panel A are available in table A3 and for Panel b in table A4. Estimates correspond to the coefficient for Category Men (ref=Women) from the OLS regressions by country and group of age. Panel A also control by day of the week. Panel B also control by day of the week, educational attainment, employment status, children in the household and union status. 
Table 1. Average time and standard deviation by activity. Men's and Women's daily minutes by country

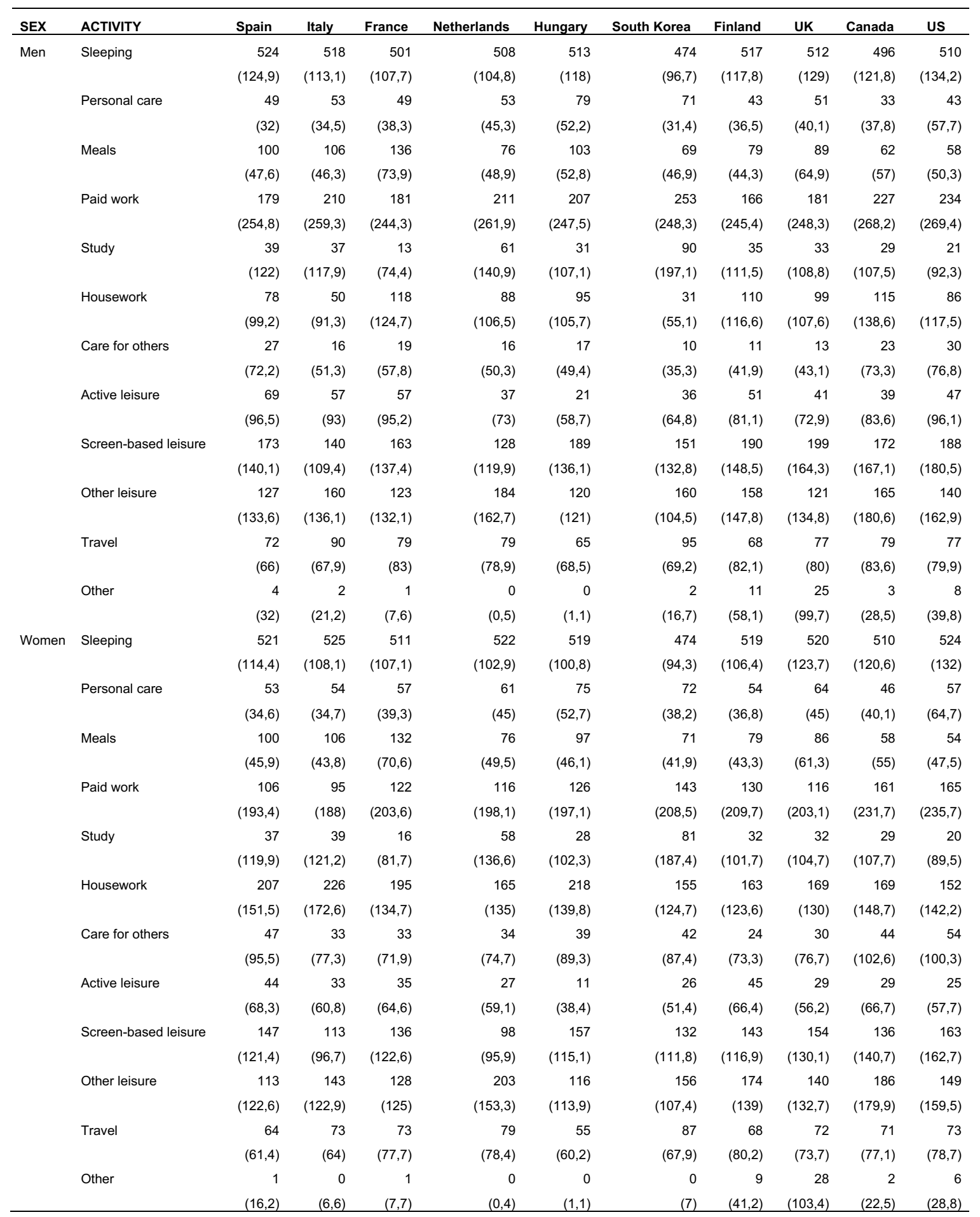

Source: Own calculations from the Multinational Time Use Study [32] 
Table 2. Gender gap measure by activity and country

\begin{tabular}{|c|c|c|c|c|c|c|c|c|c|c|c|}
\hline SEX & ACTIVITY & Spain & Italy & France & Netherlands & Hungary & South Korea & Finland & UK & Canada & US \\
\hline \multirow[t]{12}{*}{ Gender gap (difference) } & Sleeping & 3 & -7 & -11 & -14 & -6 & -1 & -2 & -8 & -14 & -14 \\
\hline & Personal care & -5 & -1 & -8 & -8 & 4 & -2 & -11 & -14 & -12 & -14 \\
\hline & Meals & -1 & 0 & 4 & 0 & 6 & -2 & 0 & 3 & 4 & 3 \\
\hline & Paid work & 73 & 116 & 59 & 94 & 81 & 108 & 37 & 65 & 66 & 71 \\
\hline & Study & 2 & -2 & -3 & 3 & 4 & 10 & 3 & 1 & -1 & 1 \\
\hline & Housework & -129 & -176 & -78 & -77 & -123 & -124 & -52 & -69 & -54 & -66 \\
\hline & Care for others & -20 & -17 & -14 & -18 & -22 & -31 & -13 & -17 & -21 & -24 \\
\hline & Active leisure & 26 & 25 & 22 & 9 & 9 & 9 & 5 & 12 & 10 & 22 \\
\hline & Screen-based leisure & 26 & 26 & 27 & 30 & 32 & 19 & 47 & 46 & 36 & 25 \\
\hline & Other leisure & 14 & 17 & -5 & -19 & 5 & 5 & -17 & -20 & -22 & -10 \\
\hline & Travel & 8 & 17 & 7 & -1 & 10 & 8 & 0 & 5 & 8 & 4 \\
\hline & Other & 3 & 1 & 0 & 0 & 0 & 1 & 2 & -3 & 1 & 2 \\
\hline \multirow[t]{12}{*}{ Gender gap (indicator) } & Sleeping & 0.003 & -0.007 & -0.011 & -0.014 & -0.006 & -0.001 & -0.002 & -0.008 & -0.014 & -0.013 \\
\hline & Personal care & -0.045 & -0.006 & -0.079 & -0.074 & 0.025 & -0.013 & -0.114 & -0.118 & -0.158 & -0.141 \\
\hline & Meals & -0.003 & 0.002 & 0.015 & -0.002 & 0.030 & -0.012 & 0.001 & 0.015 & 0.030 & 0.029 \\
\hline & Paid work & 0.257 & 0.363 & 0.195 & 0.288 & 0.243 & 0.275 & 0.124 & 0.218 & 0.172 & 0.179 \\
\hline & Study & 0.027 & -0.024 & -0.102 & 0.028 & 0.063 & 0.056 & 0.044 & 0.020 & -0.010 & 0.014 \\
\hline & Housework & -0.454 & -0.579 & -0.249 & -0.306 & -0.394 & -0.668 & -0.192 & -0.259 & -0.191 & -0.277 \\
\hline & Care for others & -0.268 & -0.338 & -0.263 & -0.348 & -0.401 & -0.601 & -0.362 & -0.410 & -0.322 & -0.284 \\
\hline & Active leisure & 0.227 & 0.275 & 0.233 & 0.146 & 0.292 & 0.153 & 0.057 & 0.167 & 0.139 & 0.311 \\
\hline & Screen-based leisure & 0.081 & 0.107 & 0.091 & 0.134 & 0.094 & 0.066 & 0.141 & 0.129 & 0.118 & 0.070 \\
\hline & Other leisure & 0.057 & 0.060 & -0.019 & -0.049 & 0.019 & 0.015 & -0.050 & -0.075 & -0.061 & -0.034 \\
\hline & Travel & 0.057 & 0.107 & 0.044 & -0.004 & 0.087 & 0.045 & 0.003 & 0.031 & 0.052 & 0.026 \\
\hline & Other & 0.516 & 0.598 & -0.034 & 0.145 & -0.028 & 0.620 & 0.123 & -0.055 & 0.235 & 0.161 \\
\hline
\end{tabular}

Source: Own calculations from the Multinational Time Use Study [32].

Note: For other, the point indicates that the value cannot be computed mathematically. 
Table 3. Average time by activity and age. Men's and women's daily minutes by country

\begin{tabular}{|c|c|c|c|c|c|c|c|c|c|c|c|c|c|c|c|c|c|c|c|c|c|}
\hline \multirow[b]{2}{*}{ AGE } & \multirow[b]{2}{*}{ ACTIVITY } & \multicolumn{2}{|c|}{ Spain } & \multicolumn{2}{|c|}{ Italy } & \multicolumn{2}{|c|}{ France } & \multicolumn{2}{|c|}{ Netherlands } & \multicolumn{2}{|c|}{ Hungary } & \multicolumn{2}{|c|}{ South Korea } & \multicolumn{2}{|c|}{ Finland } & \multicolumn{2}{|c|}{ UK } & \multicolumn{2}{|c|}{ Canada } & \multicolumn{2}{|c|}{ US } \\
\hline & & $\mathrm{M}$ & $\mathrm{W}$ & $M$ & W & $M$ & W & $\mathrm{M}$ & $\mathrm{W}$ & $M$ & W & $M$ & 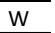 & $M$ & W & $M$ & W & $M$ & W & $M$ & W \\
\hline $10-17$ & Sleeping & 573 & 560 & 558 & 553 & 583 & 583 & 564 & 557 & 584 & $\overline{592}$ & 488 & 480 & 583 & 575 & 594 & 594 & 556 & 567 & 545 & 555 \\
\hline & Personal care & 46 & 59 & 48 & 54 & 48 & 63 & 44 & 64 & 63 & 71 & 69 & 77 & 35 & 52 & 49 & 69 & 35 & 57 & 49 & 61 \\
\hline & Meals & 98 & 98 & 103 & 99 & 116 & 112 & 68 & 69 & 95 & 97 & 63 & 61 & 69 & 69 & 71 & 71 & 50 & 43 & 44 & 47 \\
\hline & Paid work & 2 & 2 & 9 & 3 & 16 & 7 & 33 & 24 & 14 & 4 & 1 & 1 & 9 & 11 & 15 & 11 & 54 & 65 & 33 & 34 \\
\hline & Study & 254 & 267 & 262 & 279 & 218 & 230 & 276 & 279 & 210 & 218 & 453 & 466 & 197 & 164 & 190 & 195 & 212 & 235 & 234 & 262 \\
\hline & Housework & 25 & 47 & 20 & 43 & 30 & 61 & 20 & 41 & 38 & 65 & 9 & 17 & 29 & 54 & 32 & 55 & 30 & 46 & 38 & 58 \\
\hline & Care for others & 3 & 3 & 2 & 3 & 11 & 7 & 2 & 8 & 8 & 10 & 2 & 3 & 0 & 3 & 1 & 2 & 1 & 10 & 6 & 13 \\
\hline & Active leisure & 61 & 48 & 55 & 43 & 62 & 38 & 63 & 41 & 55 & 34 & 21 & 6 & 57 & 38 & 43 & 28 & 64 & 30 & 70 & 37 \\
\hline & Screen-based leisure & 181 & 156 & 152 & 129 & 181 & 158 & 138 & 88 & 198 & 161 & 130 & 111 & 221 & 187 & 228 & 162 & 204 & 138 & 152 & 147 \\
\hline & Other leisure & 133 & 138 & 150 & 155 & 101 & 116 & 154 & 186 & 109 & 124 & 121 & 135 & 160 & 203 & 126 & 150 & 160 & 177 & 192 & 157 \\
\hline $18-29$ & Sleeping & 526 & 520 & 506 & 509 & 512 & 522 & 507 & 523 & 517 & 530 & 474 & 484 & 536 & 536 & 534 & 533 & 515 & 529 & 528 & 547 \\
\hline & Personal care & 48 & 58 & 54 & 63 & 46 & 57 & 57 & 67 & 78 & 77 & 73 & 84 & 40 & 56 & 47 & 67 & 35 & 46 & 43 & 54 \\
\hline & Meals & 93 & 97 & 96 & 98 & 121 & 120 & 64 & 63 & 96 & 90 & 56 & 60 & 67 & 67 & 82 & 73 & 50 & 46 & 50 & 47 \\
\hline & Paid work & 157 & 137 & 216 & 133 & 215 & 146 & 261 & 186 & 180 & 110 & 202 & 172 & 190 & 135 & 228 & 163 & 229 & 180 & 232 & 182 \\
\hline & Study & 86 & 86 & 86 & 103 & 55 & 70 & 77 & 77 & 85 & 98 & 132 & 112 & 54 & 70 & 60 & 50 & 64 & 72 & 44 & 39 \\
\hline & Housework & 53 & 112 & 29 & 118 & 71 & 120 & 53 & 105 & 54 & 131 & 24 & 80 & 78 & 109 & 61 & 119 & 75 & 121 & 66 & 116 \\
\hline & Care for others & 12 & 37 & 6 & 25 & 14 & 43 & 6 & 29 & 8 & 57 & 5 & 37 & 13 & 43 & 9 & 48 & 15 & 58 & 28 & 80 \\
\hline & Active leisure & 59 & 39 & 43 & 36 & 36 & 25 & 23 & 21 & 27 & 14 & 23 & 14 & 38 & 42 & 33 & 21 & 37 & 26 & 43 & 15 \\
\hline & Screen-based leisure & 174 & 137 & 112 & 100 & 162 & 130 & 120 & 89 & 180 & 143 & 168 & 128 & 209 & 149 & 181 & 137 & 160 & 115 & 155 & 142 \\
\hline & Other leisure & 143 & 133 & 183 & 160 & 115 & 120 & 184 & 186 & 123 & 113 & 170 & 160 & 132 & 145 & 99 & 116 & 174 & 167 & 162 & 135 \\
\hline $30-44$ & Sleeping & 496 & 500 & 487 & 494 & 486 & 500 & 481 & 509 & 482 & 494 & 467 & 461 & 491 & 505 & 498 & 506 & 476 & 494 & 495 & 514 \\
\hline & Personal care & 47 & 49 & 52 & 52 & 43 & 52 & 51 & 55 & 78 & 71 & 68 & 66 & 43 & 56 & 48 & 61 & 32 & 42 & 41 & 53 \\
\hline & Meals & 93 & 94 & 98 & 99 & 127 & 127 & 72 & 76 & 99 & 95 & 68 & 73 & 75 & 78 & 76 & 78 & 56 & 54 & 54 & 51 \\
\hline & Paid work & 278 & 172 & 360 & 181 & 297 & 196 & 333 & 163 & 324 & 197 & 359 & 182 & 283 & 193 & 302 & 170 & 317 & 215 & 318 & 210 \\
\hline & Study & 10 & 13 & 3 & 5 & 3 & 4 & 13 & 14 & 6 & 6 & 12 & 13 & 6 & 8 & 6 & 5 & 13 & 14 & 5 & 11 \\
\hline & Housework & 84 & 201 & 52 & 241 & 98 & 174 & 91 & 185 & 85 & 223 & 29 & 191 & 103 & 171 & 85 & 174 & 114 & 182 & 85 & 159 \\
\hline & Care for others & 53 & 97 & 29 & 73 & 33 & 72 & 40 & 76 & 37 & 85 & 22 & 93 & 35 & 72 & 38 & 82 & 53 & 93 & 55 & 99 \\
\hline & Active leisure & 47 & 33 & 36 & 27 & 37 & 28 & 22 & 19 & 15 & 9 & 26 & 21 & 41 & 36 & 30 & 26 & 32 & 25 & 38 & 21 \\
\hline & Screen-based leisure & 141 & 105 & 107 & 78 & 139 & 102 & 106 & 86 & 159 & 121 & 131 & 112 & 159 & 110 & 157 & 124 & 131 & 101 & 150 & 121 \\
\hline & Other leisure & 103 & 95 & 122 & 105 & 88 & 100 & 151 & 172 & 81 & 77 & 156 & 141 & 126 & 133 & 90 & 109 & 127 & 140 & 111 & 113 \\
\hline $45-64$ & Sleeping & 504 & 497 & 491 & 494 & 488 & 499 & 494 & 510 & 499 & 501 & 459 & 458 & 496 & 497 & 485 & 502 & 480 & 496 & 497 & 509 \\
\hline & Personal care & 48 & 50 & 52 & 51 & 47 & 56 & 53 & 61 & 78 & 76 & 72 & 73 & 44 & 52 & 49 & 62 & 34 & 46 & 43 & 60 \\
\hline & Meals & 102 & 102 & 107 & 107 & 139 & 133 & 79 & 83 & 106 & 98 & 75 & 75 & 82 & 81 & 88 & 87 & 66 & 60 & 59 & 53 \\
\hline & Paid work & 235 & 127 & 272 & 128 & 205 & 148 & 247 & 118 & 237 & 158 & 329 & 186 & 215 & 189 & 233 & 162 & 259 & 191 & 268 & 204 \\
\hline & Study & 5 & 6 & 1 & 2 & 1 & 2 & 15 & 10 & 2 & 2 & 4 & 5 & 3 & 6 & 3 & 3 & 4 & 4 & 3 & 5 \\
\hline & Housework & 88 & 268 & 78 & 311 & 131 & 216 & 106 & 212 & 116 & 250 & 37 & 204 & 131 & 182 & 114 & 197 & 133 & 189 & 93 & 157 \\
\hline & Care for others & 22 & 35 & 14 & 25 & 16 & 20 & 11 & 22 & 11 & 24 & 6 & 21 & 6 & 6 & 7 & 10 & 14 & 22 & 21 & 32 \\
\hline & Active leisure & 72 & 48 & 61 & 32 & 59 & 39 & 35 & 31 & 16 & 9 & 46 & 38 & 50 & 53 & 39 & 34 & 38 & 33 & 48 & 27 \\
\hline & Screen-based leisure & 168 & 139 & 133 & 101 & 155 & 128 & 127 & 103 & 194 & 159 & 145 & 133 & 181 & 130 & 199 & 150 & 174 & 140 & 194 & 165 \\
\hline & Other leisure & 121 & 105 & 143 & 122 & 116 & 121 & 197 & 218 & 121 & 110 & 169 & 160 & 153 & 168 & 116 & 137 & 154 & 183 & 125 & 146 \\
\hline $65+$ & Sleeping & 585 & 572 & 559 & 564 & 523 & 529 & 533 & 544 & 552 & 548 & 504 & 513 & 535 & 532 & 507 & 511 & 518 & 526 & 544 & 541 \\
\hline & Personal care & 54 & 57 & 59 & 55 & 58 & 63 & 60 & 63 & 88 & 75 & 73 & 69 & 51 & 58 & 59 & 66 & 31 & 46 & 45 & 62 \\
\hline & Meals & 115 & 110 & 126 & 117 & 150 & 143 & 99 & 88 & 113 & 101 & 88 & 82 & 95 & 93 & 117 & 111 & 85 & 78 & 72 & 69 \\
\hline & Paid work & 10 & 4 & 26 & 5 & 12 & 5 & 19 & 1 & 80 & 45 & 134 & 70 & 15 & 3 & 37 & 10 & 43 & 16 & 53 & 33 \\
\hline & Study & 1 & 2 & 1 & 0 & 1 & 2 & 11 & 6 & 1 & 1 & 3 & 5 & 2 & 1 & 1 & 2 & 1 & 1 & 2 & 0 \\
\hline & Housework & 97 & 245 & 107 & 290 & 151 & 237 & 152 & 226 & 130 & 249 & 61 & 190 & 161 & 224 & 154 & 219 & 156 & 195 & 107 & 177 \\
\hline & Care for others & 18 & 18 & 15 & 16 & 12 & 11 & 10 & 14 & 10 & 15 & 9 & 14 & 2 & 5 & 4 & 4 & 8 & 9 & 12 & 13 \\
\hline & Active leisure & 119 & 55 & 96 & 34 & 85 & 43 & 58 & 31 & 19 & 11 & 75 & 46 & 71 & 49 & 59 & 33 & 46 & 33 & 59 & 30 \\
\hline & Screen-based leisure & 233 & 218 & 185 & 147 & 203 & 183 & 175 & 134 & 231 & 196 & 232 & 196 & 208 & 176 & 240 & 200 & 245 & 202 & 290 & 242 \\
\hline & Other leisure & 161 & 126 & 205 & 174 & 183 & 175 & 254 & 272 & 180 & 164 & 190 & 191 & 225 & 240 & 171 & 192 & 245 & 281 & 195 & 219 \\
\hline
\end{tabular}

Source: Own calculations from the Multinational Time Use Study [32]. 
Table 4. Gender gaps in time use (Indicator from -1 to 1). Differences in activities by age

\begin{tabular}{|c|c|c|c|c|c|c|c|c|c|c|c|}
\hline AGE & ACTIVITY & Spain & Italy & France & Netherlands & Hungary & South Korea & Finland & UK & Canada & US \\
\hline $10-17$ & Sleeping & 0.012 & 0.005 & 0.000 & 0.006 & -0.007 & 0.008 & 0.007 & 0.001 & -0.010 & -0.009 \\
\hline & Personal care & -0.117 & -0.063 & -0.131 & -0.189 & -0.058 & -0.050 & -0.194 & -0.165 & -0.235 & -0.112 \\
\hline & Meals & 0.000 & 0.022 & 0.019 & -0.009 & -0.011 & 0.018 & 0.003 & -0.001 & 0.075 & -0.031 \\
\hline & Paid work & -0.151 & 0.545 & 0.371 & 0.154 & 0.546 & 0.014 & -0.093 & 0.155 & -0.090 & -0.005 \\
\hline & Study & -0.026 & -0.032 & -0.027 & -0.007 & -0.019 & -0.014 & 0.092 & -0.014 & -0.051 & -0.056 \\
\hline & Housework & -0.310 & -0.367 & -0.331 & -0.337 & -0.262 & -0.304 & -0.307 & -0.268 & -0.204 & -0.205 \\
\hline & Care for others & 0.140 & -0.238 & 0.171 & -0.654 & -0.110 & -0.144 & -0.729 & -0.496 & -0.777 & -0.351 \\
\hline & Active leisure & 0.118 & 0.119 & 0.242 & 0.214 & 0.236 & 0.531 & 0.198 & 0.215 & 0.363 & 0.306 \\
\hline & Screen-based leisure & 0.074 & 0.082 & 0.069 & 0.218 & 0.103 & 0.077 & 0.085 & 0.171 & 0.191 & 0.016 \\
\hline & Other leisure & -0.016 & -0.016 & -0.069 & -0.096 & -0.064 & -0.055 & -0.119 & -0.089 & -0.052 & 0.102 \\
\hline $18-29$ & Sleeping & 0.006 & -0.003 & -0.009 & -0.016 & -0.012 & -0.010 & -0.001 & 0.001 & -0.013 & -0.017 \\
\hline & Personal care & -0.098 & -0.080 & -0.107 & -0.078 & 0.008 & -0.074 & -0.166 & -0.177 & -0.139 & -0.112 \\
\hline & Meals & -0.017 & -0.009 & 0.007 & 0.008 & 0.035 & -0.037 & 0.001 & 0.056 & 0.035 & 0.029 \\
\hline & Paid work & 0.070 & 0.237 & 0.192 & 0.168 & 0.243 & 0.082 & 0.169 & 0.165 & 0.118 & 0.120 \\
\hline & Study & 0.002 & -0.086 & -0.114 & 0.004 & -0.068 & 0.085 & -0.132 & 0.089 & -0.060 & 0.062 \\
\hline & Housework & -0.360 & -0.609 & -0.260 & -0.330 & -0.418 & -0.544 & -0.165 & -0.320 & -0.232 & -0.273 \\
\hline & Care for others & -0.528 & -0.607 & -0.507 & -0.645 & -0.743 & -0.775 & -0.527 & -0.672 & -0.590 & -0.481 \\
\hline & Active leisure & 0.200 & 0.090 & 0.187 & 0.030 & 0.319 & 0.238 & -0.039 & 0.222 & 0.187 & 0.470 \\
\hline & Screen-based leisure & 0.121 & 0.058 & 0.110 & 0.151 & 0.115 & 0.132 & 0.168 & 0.136 & 0.163 & 0.046 \\
\hline & Other leisure & 0.037 & 0.069 & -0.019 & -0.008 & 0.043 & 0.030 & -0.047 & -0.079 & 0.019 & 0.090 \\
\hline $30-44$ & Sleeping & -0.004 & -0.007 & -0.014 & -0.028 & -0.012 & 0.006 & -0.015 & -0.008 & -0.018 & -0.019 \\
\hline & Personal care & -0.019 & 0.003 & -0.095 & -0.038 & 0.047 & 0.014 & -0.133 & -0.123 & -0.140 & -0.123 \\
\hline & Meals & -0.007 & -0.009 & 0.004 & -0.022 & 0.020 & -0.031 & -0.016 & -0.011 & 0.022 & 0.031 \\
\hline & Paid work & 0.237 & 0.331 & 0.205 & 0.342 & 0.244 & 0.328 & 0.189 & 0.279 & 0.191 & 0.204 \\
\hline & Study & -0.134 & -0.181 & -0.235 & -0.037 & -0.012 & -0.036 & -0.155 & 0.089 & -0.049 & -0.402 \\
\hline & Housework & -0.411 & -0.646 & -0.280 & -0.338 & -0.448 & -0.733 & -0.245 & -0.341 & -0.229 & -0.305 \\
\hline & Care for others & -0.293 & -0.435 & -0.368 & -0.314 & -0.397 & -0.617 & -0.345 & -0.369 & -0.274 & -0.284 \\
\hline & Active leisure & 0.180 & 0.139 & 0.146 & 0.086 & 0.239 & 0.117 & 0.071 & 0.076 & 0.122 & 0.285 \\
\hline & Screen-based leisure & 0.145 & 0.158 & 0.153 & 0.103 & 0.137 & 0.077 & 0.180 & 0.120 & 0.130 & 0.107 \\
\hline & Other leisure & 0.039 & 0.074 & -0.063 & -0.066 & 0.022 & 0.049 & -0.028 & -0.095 & -0.048 & -0.011 \\
\hline $45-64$ & Sleeping & 0.006 & -0.003 & -0.012 & -0.016 & -0.002 & 0.001 & -0.002 & -0.017 & -0.016 & -0.012 \\
\hline & Personal care & -0.022 & 0.013 & -0.086 & -0.068 & 0.007 & -0.005 & -0.081 & -0.117 & -0.157 & -0.162 \\
\hline & Meals & -0.002 & 0.000 & 0.020 & -0.026 & 0.039 & 0.000 & 0.007 & 0.008 & 0.043 & 0.055 \\
\hline & Paid work & 0.298 & 0.359 & 0.161 & 0.355 & 0.201 & 0.279 & 0.064 & 0.180 & 0.151 & 0.137 \\
\hline & Study & -0.078 & -0.451 & -0.296 & 0.169 & -0.103 & -0.134 & -0.331 & -0.133 & 0.059 & -0.266 \\
\hline & Housework & -0.504 & -0.600 & -0.245 & -0.333 & -0.366 & -0.696 & -0.163 & -0.266 & -0.176 & -0.256 \\
\hline & Care for others & -0.232 & -0.269 & -0.109 & -0.343 & -0.362 & -0.555 & -0.004 & -0.192 & -0.245 & -0.215 \\
\hline & Active leisure & 0.201 & 0.309 & 0.205 & 0.057 & 0.290 & 0.101 & -0.031 & 0.077 & 0.076 & 0.279 \\
\hline & Screen-based leisure & 0.095 & 0.140 & 0.093 & 0.104 & 0.099 & 0.043 & 0.166 & 0.140 & 0.111 & 0.080 \\
\hline & Other leisure & 0.071 & 0.081 & -0.020 & -0.050 & 0.050 & 0.028 & -0.045 & -0.082 & -0.088 & -0.079 \\
\hline $65+$ & Sleeping & 0.012 & -0.005 & -0.006 & -0.009 & 0.004 & -0.009 & 0.002 & -0.004 & -0.008 & 0.002 \\
\hline & Personal care & -0.033 & 0.039 & -0.035 & -0.025 & 0.080 & 0.031 & -0.065 & -0.055 & -0.189 & -0.154 \\
\hline & Meals & 0.025 & 0.034 & 0.024 & 0.057 & 0.054 & 0.037 & 0.012 & 0.026 & 0.038 & 0.026 \\
\hline & Paid work & 0.466 & 0.684 & 0.435 & 0.865 & 0.283 & 0.315 & 0.678 & 0.560 & 0.447 & 0.224 \\
\hline & Study & -0.135 & 0.475 & -0.342 & 0.266 & 0.142 & -0.132 & 0.066 & -0.119 & 0.249 & 0.598 \\
\hline & Housework & -0.433 & -0.462 & -0.223 & -0.194 & -0.315 & -0.514 & -0.163 & -0.174 & -0.110 & -0.244 \\
\hline & Care for others & -0.004 & -0.006 & 0.052 & -0.164 & -0.224 & -0.232 & -0.446 & -0.020 & -0.074 & -0.026 \\
\hline & Active leisure & 0.371 & 0.478 & 0.333 & 0.303 & 0.279 & 0.240 & 0.179 & 0.278 & 0.164 & 0.319 \\
\hline & Screen-based leisure & 0.034 & 0.114 & 0.053 & 0.130 & 0.080 & 0.085 & 0.081 & 0.091 & 0.096 & 0.092 \\
\hline & Other leisure & 0.121 & 0.083 & 0.022 & -0.035 & 0.047 & -0.003 & -0.032 & -0.057 & -0.069 & -0.057 \\
\hline
\end{tabular}

Source: Own calculations from the Multinational Time Use Study [32]. 


\section{ANNEX}

Table A1. Sample size by country, gender and group of age

\begin{tabular}{|c|c|c|c|c|c|c|c|c|c|c|c|}
\hline SEX & AGE & Spain & Italy & France & Netherlands & Hungary & South Korea & Finland & UK & Canada & US \\
\hline \multirow[t]{6}{*}{ Men } & 10-17 & 747 & 1703 & 357 & 1071 & 266 & 3326 & 454 & 864 & 256 & 299 \\
\hline & $18-29$ & 1101 & 2520 & 1375 & 1036 & 619 & 2738 & 442 & 1054 & 762 & 796 \\
\hline & $30-44$ & 2322 & 4568 & 3327 & 1897 & 932 & 5330 & 685 & 1553 & 1540 & 1728 \\
\hline & $45-64$ & 3072 & 5574 & 4872 & 2149 & 1310 & 5778 & 1329 & 2393 & 2643 & 2081 \\
\hline & $65+$ & 1734 & 3850 & 2927 & 938 & 637 & 2256 & 594 & 1553 & 1500 & 908 \\
\hline & Total & 8976 & 18215 & 12858 & 7091 & 3764 & 19428 & 3504 & 7417 & 6701 & 5812 \\
\hline \multirow[t]{6}{*}{ Women } & $10-17$ & 689 & 1587 & 405 & 1092 & 262 & 3088 & 448 & 948 & 232 & 282 \\
\hline & $18-29$ & 1194 & 2499 & 1694 & 1512 & 611 & 3026 & 518 & 1349 & 979 & 1014 \\
\hline & $30-44$ & 2746 & 4841 & 3763 & 2086 & 994 & 5922 & 825 & 1946 & 1985 & 2188 \\
\hline & $45-64$ & 3388 & 5930 & 5587 & 2730 & 1733 & 5926 & 1443 & 2634 & 3354 & 2457 \\
\hline & $65+$ & 2302 & 5162 & 3590 & 917 & 1026 & 3136 & 717 & 1803 & 2139 & 1507 \\
\hline & Total & 10319 & 20019 & 15039 & 8337 & 4626 & 21098 & 3951 & 8680 & 8689 & 7448 \\
\hline
\end{tabular}

Source: Multinational Time Use Study [32]. 
Table A2. Respondent percentage spending at least 1 daily minute in activities by country, gender and age

\begin{tabular}{|c|c|c|c|c|c|c|c|c|c|c|c|c|c|c|c|c|c|c|c|c|c|}
\hline \multirow[b]{2}{*}{ AGE } & \multirow[b]{2}{*}{ ACTIVITY } & \multicolumn{2}{|c|}{ Spain } & \multicolumn{2}{|c|}{ Italy } & \multicolumn{2}{|c|}{ France } & \multicolumn{2}{|c|}{ Netherlands } & \multicolumn{2}{|c|}{ Hungary } & \multicolumn{2}{|c|}{ South Korea } & \multicolumn{2}{|c|}{ Finland } & \multicolumn{2}{|c|}{ UK } & Cane & & u & \\
\hline & & $\mathrm{M}$ & W & $\mathrm{M}$ & W & $\mathrm{M}$ & W & $\mathrm{M}$ & W & $\mathrm{M}$ & W & $\mathrm{M}$ & W & $\mathrm{M}$ & W & $\mathrm{M}$ & W & $\mathrm{M}$ & W & $\mathrm{M}$ & W \\
\hline $10-17$ & Sleeping & 100 & 100 & 100 & 100 & 100 & 100 & 100 & 100 & 100 & 100 & 100 & 100 & 100 & 100 & 100 & 100 & 100 & 100 & 100 & 100 \\
\hline & Personal care & 97 & 98 & 98 & 99 & 97 & 97 & 92 & 97 & 100 & 100 & 100 & 100 & 90 & 94 & 94 & 97 & 90 & 93 & 87 & 91 \\
\hline & Meals & 100 & 100 & 100 & 100 & 98 & 99 & 94 & 95 & 100 & 100 & 99 & 98 & 97 & 98 & 97 & 97 & 84 & 76 & 91 & 93 \\
\hline & Work & 0 & 1 & 2 & 1 & 7 & 6 & 14 & 10 & 16 & 8 & 1 & 1 & 5 & 6 & 6 & 5 & 17 & 22 & 12 & 11 \\
\hline & Study & 71 & 72 & 73 & 77 & 61 & 62 & 76 & 79 & 63 & 61 & 95 & 96 & 59 & 56 & 57 & 59 & 59 & 65 & 59 & 67 \\
\hline & Housework & 49 & 66 & 41 & 59 & 42 & 68 & 38 & 56 & 64 & 70 & 27 & 38 & 53 & 76 & 63 & 77 & 43 & 60 & 59 & 64 \\
\hline & Care for others & 4 & 6 & 2 & 4 & 6 & 12 & 3 & 9 & 10 & 10 & 4 & 6 & 2 & 6 & 1 & 4 & 2 & 5 & 21 & 27 \\
\hline & Active leisure & 50 & 41 & 46 & 39 & 41 & 30 & 46 & 37 & 44 & 30 & 35 & 12 & 44 & 46 & 40 & 31 & 42 & 24 & 49 & 37 \\
\hline & Screen-based leisure & 92 & 92 & 92 & 89 & 85 & 84 & 82 & 73 & 91 & 94 & 83 & 79 & 90 & 94 & 93 & 86 & 92 & 80 & 85 & 79 \\
\hline & Other leisure & 78 & 80 & 85 & 90 & 68 & 76 & 83 & 92 & 76 & 79 & 99 & 99 & 81 & 96 & 79 & 86 & 82 & 83 & 88 & 81 \\
\hline & Travel & 86 & 87 & 95 & 96 & 85 & 82 & 88 & 87 & 86 & 81 & 97 & 96 & 80 & 84 & 82 & 84 & 92 & 92 & 94 & 87 \\
\hline $18-29$ & Sleeping & 100 & 100 & 100 & 100 & 100 & 100 & 100 & 100 & 100 & 100 & 100 & 100 & 100 & 100 & 100 & 100 & 100 & 100 & 100 & 100 \\
\hline & Personal care & 96 & 98 & 97 & 99 & 94 & 95 & 96 & 97 & 100 & 100 & 100 & 99 & 93 & 98 & 91 & 96 & 84 & 84 & 83 & 86 \\
\hline & Meals & 100 & 100 & 99 & 100 & 99 & 99 & 94 & 92 & 100 & 100 & 93 & 95 & 97 & 97 & 95 & 94 & 83 & 80 & 89 & 87 \\
\hline & Work & 33 & 33 & 44 & 32 & 51 & 38 & 53 & 43 & 43 & 29 & 47 & 43 & 41 & 36 & 48 & 38 & 47 & 41 & 51 & 43 \\
\hline & Study & 27 & 28 & 25 & 31 & 16 & 21 & 27 & 30 & 27 & 31 & 38 & 36 & 19 & 26 & 18 & 17 & 19 & 23 & 15 & 17 \\
\hline & Housework & 55 & 82 & 40 & 80 & 70 & 86 & 59 & 79 & 70 & 89 & 45 & 75 & 80 & 88 & 77 & 90 & 74 & 85 & 73 & 87 \\
\hline & Care for others & 10 & 22 & 6 & 17 & 15 & 31 & 7 & 18 & 9 & 24 & 7 & 21 & 12 & 22 & 12 & 29 & 13 & 28 & 31 & 57 \\
\hline & Active leisure & 46 & 40 & 38 & 38 & 28 & 25 & 20 & 22 & 23 & 19 & 28 & 21 & 41 & 51 & 34 & 25 & 29 & 26 & 36 & 21 \\
\hline & Screen-based leisure & 88 & 87 & 80 & 79 & 82 & 80 & 72 & 73 & 88 & 85 & 88 & 86 & 88 & 88 & 84 & 83 & 79 & 74 & 79 & 80 \\
\hline & Other leisure & 80 & 79 & 89 & 87 & 72 & 77 & 84 & 89 & 81 & 78 & 99 & 98 & 78 & 87 & 71 & 78 & 80 & 81 & 78 & 75 \\
\hline & Travel & 88 & 87 & 96 & 93 & 90 & 89 & 87 & 89 & 88 & 82 & 95 & 93 & 82 & 88 & 85 & 86 & 92 & 91 & 94 & 89 \\
\hline $30-44$ & Sleeping & 100 & 100 & 100 & 100 & 100 & 100 & 100 & 100 & 100 & 100 & 100 & 100 & 100 & 100 & 100 & 100 & 100 & 100 & 100 & 100 \\
\hline & Personal care & 97 & 97 & 98 & 98 & 92 & 95 & 97 & 98 & 100 & 100 & 100 & 99 & 94 & 97 & 95 & 97 & 83 & 86 & 83 & 86 \\
\hline & Meals & 99 & 100 & 99 & 100 & 99 & 99 & 94 & 93 & 100 & 100 & 95 & 97 & 97 & 99 & 96 & 95 & 85 & 84 & 91 & 92 \\
\hline & Work & 56 & 43 & 72 & 45 & 65 & 52 & 67 & 43 & 71 & 52 & 79 & 47 & 60 & 46 & 63 & 43 & 64 & 49 & 66 & 50 \\
\hline & Study & 5 & 7 & 1 & 2 & 2 & 3 & 10 & 10 & 3 & 4 & 7 & 8 & 2 & 5 & 3 & 4 & 5 & 6 & 2 & 6 \\
\hline & Housework & 73 & 95 & 60 & 95 & 76 & 95 & 81 & 96 & 80 & 98 & 48 & 97 & 90 & 98 & 86 & 96 & 80 & 94 & 78 & 93 \\
\hline & Care for others & 44 & 62 & 33 & 57 & 41 & 63 & 45 & 63 & 33 & 55 & 33 & 74 & 40 & 58 & 41 & 61 & 44 & 59 & 52 & 72 \\
\hline & Active leisure & 41 & 36 & 32 & 28 & 32 & 29 & 23 & 23 & 15 & 9 & 30 & 26 & 43 & 45 & 33 & 33 & 27 & 29 & 34 & 31 \\
\hline & Screen-based leisure & 87 & 84 & 81 & 75 & 82 & 76 & 77 & 76 & 89 & 86 & 87 & 87 & 89 & 85 & 87 & 86 & 79 & 74 & 81 & 78 \\
\hline & Other leisure & 76 & 77 & 83 & 80 & 69 & 75 & 86 & 93 & 72 & 70 & 99 & 98 & 87 & 94 & 71 & 81 & 73 & 79 & 72 & 76 \\
\hline & Travel & 91 & 90 & 96 & 93 & 88 & 87 & 81 & 86 & 90 & 82 & 96 & 93 & 83 & 85 & 89 & 87 & 94 & 91 & 94 & 91 \\
\hline $45-64$ & Sleeping & 100 & 100 & 100 & 100 & 100 & 100 & 100 & 100 & 100 & 100 & 100 & 100 & 100 & 100 & 100 & 100 & 100 & 100 & 100 & 100 \\
\hline & Personal care & 97 & 98 & 98 & 97 & 94 & 96 & 97 & 97 & 100 & 100 & 100 & 99 & 93 & 97 & 94 & 97 & 81 & 87 & 79 & 87 \\
\hline & Meals & 100 & 100 & 100 & 100 & 100 & 100 & 93 & 92 & 100 & 100 & 97 & 97 & 99 & 99 & 97 & 97 & 90 & 87 & 93 & 91 \\
\hline & Work & 48 & 31 & 56 & 32 & 47 & 39 & 52 & 34 & 64 & 50 & 76 & 49 & 46 & 44 & 51 & 40 & 54 & 43 & 57 & 47 \\
\hline & Study & 3 & 4 & 1 & 1 & 1 & 2 & 12 & 10 & 1 & 2 & 3 & 4 & 2 & 3 & 2 & 3 & 2 & 3 & 1 & 2 \\
\hline & Housework & 70 & 97 & 67 & 98 & 83 & 96 & 83 & 97 & 85 & 99 & 51 & 98 & 91 & 98 & 88 & 98 & 83 & 95 & 77 & 91 \\
\hline & Care for others & 20 & 29 & 17 & 28 & 16 & 23 & 14 & 23 & 12 & 22 & 12 & 35 & 10 & 12 & 12 & 19 & 12 & 17 & 26 & 36 \\
\hline & Active leisure & 53 & 47 & 42 & 33 & 43 & 40 & 32 & 31 & 15 & 10 & 45 & 40 & 48 & 57 & 39 & 40 & 32 & 35 & 40 & 38 \\
\hline & Screen-based leisure & 91 & 87 & 88 & 83 & 84 & 81 & 83 & 78 & 93 & 91 & 91 & 90 & 91 & 89 & 90 & 90 & 85 & 80 & 84 & 82 \\
\hline & Other leisure & 80 & 78 & 87 & 84 & 77 & 82 & 93 & 95 & 85 & 80 & 99 & 99 & 90 & 96 & 76 & 86 & 79 & 87 & 77 & 82 \\
\hline & Travel & 88 & 82 & 94 & 89 & 83 & 81 & 81 & 78 & 80 & 77 & 94 & 92 & 80 & 83 & 83 & 85 & 88 & 87 & 88 & 86 \\
\hline $65+$ & Sleeping & 100 & 100 & 100 & 100 & 100 & 100 & 100 & 100 & 100 & 100 & 100 & 100 & 100 & 100 & 100 & 100 & 100 & 100 & 100 & 100 \\
\hline & Personal care & 98 & 98 & 98 & 97 & 95 & 96 & 94 & 97 & 100 & 100 & 100 & 99 & 93 & 96 & 96 & 97 & 73 & 85 & 72 & 85 \\
\hline & Meals & 100 & 100 & 100 & 100 & 100 & 100 & 90 & 91 & 100 & 100 & 99 & 99 & 100 & 100 & 98 & 99 & 93 & 92 & 96 & 96 \\
\hline & Work & 2 & 1 & 6 & 1 & 5 & 3 & 7 & 2 & 42 & 31 & 43 & 28 & 5 & 1 & 12 & 5 & 13 & 5 & 14 & 9 \\
\hline & Study & 1 & 2 & 1 & 0 & 1 & 2 & 12 & 6 & 1 & 1 & 3 & 4 & 2 & 1 & 1 & 2 & 1 & 1 & 1 & 1 \\
\hline & Housework & 72 & 92 & 78 & 92 & 89 & 97 & 89 & 98 & 86 & 99 & 71 & 95 & 94 & 98 & 94 & 98 & 86 & 95 & 78 & 94 \\
\hline & Care for others & 14 & 16 & 13 & 15 & 12 & 13 & 10 & 12 & 9 & 13 & 12 & 19 & 3 & 7 & 7 & 7 & 5 & 8 & 15 & 16 \\
\hline & Active leisure & 73 & 51 & 61 & 34 & 60 & 45 & 43 & 33 & 22 & 16 & 65 & 51 & 61 & 61 & 50 & 39 & 38 & 34 & 46 & 37 \\
\hline & Screen-based leisure & 94 & 94 & 93 & 89 & 91 & 89 & 89 & 82 & 95 & 95 & 97 & 96 & 92 & 93 & 95 & 93 & 91 & 86 & 89 & 88 \\
\hline & Other leisure & 85 & 80 & 94 & 91 & 92 & 90 & 95 & 98 & 90 & 90 & 98 & 99 & 95 & 98 & 90 & 94 & 89 & 93 & 85 & 91 \\
\hline & Travel & 73 & 61 & 81 & 67 & 69 & 60 & 69 & 66 & 61 & 57 & 81 & 81 & 58 & 52 & 72 & 68 & 78 & 70 & 72 & 69 \\
\hline
\end{tabular}

Source: Own calculations from the Multinational Time Use Study [32].

Note: values go from $0 \% 100 \%$. 
Table A3. Coefficient for Category Men (ref=Women) from the OLS regressions by country and age

\begin{tabular}{|c|c|c|c|c|c|c|c|c|c|c|c|}
\hline \multirow{2}{*}{\multicolumn{2}{|c|}{ ACT $A C$}} & ES & IT & $\mathrm{FR}$ & $\mathrm{NL}$ & $\mathrm{HU}$ & $\mathrm{KR}$ & $\begin{array}{c}\mathrm{FI} \\
\end{array}$ & UK & $\mathrm{CA}$ & \multirow{2}{*}{$\frac{\text { US }}{\text { coef. Men sig }}$} \\
\hline & & coef. Men sig & coef. Men sig & coef. Men sig & coef. Men sig & coef. Men sig & coef. Men sig & coef. Men sig & coef. Men sig & coef. Men sig & \\
\hline \multirow{5}{*}{$\frac{\frac{0}{Q}}{\frac{d}{n}}$} & 10 & $13.635^{*}$ & 4.715 & -0.051 & 6.254 & -8.132 & $8.158 * * *$ & 8.019 & 0.299 & -10.835 & -10.128 \\
\hline & 18 & 6.670 & -2.817 & $-9.271 *$ & $-16.046 * *$ & -12.548 & $-9.738 * * *$ & -0.802 & 1.078 & $-13.996 *$ & $-18.482 *$ \\
\hline & 30 & -4.351 & $-6.064 *$ & $-13.285 * * *$ & $-27.902 * * *$ & $-12.168 *$ & $6.255 * * *$ & $-13.981 *$ & -7.228 & $-17.587 * * *$ & $-19.611 * * *$ \\
\hline & 45 & $6.571^{*}$ & -3.157 & $-11.212 * * *$ & $-16.174 * * *$ & -2.104 & 1.214 & -1.447 & $-16.837 * * *$ & $-15.212 * * *$ & $-12.048 * *$ \\
\hline & 65 & $13.540 * *$ & -5.376 & $-6.563 *$ & $-10.193 *$ & 4.064 & $-8.677 * *$ & 2.326 & -4.396 & $-8.674 *$ & 2.617 \\
\hline \multirow{5}{*}{ 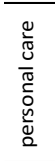 } & 10 & $-12.343 * * *$ & $-6.596 * * *$ & $-14.593 * * *$ & $-20.307^{* * *}$ & $-7.806 *$ & $-7.231 * * *$ & $-17.005^{* * *}$ & $-19.427 * * *$ & $-21.672 * * *$ & $-12.381 *$ \\
\hline & 18 & $-10.332 * * *$ & $-9.300 * * *$ & $-11.101 * * *$ & $-9.646 * * *$ & 1.201 & $-11.626 * * *$ & $-15.953 * * *$ & $-20.181 * * *$ & $-11.322 * * *$ & $-10.981 * * *$ \\
\hline & 30 & -1.833 & 0.536 & $-8.872 * * *$ & $-4.017^{* *}$ & $7.025 * *$ & $1.872 * *$ & $-13.034 * * *$ & $-13.361 * * *$ & $-10.324 * * *$ & $-11.545 * * *$ \\
\hline & 45 & $-2.151 * *$ & 1.365 & $-8.838 * * *$ & $-7.704^{* * *}$ & 1.087 & -0.672 & $-7.755 * * *$ & $-12.844 * * *$ & $-12.520 * * *$ & $-16.650 * * *$ \\
\hline & 65 & $-3.634 * *$ & $4.406 * * *$ & $-4.289 * * *$ & -3.141 & $12.981 * * *$ & $4.437 * * *$ & $-7.175 * *$ & $-7.001 * * *$ & $-14.617^{* * *}$ & $-16.487^{* * *}$ \\
\hline \multirow{5}{*}{$\frac{\frac{n}{\pi}}{\stackrel{\Perp}{E}}$} & 10 & 0.034 & $4.316^{*}$ & 4.178 & -1.296 & -2.096 & $2.242 * *$ & 0.385 & -0.239 & 7.003 & -2.851 \\
\hline & 18 & -3.210 & -1.743 & 1.688 & 0.964 & $6.423 *$ & $-4.325 * * *$ & 0.114 & $8.653 * *$ & 3.342 & 2.818 \\
\hline & 30 & -1.308 & -1.516 & 1.508 & $-3.326 *$ & 3.938 & $-4.415 * * *$ & -2.308 & -1.319 & 2.381 & $3.199 *$ \\
\hline & 45 & -0.314 & -0.060 & $5.666 * * *$ & $-4.155 * *$ & $8.048 * * *$ & 0.057 & 1.130 & 1.415 & $5.369 * * *$ & $6.230 * * *$ \\
\hline & 65 & $5.595 * * *$ & $8.299 * * *$ & $7.121^{* * *}$ & $10.708^{* * *}$ & $11.556^{* * *}$ & $6.283^{* * *}$ & 2.249 & $5.940 *$ & $6.263 * *$ & 3.725 \\
\hline \multirow{5}{*}{$\begin{array}{l}\text { ㄴ } \\
\vdots \\
3 \\
\frac{0}{\pi} \\
\stackrel{0}{0}\end{array}$} & 10 & -0.556 & $6.282 * *$ & 8.747 & $8.848 *$ & $9.917^{* *}$ & 0.033 & -1.826 & 3.974 & -10.668 & -0.350 \\
\hline & 18 & 20.044 & $82.176 * * *$ & $68.920 * * *$ & $75.037^{* * *}$ & $70.728 * * *$ & $30.708 * * *$ & $55.156 * *$ & $63.911 * * *$ & $48.330 * * *$ & $49.891 * * *$ \\
\hline & 30 & $106.915 * * *$ & $173.763 * * *$ & $96.967 * * *$ & $169.701 * * *$ & $127.026 * * *$ & $176.400 * * *$ & $87.994 * * *$ & $127.523 * * *$ & $101.569 * * *$ & $107.811 * * *$ \\
\hline & 45 & $107.438 * * *$ & $143.490 * * *$ & $55.423 * * *$ & $129.560 * * *$ & $79.279 * * *$ & $143.839 * * *$ & $24.727 *$ & $70.035 * * *$ & $67.863 * * *$ & $64.538 * * *$ \\
\hline & 65 & $6.366 * *$ & $21.012 * * *$ & $7.082 * * *$ & $17.399 * * *$ & $35.092 * * *$ & $64.170 * * *$ & $12.297^{* *}$ & $26.423 * * *$ & $26.545^{* * *}$ & $19.278 *$ \\
\hline \multirow{5}{*}{$\sum_{i}^{\overrightarrow{0}}$} & 10 & -13.690 & -15.054 & -10.669 & -3.721 & -8.141 & $-12.789 * *$ & 32.689 & -3.703 & -22.760 & -27.857 \\
\hline & 18 & 0.106 & $-16.488 * *$ & $-14.396 *$ & 0.665 & -12.417 & $20.682 * * *$ & -16.294 & 9.612 & -8.167 & 5.163 \\
\hline & 30 & -2.937 & -1.554 & -1.633 & -1.009 & -0.155 & -0.901 & -2.293 & 0.932 & -1.320 & $-6.360 * *$ \\
\hline & 45 & -0.844 & $-1.052 *$ & $-0.782 *$ & $4.260 * *$ & -0.424 & -1.256 & -2.782 & -0.803 & 0.497 & -2.124 \\
\hline & 65 & -0.400 & 0.544 & $-0.824 *$ & $4.433 * *$ & 0.294 & -1.035 & 0.213 & -0.334 & 0.513 & 1.372 \\
\hline \multirow{5}{*}{$\begin{array}{l}\text { ․ } \\
\vdots \\
3 \\
0 \\
0 \\
0 \\
0 \\
\Sigma\end{array}$} & 10 & $-22.230 * * *$ & $-23.245^{* * *}$ & $-30.244 * * *$ & $-20.773^{* * *}$ & $-27.093^{* * *}$ & $-7.873 * * *$ & $-25.373^{* * *}$ & $-23.275 * * *$ & $-15.483 *$ & $-19.542 *$ \\
\hline & 18 & $-59.408 * * *$ & $-89.090 * * *$ & $-49.592 * * *$ & $-52.296 * * *$ & $-77.275 * * *$ & $-56.700 * * *$ & $-30.792 * * *$ & $-57.780 * * *$ & $-45.590 * * *$ & $-49.762 * * *$ \\
\hline & 30 & $-117.204 * * *$ & $-188.796 * * *$ & $-75.345 * * *$ & $-93.435 * * *$ & $-138.117^{* * *}$ & $-161.463 * * *$ & $-66.955 * * *$ & $-87.946 * * *$ & $-67.720 * * *$ & $-74.113 * * *$ \\
\hline & 45 & $-179.448 * * *$ & $-233.557 * * *$ & $-84.760 * * *$ & $-105.734 * * *$ & $-133.958 * * *$ & $-167.447 * * *$ & $-50.735 * * *$ & $-82.354 * * *$ & $-56.707^{* * *}$ & $-63.940 * * *$ \\
\hline & 65 & $-148.224 * * *$ & $-183.661 * * *$ & $-86.445 * * *$ & $-73.475 * * *$ & $-119.637 * * *$ & $-128.772 * * *$ & $-62.585 * * *$ & $-64.780 * * *$ & $-38.604 * * *$ & $-69.186 * * *$ \\
\hline & 10 & 0.841 & -1.112 & 3.106 & $-6.538 * * *$ & -1.957 & -0.631 & $-2.203 *$ & $-1.172 * *$ & -8.495 & $-6.952 *$ \\
\hline$\frac{0}{0}$ & 18 & $-25.902 * * *$ & $-18.905 * * *$ & $-29.171 * * *$ & $-22.523 * * *$ & $-48.793 * * *$ & $-32.096 * * *$ & $-29.442 * * *$ & $-38.183 * * *$ & $-42.696 * * *$ & $-51.968 * * *$ \\
\hline tँ & 30 & $-43.868 * * *$ & $-44.250 * * *$ & $-38.686 * * *$ & $-36.517 * * *$ & $-48.292 * * *$ & $-71.338 * * *$ & $-36.838 * * *$ & $-43.992 * * *$ & $-40.079 * * *$ & $-43.703 * * *$ \\
\hline$\stackrel{4}{0}$ & 45 & $-13.229 * * *$ & $-10.508 * * *$ & $-3.898 * *$ & $-11.026 * * *$ & $-12.677^{* * *}$ & $-15.322 * * *$ & -0.055 & $-3.284 * * *$ & $-8.823 * * *$ & $-11.488 * * *$ \\
\hline & 65 & -0.135 & -0.222 & 1.214 & -3.983 & $-5.508 *$ & $-5.284 * * *$ & $-3.068 *$ & -0.173 & -1.306 & -0.638 \\
\hline & 10 & $12.755^{* *}$ & $11.491^{* * *}$ & $24.111^{* *}$ & $22.102 * * *$ & $21.128^{*}$ & $14.591^{* * *}$ & $18.892 * *$ & $15.191^{* * *}$ & $33.835^{* * *}$ & $33.019^{* * *}$ \\
\hline$\bigsqcup_{\bar{n}}^{\circ}$ & 18 & $19.678^{* * *}$ & $7.212 * *$ & $11.501 * * *$ & 1.335 & $13.190 * *$ & $8.878^{* * *}$ & -3.165 & $11.924 * * *$ & $11.799 * *$ & 27.391 *** \\
\hline$\frac{\pi}{\omega}$ & 30 & $14.273 * * *$ & $9.320 * * *$ & $10.036 * * *$ & $3.532 *$ & $5.737^{* *}$ & $5.552 * * *$ & 5.549 & $4.473 *$ & $6.968 * *$ & $16.767 * * *$ \\
\hline$\sum_{i}^{\infty}$ & 45 & $24.153^{* * *}$ & $28.632 * * *$ & $20.199 * * *$ & $3.757^{*}$ & $7.015^{* * *}$ & $8.547^{* * *}$ & -3.142 & $5.645^{* *}$ & $5.363 *$ & $20.773^{* * *}$ \\
\hline$\breve{\sigma}_{\tilde{\sigma}}$ & 65 & $64.393 * * *$ & $61.861^{* * *}$ & $42.656^{* * *}$ & 27.071 *** & $8.400 * * *$ & $28.926^{* * *}$ & $21.422 * * *$ & $25.558 * * *$ & $12.890 * * *$ & $28.402 * * *$ \\
\hline & 10 & $24.949 * * *$ & $23.016 * * *$ & $23.177^{*}$ & $49.166 * * *$ & $36.918 * *$ & $18.622 * * *$ & $34.841 * *$ & $65.915^{* * *}$ & $65.296 * * *$ & 4.795 \\
\hline & 18 & $37.766 * * *$ & $12.226 * * *$ & $31.994 * * *$ & $31.517^{* * *}$ & $37.058 * * *$ & $39.144 * * *$ & $59.953 * * *$ & $43.568 * * *$ & $44.956 * * *$ & 13.530 \\
\hline 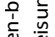 & 30 & $35.507 * * *$ & $29.615 * * *$ & $37.386 * * *$ & $19.664 * * *$ & $38.466 * * *$ & $18.807^{* * *}$ & $48.640 * * *$ & $34.622 * * *$ & $30.297 * * *$ & $28.960 * * *$ \\
\hline $\bar{\Phi} \overline{0}$ & 45 & $29.419 * * *$ & $32.661 * * *$ & $26.324 * * *$ & $23.892 * * *$ & $34.921 * * *$ & $12.023 * * *$ & $51.859 * * *$ & $48.908^{* * *}$ & $34.933 * * *$ & $28.814^{* * *}$ \\
\hline & 65 & $15.179 * *$ & $37.683 * * *$ & $20.336 * * *$ & $40.254 * * *$ & $34.364 * * *$ & $36.229 * * *$ & $31.108 * *$ & $40.149 * * *$ & $42.859 * * *$ & $48.683 * * *$ \\
\hline & 10 & -4.460 & -5.691 & -15.376 & $-32.741 * * *$ & -15.023 & $-14.182 * * *$ & $-43.054 * * *$ & $-25.098 * * *$ & -17.500 & $35.445 *$ \\
\hline 光 & 18 & 10.468 & $24.117^{* * *}$ & -4.332 & -2.913 & 10.270 & $9.871 * *$ & -13.248 & $-16.612 * *$ & 6.447 & $26.698 * *$ \\
\hline$\stackrel{\varrho}{\underline{u}}$ & 30 & $7.554 *$ & $18.815 * * *$ & $-10.760 * * *$ & $-21.380 * * *$ & 3.490 & $14.654 * * *$ & -6.841 & $-17.912 * * *$ & $-12.850 *$ & -2.440 \\
\hline 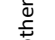 & 45 & $16.253^{* * *}$ & $21.340 * * *$ & -4.181 & $-20.753 * * *$ & $11.524 * *$ & $9.070 * * *$ & $-14.300 *$ & $-20.415 * * *$ & $-29.700 * * *$ & $-21.467 * * *$ \\
\hline & 65 & $34.639 * * *$ & $31.637^{* * *}$ & 7.916 * & $-18.377^{*}$ & $16.384 *$ & -1.347 & -15.176 & $-20.946 * * *$ & $-36.301 * * *$ & $-23.602 * *$ \\
\hline
\end{tabular}

Notes: OLS regressions control for day of the week. ${ }^{* * *} \mathrm{p}<0.001,{ }^{* *} \mathrm{p}<0.01,{ }^{*} \mathrm{p}<0.05$ 
Table A4. Coefficient for Category Men (ref=Women) from the OLS regressions by country and age

\begin{tabular}{|c|c|c|c|c|c|c|c|c|c|c|c|}
\hline \multirow{2}{*}{\multicolumn{3}{|c|}{$\begin{array}{c} \\
\text { ACT AGE coef. Men sig }\end{array}$}} & IT & $F R$ & $\mathrm{NL}$ & $\mathrm{HU}$ & $\mathrm{KR}$ & $\mathrm{FI}$ & UK & $\mathrm{CA}$ & US \\
\hline & & & coef. Men sig & coef. Men sig & coef. Men sig & coef. Men sig & coef. Men sig & coef. Men sig & coef. Men sig & coef. Men sig & coef. Men sig \\
\hline \multirow{5}{*}{$\frac{\frac{0}{\mathscr{U}}}{n}$} & 10 & $13.423 *$ & 5.201 & 3.026 & 6.824 & -7.664 & $8.146 * * *$ & 8.223 & -1.213 & -13.186 & -10.128 \\
\hline & 18 & 3.794 & 0.580 & -7.662 & $-19.164 * * *$ & -13.508 & $-7.669 * *$ & -5.539 & 1.047 & $-15.393 *$ & $-19.324 *$ \\
\hline & 30 & 0.341 & 0.557 & $-13.831 * * *$ & $-21.823 * * *$ & -6.317 & $13.140 * * *$ & $-12.112 *$ & -4.853 & $-17.134 * * *$ & $-15.855 * *$ \\
\hline & 45 & $17.093 * * *$ & $7.033 * *$ & $-10.342 * * *$ & $-7.129 * *$ & 2.102 & $19.092 * * *$ & -1.921 & $-14.768 * * *$ & $-11.033 * * *$ & -7.106 \\
\hline & 65 & $27.105 * * *$ & $11.315^{* *}$ & 2.248 & 2.485 & 6.665 & $14.429 * * *$ & 5.004 & -0.982 & -3.033 & 4.865 \\
\hline \multirow{5}{*}{ 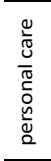 } & 10 & $-12.318^{* * *}$ & $-6.734 * * *$ & $-14.561 * * *$ & $-20.470 * * *$ & $-7.651 *$ & $-7.235 * * *$ & $-17.068 * * *$ & $-19.062 * * *$ & $-21.994 * * *$ & $-12.322 *$ \\
\hline & 18 & $-11.500 * * *$ & $-10.414 * * *$ & $-12.146 * * *$ & $-11.551 * * *$ & -0.606 & $-14.394^{* * *}$ & $-16.359 * * *$ & $-20.669 * * *$ & $-13.526 * * *$ & $-15.113^{* * *}$ \\
\hline & 30 & -1.727 & -1.351 & $-9.591 * * *$ & $-4.368 * *$ & $5.228 *$ & $-3.772 * * *$ & $-12.517 * * *$ & $-13.541 * * *$ & $-11.354 * * *$ & $-11.626^{* * *}$ \\
\hline & 45 & -1.289 & $2.078 * *$ & $-8.313^{* * *}$ & $-5.789 * * *$ & 1.441 & -1.350 & $-7.319 * * *$ & $-12.001 * * *$ & $-12.633 * * *$ & $-15.890 * * *$ \\
\hline & 65 & -1.971 & $6.551 * * *$ & $-4.297 * *$ & -2.059 & $13.112 * * *$ & $3.613^{* *}$ & $6.266 *$ & $-5.820 * *$ & $-12.939 * * *$ & $-17.035 * * *$ \\
\hline \multirow{5}{*}{$\frac{n}{\frac{n}{\pi}}$} & 10 & -0.015 & $4.435^{*}$ & 4.967 & -1.362 & -1.843 & $2.260 * *$ & 0.221 & -0.268 & $7.247 *$ & -2.842 \\
\hline & 18 & -3.306 & 0.712 & 2.262 & 1.068 & $7.291 *$ & $-3.143 * *$ & 0.357 & $8.524 * *$ & $5.232 *$ & 4.497 \\
\hline & 30 & 0.808 & 3.470 ** & 2.063 & -1.530 & $5.225 *$ & 0.506 & -0.056 & 0.015 & 3.023 & $3.816^{*}$ \\
\hline & 45 & $2.609 *$ & $4.896^{* * *}$ & $5.104^{* * *}$ & $-3.386 *$ & $8.452 * * *$ & $3.750^{* * *}$ & 0.057 & 2.233 & $5.481 * * *$ & $5.277^{* *}$ \\
\hline & 65 & 3.186 * & $5.623 * * *$ & 1.408 & $7.229 *$ & 11.952 *** & 2.102 & 0.185 & 2.031 & 2.515 & 1.759 \\
\hline \multirow{5}{*}{$\begin{array}{l}\text { ㄴ. } \\
\vdots \\
\frac{0}{\pi} \\
\frac{0}{\pi}\end{array}$} & 10 & 0.159 & $3.398^{*}$ & -4.066 & 7.389 & $8.905 * *$ & -0.109 & -4.657 & 7.203 & -1.065 & -1.489 \\
\hline & 18 & $22.431 * *$ & $30.655 * * *$ & $47.630 * * *$ & $53.972 * * *$ & $48.414 * * *$ & $28.407^{* * *}$ & $55.919 * * *$ & $48.602 * * *$ & $30.913 * *$ & 17.408 \\
\hline & 30 & $56.620 * * *$ & $91.694 * * *$ & $93.192 * * *$ & $139.362 * * *$ & $73.166 * * *$ & $66.532 * * *$ & $62.468 * * *$ & $89.442 * * *$ & $65.015^{* * *}$ & $54.376 * * *$ \\
\hline & 45 & $40.114 * * *$ & $54.353 * * *$ & $52.763 * * *$ & $88.187^{* * *}$ & $55.479 * * *$ & $45.724 * * *$ & $25.284^{* *}$ & $51.392 * * *$ & $38.972 * * *$ & $40.948^{* * *}$ \\
\hline & 65 & -0.076 & 2.151 & $4.227 * *$ & $8.536 * * *$ & $28.705 * * *$ & $9.689 *$ & 4.749 & $16.651 * * *$ & 4.160 & 6.762 \\
\hline \multirow{5}{*}{$\frac{\vec{c}}{\overrightarrow{2}}$} & 10 & -14.403 & -12.881 & -6.296 & -1.779 & -6.870 & $-12.536^{* *}$ & $34.389 *$ & -5.194 & -26.213 & -26.986 \\
\hline & 18 & -3.233 & 0.611 & $-12.909 *$ & 6.904 & -18.302 & $11.594^{*}$ & $-22.833 *$ & 11.073 & -6.539 & 4.264 \\
\hline & 30 & -0.878 & 1.526 & -1.274 & 0.803 & 1.427 & $5.450 * *$ & 0.197 & 2.832 & 2.907 & -3.451 \\
\hline & 45 & -0.205 & $-0.879 *$ & $-0.820 *$ & $3.400 *$ & -0.435 & -0.615 & -2.673 & -0.458 & 0.738 & -1.754 \\
\hline & 65 & -0.535 & 0.324 & $-1.288 * *$ & $4.731 * *$ & 0.041 & $-2.954 *$ & 0.370 & -0.382 & 0.233 & 0.960 \\
\hline \multirow{5}{*}{ 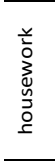 } & 10 & $-22.124 * * *$ & $-23.366 * * *$ & $-27.362 * * *$ & $-20.786 * * *$ & $-27.546 * * *$ & $-7.901 * * *$ & $-25.537^{* * *}$ & $-23.253 * * *$ & $-15.521 *$ & $-19.457^{*}$ \\
\hline & 18 & $-52.488 * * *$ & $-72.875 * * *$ & $-42.985 * * *$ & $-44.927 * * *$ & $-62.908 * * *$ & $-48.483 * * *$ & $-23.219 * *$ & $-51.755 * * *$ & $-36.691 * * *$ & $-35.569 * * *$ \\
\hline & 30 & $-99.646 * * *$ & $-147.941 * * *$ & $-72.535 * * *$ & $-80.665 * * *$ & $-121.377 * * *$ & $-122.337 * * *$ & $-59.657 * * *$ & $-75.603 * * *$ & $-54.677 * * *$ & $-59.334 * * *$ \\
\hline & 45 & $-162.907 * * *$ & $-203.780 * * *$ & $-84.567 * * *$ & $-95.875 * * *$ & $-127.747 * * *$ & $-141.470 * * *$ & $-54.756 * * *$ & $-77.596 * * *$ & $-51.685 * * *$ & $-61.711 * * *$ \\
\hline & 65 & $-160.648 * * *$ & $-195.577 * * *$ & $-94.618 * * *$ & $-73.691 * * *$ & $-118.335 * * *$ & $-136.419 * * *$ & $-72.002 * * *$ & $-67.033 * * *$ & $-42.606 * * *$ & $-71.957^{* * *}$ \\
\hline \multirow{5}{*}{ 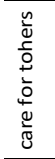 } & 10 & 0.865 & -1.073 & 4.385 & $-6.484 * * *$ & -1.922 & -0.640 & $-2.245^{*}$ & $-1.184 * *$ & -8.134 & $-6.991 *$ \\
\hline & 18 & $-15.851 * * *$ & $-8.410 * * *$ & $-16.158 * * *$ & $-11.780 * * *$ & $-21.173 * * *$ & $-19.741 * * *$ & $-20.051 * * *$ & $-29.565 * * *$ & $-26.600 * * *$ & $-18.772 * * *$ \\
\hline & 30 & $-32.031 * * *$ & $-30.955 * * *$ & $-33.385 * * *$ & $-31.158 * * *$ & $-27.918 * * *$ & $-48.870 * * *$ & $-27.582 * * *$ & $-34.833 * * *$ & $-33.182 * * *$ & $-26.648 * * *$ \\
\hline & 45 & $-11.332 * * *$ & $-8.016 * * *$ & $-5.680 * * *$ & $-9.977^{* * *}$ & $-12.714 * * *$ & $-12.246 * * *$ & -1.870 & $-3.832 * * *$ & $-9.491 * * *$ & $-10.921 * * *$ \\
\hline & 65 & -3.648 & -2.852 & -0.678 & $5.079 *$ & $5.341 *$ & $-6.841 * * *$ & $4.168 * *$ & -0.407 & -2.687 & -1.725 \\
\hline \multirow{5}{*}{ 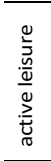 } & 10 & $12.791 * *$ & $11.366 * * *$ & $24.881 * *$ & $22.363 * * *$ & $21.445 *$ & $14.592 * * *$ & $18.738 * *$ & $14.895 * * *$ & $33.577 * * *$ & $33.085 * * *$ \\
\hline & 18 & $19.430 * * *$ & $8.798 * * *$ & $12.996 * * *$ & -0.025 & $11.267^{* *}$ & $8.542 * * *$ & -0.850 & $12.061 * * *$ & $11.681 * *$ & $24.636 * * *$ \\
\hline & 30 & $16.192 * * *$ & $13.052 * * *$ & $10.139 * * *$ & 3.244 & $7.259 * *$ & $12.347^{* * *}$ & 5.835 & $4.287^{*}$ & $7.476 * *$ & $18.413 * * *$ \\
\hline & 45 & $34.608 * * *$ & $40.222 * * *$ & $20.349 * * *$ & $5.791 * *$ & $8.236^{* * *}$ & $20.911^{* * *}$ & -1.968 & $6.379 * *$ & $6.972 * *$ & $20.986 * * *$ \\
\hline & 65 & $65.462 * * *$ & $62.411 * * *$ & $43.160 * * *$ & $26.573 * * *$ & $8.499 * * *$ & $32.271 * * *$ & $22.850 * * *$ & $22.853 * * *$ & $11.479 * * *$ & $25.085 * * *$ \\
\hline \multirow{5}{*}{ 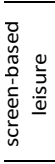 } & 10 & $24.905 * * *$ & $23.554 * * *$ & $25.263 *$ & $49.439 * * *$ & $36.505^{* *}$ & $18.580^{* * *}$ & $35.362 * *$ & $64.661 * * *$ & $62.289 * * *$ & 5.091 \\
\hline & 18 & $32.448 * * *$ & $17.463 * * *$ & $29.798 * * *$ & $35.513 * * *$ & $36.806 * * *$ & $37.515^{* * *}$ & $51.434^{* * *}$ & $44.672 * * *$ & $42.408 * * *$ & 8.031 \\
\hline & 30 & $41.868 * * *$ & $37.039 * * *$ & $31.877^{* * *}$ & $21.850 * * *$ & $42.914 * * *$ & $46.287^{* * *}$ & $47.818^{* * *}$ & $40.108^{* * *}$ & $35.215 * * *$ & $33.410 * * *$ \\
\hline & 45 & $47.761 * * *$ & $46.010 * * *$ & $29.670 * * *$ & $30.451 * * *$ & $41.077^{* * *}$ & $46.503 * * *$ & $52.640 * * *$ & $54.228 * * *$ & $46.720 * * *$ & $38.405 * * *$ \\
\hline & 65 & $21.413 * * *$ & $44.452 * * *$ & $28.147 * * *$ & $39.311^{* * *}$ & $36.347 * * *$ & $70.401 * * *$ & $33.787^{* * *}$ & $51.195 * * *$ & $51.654 * * *$ & $68.175 * * *$ \\
\hline \multirow{5}{*}{ 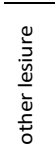 } & 10 & -4.423 & -5.513 & -16.464 & $-33.912 * * *$ & -15.474 & $-14.190 * * *$ & $-42.260 * * *$ & $-24.686 * * *$ & -18.985 & $35.326^{*}$ \\
\hline & 18 & 5.447 & $23.509 * * *$ & -4.003 & -6.157 & 4.820 & 5.147 & -13.902 & $-16.580 * *$ & 2.990 & $22.531 *$ \\
\hline & 30 & $9.582 * *$ & $24.168 * * *$ & $-10.850 * * *$ & $-20.351 * * *$ & 9.325 & $20.228 * * *$ & -1.892 & $-12.239 * *$ & -5.854 & 4.166 \\
\hline & 45 & $24.653 * * *$ & $40.038 * * *$ & -2.757 & -7.855 & $18.031 * * *$ & $16.061 * * *$ & $-11.369 *$ & $-13.867 * *$ & $-20.718 * * *$ & $-15.768 * *$ \\
\hline & 65 & $39.335 * * *$ & $44.331 * * *$ & $15.090 * * *$ & 8.087 & $17.582 *$ & $15.622 * * *$ & 3.722 & $-16.617^{* *}$ & $-14.457 *$ & $-19.368 *$ \\
\hline
\end{tabular}

Notes: OLS regressions control for day of the week (as in Table A3), but also for educational attainment, employment status, children in the household and union status. $* * * p<0.001, * * p<0.01,{ }^{*} \mathrm{p}<0.05$ 
Table A5. Median and Interquartile Range by activity. Men's and Women's daily minutes by country

\begin{tabular}{|c|c|c|c|c|c|c|c|c|c|c|c|c|}
\hline SEX & ACTIVITY & & Spain & Italy & France & Netherlands & Hungary & $\begin{array}{l}\text { South } \\
\text { Korea }\end{array}$ & Finland & UK & Canada & US \\
\hline \multirow[t]{36}{*}{ Men } & \multirow[t]{3}{*}{ Sleeping } & Median & 520 & 520 & 500 & 495 & 510 & 470 & 520 & 520 & 490 & 510 \\
\hline & & p25 & 450 & 450 & 450 & 435 & 445 & 420 & 460 & 450 & 420 & 440 \\
\hline & & p75 & 600 & 590 & 570 & 570 & 580 & 540 & 600 & 590 & 560 & 600 \\
\hline & \multirow[t]{3}{*}{ Personal care } & Median & 40 & 50 & 40 & 45 & 70 & 70 & 40 & 40 & 30 & 30 \\
\hline & & p25 & 30 & 30 & 30 & 30 & 50 & 50 & 20 & 20 & 10 & 5 \\
\hline & & p75 & 60 & 70 & 60 & 60 & 95 & 90 & 60 & 70 & 45 & 60 \\
\hline & \multirow[t]{3}{*}{ Meals } & Median & 90 & 110 & 130 & 75 & 90 & 60 & 80 & 80 & 60 & 45 \\
\hline & & p25 & 70 & 80 & 90 & 45 & 70 & 40 & 50 & 40 & 25 & 25 \\
\hline & & p75 & 130 & 140 & 170 & 105 & 120 & 90 & 100 & 120 & 90 & 75 \\
\hline & \multirow[t]{3}{*}{ Paid work } & Median & 0 & 0 & 0 & 0 & 60 & 90 & 0 & 0 & 0 & 0 \\
\hline & & p25 & 0 & 0 & 0 & 0 & 0 & 0 & 0 & 0 & 0 & 0 \\
\hline & & p75 & 420 & 360 & 360 & 495 & 440 & 460 & 160 & 360 & 475 & 455 \\
\hline & \multirow{3}{*}{ Study } & Median & 0 & 0 & 0 & 0 & 0 & 0 & 0 & 0 & 0 & 0 \\
\hline & & p25 & 0 & 0 & 0 & 0 & 0 & 0 & 0 & 0 & 0 & 0 \\
\hline & & p75 & 0 & 0 & 0 & 0 & 0 & 0 & 0 & 0 & 0 & 0 \\
\hline & Housework & Median & 40 & 30 & 90 & 45 & 60 & 0 & 80 & 70 & 70 & 45 \\
\hline & & p25 & 0 & 0 & 20 & 0 & 10 & 0 & 30 & 20 & 15 & 2 \\
\hline & & p75 & 120 & 110 & 180 & 135 & 150 & 40 & 170 & 160 & 180 & 125 \\
\hline & Care for others & Median & 0 & 0 & 0 & 0 & 0 & 0 & 0 & 0 & 0 & 0 \\
\hline & & p25 & 0 & 0 & 0 & 0 & 0 & 0 & 0 & 0 & 0 & 0 \\
\hline & & p75 & 0 & 0 & 0 & 0 & 0 & 0 & 0 & 0 & 0 & 15 \\
\hline & Active leisure & Median & 30 & 0 & 0 & 0 & 0 & 0 & 0 & 0 & 0 & 0 \\
\hline & & p25 & 0 & 0 & 0 & 0 & 0 & 0 & 0 & 0 & 0 & 0 \\
\hline & & p75 & 120 & 110 & 90 & 60 & 0 & 60 & 90 & 60 & 45 & 60 \\
\hline & Screen-based leisure & Median & 150 & 120 & 140 & 105 & 170 & 130 & 180 & 180 & 145 & 150 \\
\hline & & p25 & 70 & 60 & 60 & 30 & 90 & 60 & 90 & 80 & 60 & 60 \\
\hline & & p75 & 260 & 210 & 240 & 195 & 260 & 230 & 290 & 300 & 260 & 300 \\
\hline & Other leisure & Median & 100 & 160 & 90 & 150 & 90 & 140 & 130 & 90 & 118 & 95 \\
\hline & & p25 & 30 & 70 & 20 & 60 & 25 & 90 & 50 & 20 & 30 & 15 \\
\hline & & p75 & 200 & 270 & 200 & 270 & 180 & 220 & 260 & 200 & 265 & 230 \\
\hline & Travel & Median & 60 & 70 & 60 & 60 & 50 & 80 & 50 & 60 & 60 & 55 \\
\hline & & p25 & 20 & 40 & 20 & 30 & 20 & 50 & 10 & 20 & 20 & 20 \\
\hline & & p75 & 100 & 120 & 110 & 105 & 90 & 120 & 90 & 110 & 100 & 100 \\
\hline & Other & Median & 0 & 0 & 0 & 0 & 0 & 0 & 0 & 0 & 0 & 0 \\
\hline & & p25 & 0 & 0 & 0 & 0 & 0 & 0 & 0 & 0 & 0 & 0 \\
\hline & & p75 & 0 & 0 & 0 & 0 & 0 & 0 & 0 & 10 & 0 & 0 \\
\hline Women & Sleeping & Median & 510 & 520 & 510 & 510 & 510 & 470 & 530 & 520 & 510 & 530 \\
\hline & & p25 & 450 & 460 & 450 & 465 & 450 & 420 & 470 & 460 & 450 & 450 \\
\hline & & p75 & 590 & 580 & 570 & 570 & 570 & 540 & 600 & 590 & 570 & 603 \\
\hline & Personal care & Median & 50 & 50 & 50 & 45 & 65 & 70 & 50 & 60 & 40 & 45 \\
\hline & & p25 & 30 & 30 & 30 & 30 & 45 & 50 & 30 & 40 & 20 & 20 \\
\hline & & p75 & 70 & 80 & 70 & 75 & 90 & 90 & 70 & 80 & 60 & 75 \\
\hline & Meals & Median & 100 & 110 & 120 & 75 & 90 & 70 & 70 & 80 & 50 & 45 \\
\hline & & p25 & 70 & 80 & 90 & 45 & 70 & 40 & 50 & 40 & 20 & 20 \\
\hline & & p75 & 120 & 140 & 170 & 105 & 110 & 90 & 100 & 120 & 90 & 75 \\
\hline & Paid work & Median & 0 & 0 & 0 & 0 & 0 & 0 & 0 & 0 & 0 & 0 \\
\hline & & p25 & 0 & 0 & 0 & 0 & 0 & 0 & 0 & 0 & 0 & 0 \\
\hline & & p75 & 0 & 0 & 90 & 195 & 240 & 290 & 10 & 0 & 375 & 225 \\
\hline & Study & Median & 0 & 0 & 0 & 0 & 0 & 0 & 0 & 0 & 0 & 0 \\
\hline & & p25 & 0 & 0 & 0 & 0 & 0 & 0 & 0 & 0 & 0 & 0 \\
\hline & & p75 & 0 & 0 & 0 & 0 & 0 & 0 & 0 & 0 & 0 & 0 \\
\hline & Housework & Median & 190 & 230 & 180 & 135 & 210 & 140 & 140 & 150 & 140 & 120 \\
\hline & & p25 & 90 & 100 & 90 & 45 & 110 & 40 & 70 & 70 & 60 & 40 \\
\hline & & p75 & 310 & 370 & 280 & 255 & 315 & 240 & 240 & 260 & 260 & 235 \\
\hline & Care for others & Median & 0 & 0 & 0 & 0 & 0 & 0 & 0 & 0 & 0 & 0 \\
\hline & & p25 & 0 & 0 & 0 & 0 & 0 & 0 & 0 & 0 & 0 & 0 \\
\hline & & p75 & 40 & 10 & 30 & 30 & 20 & 30 & 0 & 10 & 9 & 60 \\
\hline & Active leisure & Median & 0 & 0 & 0 & 0 & 0 & 0 & 20 & 0 & 0 & 0 \\
\hline & & p25 & 0 & 0 & 0 & 0 & 0 & 0 & 0 & 0 & 0 & 0 \\
\hline & & p75 & 80 & 60 & 60 & 30 & 0 & 40 & 70 & 40 & 30 & 20 \\
\hline & Screen-based leisure & Median & 120 & 90 & 120 & 75 & 135 & 110 & 130 & 140 & 110 & 120 \\
\hline & & p25 & 60 & 30 & 40 & 15 & 75 & 50 & 60 & 60 & 30 & 40 \\
\hline & & p75 & 220 & 160 & 200 & 150 & 220 & 200 & 220 & 230 & 210 & 245 \\
\hline & Other leisure & Median & 90 & 140 & 110 & 180 & 90 & 130 & 160 & 120 & 150 & 120 \\
\hline & & p25 & 20 & 60 & 30 & 75 & 20 & 80 & 70 & 40 & 45 & 30 \\
\hline & & p75 & 180 & 230 & 210 & 285 & 180 & 210 & 270 & 230 & 300 & 245 \\
\hline & Travel & Median & 50 & 50 & 60 & 60 & 40 & 70 & 50 & 50 & 50 & 51 \\
\hline & & p25 & 20 & 20 & 10 & 30 & 10 & 40 & 10 & 20 & 20 & 20 \\
\hline & & p75 & 90 & 100 & 100 & 105 & 80 & 120 & 90 & 100 & 95 & 100 \\
\hline & Other & Median & 0 & 0 & 0 & 0 & 0 & 0 & 0 & 0 & 0 & 0 \\
\hline & & p25 & 0 & 0 & 0 & 0 & 0 & 0 & 0 & 0 & 0 & 0 \\
\hline & & p75 & 0 & 0 & 0 & 0 & 0 & 0 & 0 & 10 & 0 & 0 \\
\hline
\end{tabular}

Source: Multinational Time Use Study [32]. 
Table A6. Net differences between retired and other employment status.

\begin{tabular}{|c|c|c|c|c|c|c|c|c|c|c|}
\hline & Sleeping & $\begin{array}{c}\text { Personal } \\
\text { care }\end{array}$ & Meals & Paid work & Study & Housework & $\begin{array}{c}\text { Care for } \\
\text { others }\end{array}$ & $\begin{array}{l}\text { Active } \\
\text { leisure }\end{array}$ & $\begin{array}{l}\text { Screen-based } \\
\text { leisure }\end{array}$ & $\begin{array}{l}\text { Other } \\
\text { leisure }\end{array}$ \\
\hline \multicolumn{11}{|l|}{ AGE GROUP: 45 to 64} \\
\hline Employed (ref. retired) & $\begin{array}{c}-31,560 * * * \\
(1,526)\end{array}$ & $\begin{array}{c}0,125 \\
(0,615)\end{array}$ & $\begin{array}{c}-12,814^{* * *} \\
(0,791)\end{array}$ & $\begin{array}{c}300,678^{* * *} \\
(1,286)\end{array}$ & $\begin{array}{c}-2,826^{* * *} \\
(0,404)\end{array}$ & $\begin{array}{c}-76,538^{* * * *} \\
(1,993)\end{array}$ & $\begin{array}{c}-13,545^{* * *} \\
(0,931)\end{array}$ & $\begin{array}{c}-39,491 * * * \\
(1,372)\end{array}$ & $\begin{array}{c}-62,949 * * * \\
(1,917)\end{array}$ & $\begin{array}{c}-60,318^{* * *} \\
(1,972)\end{array}$ \\
\hline Non employed (ref. retired) & $\begin{array}{c}0,51 \\
(1,691)\end{array}$ & $\begin{array}{c}0,934 \\
(0,711)\end{array}$ & $\begin{array}{c}-2,412^{* *} \\
(0,859)\end{array}$ & $\begin{array}{c}26,424^{* * * *} \\
(1,232)\end{array}$ & $\begin{array}{l}1,388^{* *} \\
(0,516)\end{array}$ & $\begin{array}{c}11,951^{* * * *} \\
(2,244)\end{array}$ & $\begin{array}{c}1,249 \\
(1,065)\end{array}$ & $\begin{array}{c}-20,968^{* * *} \\
(1,443)\end{array}$ & $\begin{array}{l}-0,535 \\
(2,155)\end{array}$ & $\begin{array}{c}-16,444^{* * *} \\
(2,157)\end{array}$ \\
\hline Constant & $\begin{array}{c}503,158^{* * *} \\
(8,869)\end{array}$ & $\begin{array}{c}44,057 * * * \\
(2,956)\end{array}$ & $\begin{array}{c}69,893^{* * *} \\
(3,984)\end{array}$ & $\begin{array}{c}-14,627^{* * *} \\
(2,358)\end{array}$ & $\begin{array}{c}18,891 * * * \\
(2,629)\end{array}$ & $\begin{array}{c}240,698 * * * \\
(9,608)\end{array}$ & $\begin{array}{c}32,539 * * * \\
(3,835)\end{array}$ & $\begin{array}{c}56,064 * * * \\
(5,246)\end{array}$ & $\begin{array}{c}180,406 * * * \\
(10,43)\end{array}$ & $\begin{array}{c}92,667 * * * \\
(9,571)\end{array}$ \\
\hline Observations & 63.611 & 63.611 & 63.611 & 201.972 & 63.611 & 63.611 & 63.611 & 63.611 & 63.611 & 63.611 \\
\hline R-squared & 0,079 & 0,069 & 0,198 & 0,481 & 0,018 & 0,316 & 0,064 & 0,074 & 0,125 & 0,124 \\
\hline \multicolumn{11}{|l|}{ AGE GROUP: 65 or older } \\
\hline Employed (ref. retired) & $\begin{array}{c}-23,483 * * * \\
(2,154)\end{array}$ & $\begin{array}{c}-2,339 * * \\
(0,899)\end{array}$ & $\begin{array}{c}-7,779 * * * \\
(1,105)\end{array}$ & $\begin{array}{c}251,016^{* * *} \\
(4,35)\end{array}$ & $\begin{array}{c}-1,966 * * * \\
(0,43)\end{array}$ & $\begin{array}{c}-49,316^{* * *} \\
(2,629)\end{array}$ & $\begin{array}{c}-7,045^{* * *} \\
(0,835)\end{array}$ & $\begin{array}{c}-31,608 * * * \\
(1,772)\end{array}$ & $\begin{array}{c}-75,702^{* * *} \\
(2,798)\end{array}$ & $\begin{array}{c}-58,928 * * * \\
(2,822)\end{array}$ \\
\hline Non employed (ref. retired) & $\begin{array}{c}7,740 * * * \\
(2,273)\end{array}$ & $\begin{array}{c}1,43 \\
(0,955)\end{array}$ & $\begin{array}{c}-0,073 \\
(0,907)\end{array}$ & $\begin{array}{c}7,576 * * * \\
(1,178)\end{array}$ & $\begin{array}{c}-0,548 * * \\
(0,207)\end{array}$ & $\begin{array}{c}14,230 * * * \\
(2,671)\end{array}$ & $\begin{array}{c}-1,332 \\
(1,083)\end{array}$ & $\begin{array}{c}-15,744^{* * *} \\
(1,338)\end{array}$ & $\begin{array}{c}2,493 \\
(2,536)\end{array}$ & $\begin{array}{c}-9,601 * * * \\
(2,475)\end{array}$ \\
\hline Constant & $\begin{array}{c}276,628^{* * *} \\
(11,661)\end{array}$ & $\begin{array}{c}38,083^{* * *} \\
(3,986)\end{array}$ & $\begin{array}{c}58,074^{* * *} \\
(5,02)\end{array}$ & $\begin{array}{c}49,043^{* * *} \\
(6,091)\end{array}$ & $\begin{array}{c}9,400 * * * \\
(1,482)\end{array}$ & $\begin{array}{c}468,358^{* * *} \\
(11,605)\end{array}$ & $\begin{array}{c}64,943^{* * *} \\
(4,228)\end{array}$ & $\begin{array}{c}161,083^{* * *} \\
(7,401)\end{array}$ & $\begin{array}{c}106,807^{* * *} \\
(12,656)\end{array}$ & $\begin{array}{c}24,088^{*} \\
(12,217)\end{array}$ \\
\hline Observations & 37.885 & 37.885 & 37.885 & 37.885 & 37.885 & 37.885 & 37.885 & 37.885 & 37.885 & 37.885 \\
\hline R-squared & 0,105 & 0,038 & 0,172 & 0,494 & 0,022 & 0,233 & 0,025 & 0,103 & 0,091 & 0,092 \\
\hline
\end{tabular}

Source: Multinational Time Use Study [32]. OLS also control by country, continuous age, educational attainment, employment status, children in the household, union status and day of the week. $* * * p<0.001$, $* * \mathrm{p}<0.01, * \mathrm{p}<0.05$ 
Table A7. Median by activity for those who spend at least 1 minute in the activity. Men's and Women's daily minutes by country

\begin{tabular}{|c|c|c|c|c|c|c|c|c|c|c|c|c|c|c|c|c|c|c|c|c|c|}
\hline \multirow[b]{2}{*}{ AGE } & \multirow[b]{2}{*}{ ACTIVITY } & \multicolumn{2}{|c|}{ Spain } & \multicolumn{2}{|c|}{ Italy } & \multicolumn{2}{|c|}{ France } & \multicolumn{2}{|c|}{ Netherlands } & \multicolumn{2}{|c|}{ Hungary } & \multicolumn{2}{|c|}{ South Korea } & \multicolumn{2}{|c|}{ Finland } & \multicolumn{2}{|c|}{ UK } & \multicolumn{2}{|c|}{ Canada } & \multicolumn{2}{|c|}{ US } \\
\hline & & $M$ & W & $M$ & W & $M$ & W & $M$ & W & $M$ & W & $\mathrm{M}$ & w & $M$ & W & $M$ & W & $M$ & W & $M$ & W \\
\hline & 10-17 Sleeping & 570 & 560 & 560 & 560 & 600 & 590 & 555 & 540 & 570 & 573 & 490 & 490 & 600 & 585 & 600 & 600 & 540 & 554 & 570 & 575 \\
\hline & Personal care & 40 & 50 & 50 & 50 & 40 & 60 & 45 & 60 & 55 & 65 & 70 & 70 & 40 & 50 & 40 & 60 & 30 & 60 & 40 & 60 \\
\hline & Meals & 90 & 90 & 100 & 100 & 110 & 110 & 60 & 60 & 90 & 85 & 60 & 60 & 70 & 60 & 70 & 70 & 55 & 50 & 40 & 45 \\
\hline & Paid work & 430 & 385 & 435 & 225 & 110 & 65 & 180 & 180 & 50 & 40 & 165 & 240 & 140 & 175 & 180 & 190 & 310 & 320 & 245 & 232 \\
\hline & Study & 390 & 385 & 360 & 350 & 350 & 320 & 390 & 390 & 378 & 400 & 470 & 480 & 320 & 300 & 350 & 340 & 370 & 375 & 397 & 368 \\
\hline & Housework & 40 & 50 & 30 & 60 & 60 & 60 & 30 & 45 & 45 & 60 & 20 & 30 & 40 & 50 & 30 & 50 & 45 & 50 & 40 & 60 \\
\hline & Care for others & 60 & 30 & 30 & 30 & 90 & 40 & 45 & 60 & 60 & 80 & 30 & 30 & 20 & 30 & 30 & 30 & 48 & 104 & 10 & 27 \\
\hline & Active leisure & 110 & 110 & 120 & 100 & 120 & 110 & 120 & 90 & 90 & 85 & 50 & 40 & 100 & 70 & 90 & 70 & 127 & 95 & 120 & 90 \\
\hline & Screen-based leisure & 170 & 150 & 150 & 130 & 210 & 180 & 150 & 105 & 182 & 150 & 140 & 130 & 220 & 190 & 235 & 170 & 180 & 148 & 151 & 175 \\
\hline & Other leisure & 140 & 150 & 170 & 170 & 120 & 140 & 150 & 165 & 113 & 130 & 110 & 120 & 180 & 190 & 130 & 160 & 150 & 175 & 180 & 180 \\
\hline & 18-29 Sleeping & 520 & 520 & 510 & 510 & 510 & 520 & 495 & 510 & 510 & 530 & 470 & 480 & 540 & 540 & 540 & 540 & 510 & 530 & 540 & 550 \\
\hline & Personal care & 40 & 50 & 50 & 60 & 40 & 50 & 45 & 60 & 70 & 70 & 70 & 80 & 40 & 50 & 40 & 60 & 30 & 50 & 40 & 60 \\
\hline & Meals & 90 & 90 & 90 & 90 & 110 & 110 & 60 & 60 & 85 & 80 & 50 & 60 & 60 & 60 & 70 & 70 & 50 & 45 & 45 & 45 \\
\hline & Paid work & 480 & 430 & 490 & 440 & 470 & 420 & 510 & 480 & 450 & 440 & 450 & 420 & 450 & 410 & 480 & 450 & 485 & 464 & 469 & 450 \\
\hline & Study & 290 & 300 & 310 & 290 & 330 & 300 & 285 & 225 & 343 & 330 & 320 & 270 & 220 & 225 & 300 & 260 & 340 & 305 & 243 & 180 \\
\hline & Housework & 60 & 110 & 50 & 110 & 70 & 120 & 60 & 105 & 55 & 130 & 40 & 80 & 70 & 90 & 60 & 110 & 60 & 115 & 60 & 113 \\
\hline & Care for others & 80 & 150 & 60 & 110 & 60 & 110 & 60 & 150 & 70 & 210 & 40 & 160 & 70 & 160 & 50 & 130 & 70 & 168 & 45 & 95 \\
\hline & Active leisure & 110 & 80 & 110 & 80 & 110 & 80 & 90 & 90 & 80 & 60 & 70 & 60 & 80 & 70 & 80 & 60 & 105 & 60 & 90 & 55 \\
\hline & Screen-based leisure & 160 & 130 & 120 & 110 & 170 & 140 & 135 & 90 & 174 & 135 & 160 & 130 & 200 & 150 & 180 & 140 & 150 & 120 & 180 & 140 \\
\hline & Other leisure & 150 & 140 & 210 & 190 & 130 & 130 & 180 & 180 & 120 & 110 & 150 & 140 & 130 & 140 & 110 & 120 & 155 & 160 & 175 & 150 \\
\hline & 30-44 Sleeping & 480 & 500 & 500 & 500 & 480 & 510 & 465 & 495 & 480 & 490 & 460 & 460 & 500 & 520 & 510 & 510 & 480 & 495 & 502 & 518 \\
\hline & Personal care & 40 & 40 & 50 & 50 & 40 & 50 & 45 & 45 & 70 & 60 & 60 & 60 & 40 & 50 & 40 & 60 & 30 & 45 & 40 & 50 \\
\hline & Meals & 90 & 90 & 100 & 100 & 120 & 110 & 75 & 75 & 90 & 90 & 60 & 70 & 70 & 70 & 70 & 70 & 60 & 60 & 50 & 45 \\
\hline & Paid work & 490 & 420 & 490 & 410 & 480 & 420 & 510 & 420 & 470 & 440 & 470 & 400 & 480 & 450 & 480 & 420 & 500 & 455 & 481 & 450 \\
\hline & Study & 160 & 150 & 230 & 170 & 90 & 60 & 90 & 90 & 155 & 120 & 110 & 110 & 180 & 150 & 120 & 90 & 235 & 153 & 210 & 142 \\
\hline & Housework & 90 & 190 & 70 & 240 & 100 & 170 & 75 & 180 & 75 & 210 & 40 & 190 & 90 & 160 & 80 & 170 & 90 & 155 & 75 & 150 \\
\hline & Care for others & 90 & 120 & 80 & 100 & 60 & 90 & 60 & 105 & 90 & 125 & 50 & 80 & 70 & 70 & 70 & 100 & 85 & 125 & 75 & 103 \\
\hline & Active leisure & 90 & 80 & 100 & 90 & 90 & 80 & 75 & 60 & 75 & 75 & 70 & 70 & 80 & 70 & 70 & 70 & 90 & 60 & 90 & 60 \\
\hline & Screen-based leisure & 130 & 100 & 120 & 90 & 150 & 120 & 113 & 105 & 150 & 120 & 120 & 110 & 170 & 120 & 160 & 120 & 130 & 105 & 155 & 125 \\
\hline & Other leisure & 100 & 100 & 150 & 130 & 110 & 110 & 135 & 150 & 80 & 85 & 140 & 120 & 110 & 120 & 100 & 120 & 120 & 125 & 120 & 120 \\
\hline & 45-64 Sleeping & 500 & 490 & 490 & 500 & 490 & 500 & 480 & 510 & 495 & 500 & 460 & 460 & 510 & 510 & 490 & 510 & 480 & 490 & 507 & 510 \\
\hline & Personal care & 40 & 50 & 50 & 50 & 40 & 50 & 45 & 60 & 70 & 65 & 70 & 70 & 40 & 50 & 40 & 60 & 30 & 45 & 40 & 60 \\
\hline & Meals & 100 & 100 & 110 & 110 & 130 & 120 & 75 & 90 & 95 & 90 & 70 & 70 & 80 & 80 & 80 & 80 & 60 & 60 & 50 & 50 \\
\hline & Paid work & 490 & 420 & 480 & 390 & 470 & 420 & 495 & 375 & 400 & 360 & 450 & 400 & 470 & 450 & 475 & 420 & 495 & 465 & 484 & 455 \\
\hline & Study & 155 & 110 & 110 & 130 & 60 & 75 & 90 & 75 & 75 & 93 & 80 & 90 & 100 & 170 & 75 & 100 & 143 & 120 & 180 & 160 \\
\hline & Housework & 100 & 260 & 90 & 320 & 130 & 210 & 90 & 195 & 115 & 241 & 50 & 190 & 110 & 170 & 110 & 190 & 120 & 165 & 85 & 140 \\
\hline & Care for others & 60 & 80 & 60 & 60 & 60 & 60 & 45 & 60 & 65 & 90 & 30 & 30 & 30 & 30 & 40 & 40 & 85 & 90 & 45 & 60 \\
\hline & Active leisure & 110 & 90 & 120 & 90 & 120 & 80 & 90 & 75 & 73 & 60 & 80 & 80 & 90 & 70 & 70 & 60 & 90 & 60 & 80 & 58 \\
\hline & Screen-based leisure & 160 & 140 & 140 & 110 & 160 & 130 & 135 & 120 & 180 & 150 & 130 & 130 & 180 & 140 & 200 & 150 & 177 & 145 & 195 & 166 \\
\hline & Other leisure & 120 & 120 & 160 & 140 & 120 & 120 & 180 & 210 & 120 & 120 & 150 & 140 & 140 & 170 & 130 & 140 & 150 & 170 & 120 & 150 \\
\hline & 65+ Sleeping & 570 & 560 & 540 & 540 & 520 & 530 & 525 & 540 & 550 & 540 & 500 & 510 & 530 & 540 & 510 & 510 & 510 & 525 & 540 & 540 \\
\hline & Personal care & 50 & 50 & 50 & 50 & 50 & 60 & 45 & 60 & 75 & 65 & 70 & 60 & 50 & 50 & 50 & 60 & 30 & 45 & 43 & 43 \\
\hline & Meals & 110 & 100 & 120 & 120 & 140 & 130 & 105 & 90 & 100 & 90 & 90 & 80 & 90 & 90 & 110 & 100 & 80 & 70 & 60 & 60 \\
\hline & Paid work & 520 & 405 & 430 & 390 & 140 & 60 & 225 & 30 & 160 & 90 & 305 & 210 & 250 & 165 & 260 & 160 & 330 & 368 & 374 & 374 \\
\hline & Study & 100 & 105 & 120 & 110 & 60 & 70 & 75 & 68 & 215 & 145 & 100 & 100 & 70 & 100 & 80 & 80 & 120 & 99 & 90 & 90 \\
\hline & Housework & 110 & 250 & 110 & 300 & 140 & 230 & 150 & 225 & 135 & 250 & 60 & 190 & 140 & 210 & 140 & 210 & 140 & 180 & 90 & 90 \\
\hline & Care for others & 100 & 90 & 70 & 70 & 60 & 60 & 53 & 60 & 90 & 90 & 50 & 40 & 30 & 60 & 30 & 30 & 113 & 75 & 32 & 32 \\
\hline & Active leisure & 140 & 90 & 130 & 80 & 120 & 80 & 105 & 75 & 60 & 60 & 100 & 70 & 80 & 70 & 90 & 60 & 85 & 60 & 82 & 82 \\
\hline & Screen-based leisure & 230 & 220 & 180 & 150 & 210 & 180 & 180 & 135 & 220 & 190 & 220 & 180 & 210 & 170 & 240 & 190 & 240 & 210 & 310 & 310 \\
\hline & Other leisure & 170 & 130 & 220 & 180 & 180 & 180 & 240 & 255 & 170 & 165 & 170 & 170 & 230 & 220 & 170 & 190 & 240 & 270 & 205 & 205 \\
\hline
\end{tabular}

Source: Multinational Time Use Study [32]. 
Table A8. IQR by activity for those who spend at least 1 minute.

Men's and Women's daily minutes by country

\begin{tabular}{|c|c|c|c|c|c|c|c|c|c|c|c|c|c|c|c|c|c|c|c|c|c|}
\hline \multirow{3}{*}{\multicolumn{2}{|c|}{ AGE }} & \multicolumn{4}{|c|}{ Spain } & \multicolumn{4}{|c|}{ Italy } & \multicolumn{4}{|c|}{ France } & \multicolumn{4}{|c|}{ Netherlands } & \multicolumn{4}{|c|}{ Hungary } \\
\hline & & \multicolumn{2}{|c|}{$\mathrm{M}$} & \multicolumn{2}{|c|}{ W } & \multicolumn{2}{|c|}{$\mathrm{M}$} & \multicolumn{2}{|c|}{ W } & \multicolumn{2}{|c|}{$M$} & \multicolumn{2}{|c|}{ W } & $M$ & & W & & $\mathrm{M}$ & & W & \\
\hline & & $\mathrm{p} 25$ & $\mathrm{p} 75$ & $\mathrm{p} 25$ & $p 75$ & $\mathrm{p} 25$ & $\mathrm{p} 75$ & $p 25$ & $\mathrm{p} 75$ & $\mathrm{p} 25$ & p75 & $\mathrm{p} 25$ & $\mathrm{p} 75$ & p25 & $\mathrm{p} 75$ & $\mathrm{p} 25$ & $\mathrm{p} 75$ & $\mathrm{p} 25$ & $\mathrm{p} 75$ & $\mathrm{p} 25$ & p75 \\
\hline & 10-17 Sleeping & 500 & 640 & 500 & 640 & 500 & 650 & 500 & 640 & 520 & 680 & 530 & 670 & 495 & 615 & 495 & 615 & 510 & 630 & 520 & 640 \\
\hline & Personal care & 30 & 60 & 40 & 80 & 30 & 70 & 30 & 80 & 30 & 60 & 40 & 80 & 30 & 60 & 30 & 75 & 40 & 75 & 50 & 90 \\
\hline & Meals & 70 & 120 & 70 & 120 & 80 & 130 & 70 & 130 & 70 & 140 & 80 & 140 & 45 & 90 & 45 & 90 & 70 & 110 & 65 & 110 \\
\hline & Paid work & 110 & 480 & 250 & 475 & 275 & 490 & 190 & 300 & 60 & 530 & 50 & 255 & 75 & 420 & 75 & 375 & 20 & 170 & 15 & 68 \\
\hline & Study & 170 & 470 & 150 & 495 & 150 & 440 & 120 & 450 & 120 & 490 & 120 & 480 & 270 & 465 & 270 & 465 & 208 & 450 & 250 & 470 \\
\hline & Housework & 20 & 70 & 20 & 100 & 20 & 70 & 30 & 110 & 30 & 110 & 30 & 120 & 15 & 60 & 30 & 90 & 15 & 90 & 25 & 135 \\
\hline & Care for others & 20 & 120 & 20 & 50 & 20 & 80 & 20 & 70 & 45 & 145 & 20 & 70 & 23 & 75 & 30 & 120 & 30 & 120 & 20 & 120 \\
\hline & Active leisure & 60 & 150 & 60 & 160 & 70 & 170 & 60 & 150 & 70 & 200 & 60 & 180 & 75 & 165 & 60 & 135 & 60 & 145 & 45 & 150 \\
\hline & Screen-based leisure & 100 & 270 & 90 & 240 & 90 & 230 & 70 & 200 & 110 & 300 & 90 & 270 & 75 & 225 & 60 & 165 & 108 & 285 & 90 & 230 \\
\hline & Other leisure & 70 & 250 & 70 & 270 & 90 & 290 & 90 & 280 & 60 & 210 & 70 & 240 & 60 & 270 & 90 & 285 & 55 & 190 & 60 & 210 \\
\hline & 18-29 Sleeping & 440 & 610 & 450 & 600 & 440 & 600 & 440 & 590 & 450 & 600 & 460 & 600 & 435 & 570 & 465 & 585 & 435 & 600 & 455 & 600 \\
\hline & Personal care & 30 & 60 & 30 & 80 & 30 & 80 & 40 & 90 & 30 & 60 & 30 & 80 & 30 & 75 & 45 & 90 & 50 & 97 & 50 & 95 \\
\hline & Meals & 60 & 120 & 70 & 120 & 60 & 130 & 70 & 130 & 70 & 160 & 80 & 150 & 45 & 90 & 45 & 90 & 70 & 110 & 60 & 105 \\
\hline & Paid work & 400 & 550 & 300 & 490 & 420 & 540 & 320 & 500 & 340 & 520 & 240 & 500 & 435 & 570 & 345 & 525 & 285 & 515 & 280 & 480 \\
\hline & Study & 170 & 440 & 150 & 440 & 180 & 440 & 170 & 410 & 125 & 500 & 120 & 450 & 150 & 420 & 120 & 360 & 210 & 435 & 158 & 465 \\
\hline & Housework & 30 & 130 & 50 & 200 & 20 & 100 & 50 & 220 & 40 & 130 & 60 & 200 & 30 & 120 & 45 & 195 & 20 & 108 & 52 & 225 \\
\hline & Care for others & 40 & 150 & 70 & 230 & 30 & 150 & 40 & 200 & 40 & 135 & 60 & 190 & 30 & 113 & 90 & 225 & 35 & 130 & 120 & 330 \\
\hline & Active leisure & 70 & 180 & 50 & 130 & 60 & 160 & 60 & 130 & 60 & 180 & 40 & 130 & 75 & 135 & 60 & 120 & 60 & 125 & 30 & 100 \\
\hline & Screen-based leisure & 90 & 280 & 80 & 210 & 70 & 200 & 60 & 170 & 100 & 280 & 80 & 220 & 75 & 225 & 45 & 165 & 100 & 280 & 90 & 215 \\
\hline & Other leisure & 70 & 280 & 60 & 260 & 120 & 340 & 100 & 300 & 60 & 250 & 60 & 240 & 75 & 315 & 90 & 285 & 55 & 210 & 55 & 185 \\
\hline & 30-44 Sleeping & 420 & 570 & 440 & 570 & 430 & 570 & 450 & 560 & 430 & 550 & 450 & 570 & 420 & 525 & 450 & 555 & 420 & 540 & 440 & 550 \\
\hline & Personal care & 30 & 60 & 30 & 60 & 30 & 70 & 30 & 70 & 30 & 60 & 30 & 70 & 30 & 60 & 30 & 60 & 50 & 95 & 45 & 85 \\
\hline & Meals & 60 & 120 & 70 & 120 & 70 & 130 & 70 & 130 & 80 & 160 & 80 & 160 & 45 & 90 & 45 & 105 & 70 & 115 & 70 & 110 \\
\hline & Paid work & 420 & 580 & 300 & 480 & 410 & 560 & 300 & 490 & 350 & 540 & 210 & 490 & 465 & 570 & 270 & 510 & 360 & 540 & 270 & 480 \\
\hline & Study & 90 & 260 & 80 & 240 & 120 & 370 & 110 & 300 & 40 & 180 & 30 & 180 & 30 & 195 & 45 & 158 & 90 & 250 & 75 & 270 \\
\hline & Housework & 40 & 160 & 110 & 290 & 30 & 140 & 140 & 360 & 50 & 190 & 90 & 260 & 45 & 150 & 90 & 270 & 30 & 150 & 120 & 320 \\
\hline & Care for others & 40 & 170 & 60 & 210 & 40 & 140 & 40 & 180 & 30 & 110 & 50 & 160 & 30 & 120 & 60 & 165 & 50 & 150 & 60 & 215 \\
\hline & Active leisure & 60 & 150 & 50 & 120 & 60 & 170 & 60 & 130 & 60 & 170 & 40 & 130 & 45 & 120 & 45 & 105 & 53 & 130 & 60 & 120 \\
\hline & Screen-based leisure & 80 & 220 & 60 & 170 & 70 & 190 & 60 & 140 & 90 & 230 & 60 & 180 & 60 & 180 & 60 & 150 & 90 & 240 & 70 & 180 \\
\hline & Other leisure & 50 & 190 & 50 & 180 & 70 & 260 & 60 & 210 & 50 & 200 & 60 & 190 & 60 & 240 & 75 & 255 & 40 & 150 & 40 & 150 \\
\hline & 45-64 Sleeping & 440 & 570 & 440 & 550 & 440 & 560 & 440 & 550 & 430 & 540 & 450 & 560 & 435 & 540 & 450 & 555 & 435 & 555 & 450 & 555 \\
\hline & Personal care & 30 & 60 & 30 & 70 & 30 & 70 & 30 & 70 & 30 & 60 & 30 & 70 & 30 & 60 & 30 & 75 & 50 & 93 & 45 & 90 \\
\hline & Meals & 70 & 130 & 70 & 130 & 80 & 140 & 80 & 140 & 90 & 180 & 90 & 170 & 60 & 105 & 60 & 120 & 75 & 123 & 70 & 115 \\
\hline & Paid work & 420 & 570 & 330 & 480 & 370 & 550 & 290 & 480 & 300 & 540 & 210 & 490 & 435 & 555 & 225 & 495 & 175 & 505 & 130 & 475 \\
\hline & Study & 80 & 250 & 70 & 180 & 95 & 170 & 110 & 240 & 40 & 120 & 30 & 130 & 45 & 180 & 45 & 135 & 35 & 295 & 60 & 180 \\
\hline & Housework & 50 & 180 & 160 & 370 & 40 & 170 & 200 & 430 & 60 & 220 & 120 & 310 & 45 & 180 & 120 & 300 & 50 & 200 & 150 & 345 \\
\hline & Care for others & 30 & 140 & 40 & 160 & 20 & 120 & 20 & 120 & 30 & 120 & 30 & 120 & 30 & 90 & 30 & 120 & 40 & 115 & 45 & 145 \\
\hline & Active leisure & 60 & 180 & 60 & 130 & 70 & 200 & 60 & 130 & 60 & 190 & 50 & 130 & 60 & 135 & 45 & 120 & 40 & 120 & 35 & 110 \\
\hline & Screen-based leisure & 90 & 260 & 80 & 220 & 90 & 220 & 60 & 160 & 100 & 240 & 80 & 210 & 75 & 210 & 60 & 180 & 120 & 270 & 95 & 225 \\
\hline & Other leisure & 60 & 220 & 60 & 200 & 90 & 270 & 70 & 220 & 60 & 220 & 60 & 210 & 90 & 300 & 120 & 315 & 60 & 195 & 60 & 190 \\
\hline & $65+$ Sleeping & 510 & 650 & 500 & 630 & 480 & 620 & 490 & 620 & 480 & 570 & 480 & 580 & 480 & 570 & 495 & 585 & 490 & 610 & 490 & 600 \\
\hline & Personal care & 30 & 70 & 30 & 70 & 30 & 80 & 30 & 80 & 30 & 80 & 40 & 80 & 30 & 75 & 30 & 75 & 50 & 105 & 45 & 90 \\
\hline & Meals & 90 & 140 & 80 & 130 & 100 & 150 & 90 & 140 & 110 & 180 & 100 & 170 & 75 & 135 & 60 & 120 & 80 & 130 & 70 & 115 \\
\hline & Paid work & 350 & 600 & 360 & 475 & 270 & 540 & 280 & 500 & 40 & 390 & 40 & 180 & 105 & 405 & 30 & 60 & 70 & 260 & 50 & 193 \\
\hline & Study & 70 & 130 & 60 & 145 & 60 & 240 & 90 & 140 & 30 & 130 & 45 & 125 & 45 & 120 & 30 & 120 & 158 & 290 & 100 & 160 \\
\hline & Housework & 50 & 190 & 170 & 340 & 50 & 190 & 210 & 390 & 80 & 230 & 150 & 320 & 75 & 240 & 135 & 315 & 65 & 210 & 175 & 325 \\
\hline & Care for others & 50 & 160 & 40 & 160 & 40 & 150 & 30 & 140 & 30 & 120 & 30 & 110 & 30 & 135 & 30 & 165 & 55 & 133 & 50 & 150 \\
\hline & Active leisure & 90 & 220 & 60 & 140 & 80 & 210 & 60 & 120 & 60 & 180 & 50 & 120 & 60 & 180 & 45 & 120 & 30 & 115 & 35 & 90 \\
\hline & Screen-based leisure & 150 & 330 & 140 & 310 & 120 & 260 & 90 & 220 & 130 & 300 & 120 & 270 & 120 & 255 & 90 & 225 & 150 & 315 & 120 & 270 \\
\hline & Other leisure & 90 & 265 & 70 & 220 & 130 & 310 & 110 & 270 & 100 & 280 & 100 & 270 & 150 & 375 & 165 & 375 & 100 & 270 & 100 & 255 \\
\hline
\end{tabular}

Source: Multinational Time Use Study [32]. 
Table A8 (continuation).

\begin{tabular}{|c|c|c|c|c|c|c|c|c|c|c|c|c|c|c|c|c|c|c|c|c|c|}
\hline \multirow[b]{3}{*}{$\underline{\text { AGE }}$} & \multirow[b]{3}{*}{ ACTIVITY } & \multicolumn{4}{|c|}{ South Korea } & \multicolumn{4}{|c|}{ Finland } & \multicolumn{4}{|c|}{ UK } & \multicolumn{4}{|c|}{ Canada } & \multicolumn{4}{|c|}{ US } \\
\hline & & \multicolumn{2}{|c|}{ M } & \multicolumn{2}{|c|}{ W } & \multicolumn{2}{|c|}{$\mathrm{M}$} & \multicolumn{2}{|c|}{ W } & \multicolumn{2}{|c|}{$\mathrm{M}$} & v & & $\mathrm{M}$ & & W & & $\mathrm{N}$ & & W & \\
\hline & & $\mathrm{p} 25$ & $\mathrm{p} 75$ & $\mathrm{p} 25$ & $\mathrm{p} 75$ & $\mathrm{p} 25$ & $\mathrm{p} 75$ & $\mathrm{p} 25$ & $\mathrm{p} 75$ & $\mathrm{p} 25$ & $\mathrm{p} 75$ & $\mathrm{p} 25$ & $\mathrm{p} 75$ & $\mathrm{p} 25$ & $\mathrm{p} 75$ & $\mathrm{p} 25$ & $\mathrm{p} 75$ & $\mathrm{p} 25$ & p75 & $\mathrm{p} 25$ & p75 \\
\hline & 10-17 Sleeping & 440 & 550 & 430 & 550 & 520 & 660 & 520 & 660 & 540 & 670 & 540 & 680 & 477 & 645 & 480 & 653 & 480 & 665 & 485 & 675 \\
\hline & Personal care & 50 & 90 & 60 & 90 & 20 & 50 & 30 & 70 & 30 & 60 & 40 & 90 & 20 & 50 & 30 & 80 & 25 & 60 & 30 & 90 \\
\hline & Meals & 40 & 90 & 40 & 80 & 40 & 90 & 40 & 90 & 40 & 100 & 40 & 100 & 30 & 90 & 30 & 85 & 23 & 65 & 25 & 65 \\
\hline & Paid work & 70 & 300 & 80 & 340 & 60 & 270 & 75 & 295 & 40 & 430 & 35 & 320 & 150 & 460 & 180 & 450 & 120 & 393 & 150 & 450 \\
\hline & Study & 280 & 590 & 290 & 610 & 210 & 390 & 90 & 380 & 150 & 410 & 150 & 420 & 300 & 440 & 285 & 460 & 285 & 469 & 150 & 480 \\
\hline & Housework & 10 & 50 & 20 & 60 & 20 & 80 & 30 & 100 & 10 & 70 & 20 & 110 & 20 & 80 & 30 & 110 & 10 & 90 & 20 & 150 \\
\hline & Care for others & 10 & 50 & 20 & 60 & 10 & 30 & 20 & 60 & 20 & 85 & 20 & 60 & 30 & 60 & 38 & 283 & 4 & 45 & 5 & 61 \\
\hline & Active leisure & 30 & 90 & 30 & 70 & 50 & 170 & 40 & 120 & 60 & 150 & 40 & 120 & 90 & 180 & 60 & 175 & 63 & 228 & 45 & 160 \\
\hline & Screen-based leisure & 70 & 250 & 60 & 220 & 140 & 350 & 100 & 280 & 130 & 375 & 90 & 270 & 102 & 305 & 85 & 240 & 90 & 243 & 90 & 244 \\
\hline & Other leisure & 70 & 160 & 80 & 170 & 90 & 305 & 90 & 310 & 70 & 240 & 80 & 260 & 60 & 288 & 70 & 330 & 105 & 305 & 85 & 320 \\
\hline & 18-29 Sleeping & 410 & 540 & 420 & 550 & 450 & 640 & 470 & 620 & 460 & 620 & 460 & 630 & 435 & 600 & 450 & 600 & 445 & 648 & 474 & 640 \\
\hline & Personal care & 50 & 90 & 60 & 110 & 20 & 60 & 30 & 80 & 30 & 70 & 40 & 90 & 20 & 55 & 30 & 70 & 25 & 60 & 30 & 80 \\
\hline & Meals & 30 & 80 & 30 & 80 & 40 & 90 & 40 & 90 & 40 & 110 & 40 & 100 & 30 & 75 & 30 & 80 & 25 & 70 & 30 & 70 \\
\hline & Paid work & 340 & 520 & 310 & 490 & 330 & 520 & 300 & 470 & 400 & 560 & 340 & 520 & 415 & 550 & 385 & 520 & 350 & 532 & 284 & 525 \\
\hline & Study & 180 & 470 & 120 & 430 & 110 & 370 & 100 & 335 & 170 & 430 & 120 & 390 & 180 & 491 & 150 & 455 & 120 & 395 & 94 & 338 \\
\hline & Housework & 20 & 80 & 40 & 160 & 40 & 130 & 50 & 160 & 30 & 120 & 50 & 200 & 30 & 130 & 55 & 203 & 20 & 135 & 50 & 195 \\
\hline & Care for others & 20 & 80 & 60 & 260 & 40 & 180 & 60 & 320 & 30 & 120 & 70 & 230 & 30 & 120 & 90 & 305 & 10 & 120 & 35 & 197 \\
\hline & Active leisure & 40 & 110 & 40 & 90 & 50 & 130 & 40 & 110 & 50 & 120 & 40 & 100 & 60 & 170 & 50 & 120 & 60 & 180 & 25 & 108 \\
\hline & Screen-based leisure & 90 & 280 & 70 & 210 & 110 & 350 & 80 & 240 & 100 & 310 & 80 & 240 & 90 & 270 & 60 & 210 & 90 & 285 & 90 & 240 \\
\hline & Other leisure & 100 & 230 & 90 & 230 & 60 & 280 & 60 & 250 & 50 & 210 & 60 & 230 & 60 & 328 & 67 & 285 & 60 & 330 & 60 & 270 \\
\hline & 30-44 Sleeping & 420 & 530 & 410 & 520 & 440 & 580 & 450 & 580 & 440 & 580 & 450 & 580 & 420 & 540 & 435 & 555 & 425 & 585 & 450 & 600 \\
\hline & Personal care & 50 & 80 & 40 & 90 & 20 & 60 & 30 & 80 & 30 & 60 & 40 & 80 & 20 & 45 & 30 & 60 & 30 & 60 & 30 & 75 \\
\hline & Meals & 40 & 90 & 50 & 100 & 50 & 100 & 50 & 100 & 40 & 100 & 40 & 110 & 30 & 90 & 30 & 85 & 30 & 80 & 30 & 75 \\
\hline & Paid work & 370 & 550 & 290 & 480 & 390 & 530 & 360 & 490 & 400 & 560 & 250 & 490 & 430 & 585 & 375 & 523 & 360 & 590 & 245 & 513 \\
\hline & Study & 60 & 240 & 60 & 200 & 130 & 360 & 90 & 290 & 70 & 260 & 55 & 155 & 110 & 450 & 60 & 305 & 118 & 344 & 90 & 295 \\
\hline & Housework & 20 & 90 & 110 & 280 & 40 & 160 & 100 & 250 & 30 & 160 & 90 & 270 & 45 & 185 & 80 & 276 & 30 & 160 & 65 & 255 \\
\hline & Care for others & 30 & 90 & 30 & 180 & 30 & 130 & 30 & 170 & 30 & 140 & 50 & 190 & 45 & 150 & 60 & 213 & 30 & 152 & 45 & 195 \\
\hline & Active leisure & 40 & 110 & 50 & 100 & 40 & 140 & 40 & 100 & 50 & 120 & 40 & 110 & 60 & 149 & 35 & 105 & 30 & 160 & 27 & 90 \\
\hline & Screen-based leisure & 70 & 210 & 60 & 180 & 90 & 250 & 60 & 190 & 90 & 260 & 70 & 200 & 65 & 220 & 60 & 180 & 90 & 270 & 75 & 230 \\
\hline & Other leisure & 90 & 210 & 80 & 190 & 50 & 220 & 60 & 220 & 40 & 190 & 50 & 200 & 55 & 250 & 60 & 246 & 60 & 240 & 60 & 237 \\
\hline & 45-64 Sleeping & 410 & 510 & 410 & 510 & 440 & 570 & 450 & 570 & 420 & 560 & 450 & 570 & 420 & 540 & 430 & 565 & 425 & 597 & 450 & 600 \\
\hline & Personal care & 50 & 90 & 50 & 90 & 20 & 60 & 30 & 70 & 30 & 70 & 40 & 80 & 20 & 55 & 30 & 65 & 30 & 60 & 30 & 80 \\
\hline & Meals & 40 & 100 & 50 & 100 & 50 & 100 & 50 & 110 & 50 & 120 & 50 & 120 & 35 & 95 & 30 & 90 & 30 & 80 & 30 & 75 \\
\hline & Paid work & 330 & 530 & 250 & 500 & 390 & 520 & 360 & 490 & 360 & 550 & 270 & 500 & 415 & 575 & 375 & 525 & 330 & 580 & 285 & 530 \\
\hline & Study & 50 & 180 & 60 & 150 & 70 & 280 & 75 & 250 & 50 & 150 & 30 & 150 & 60 & 260 & 60 & 195 & 90 & 450 & 90 & 255 \\
\hline & Housework & 20 & 100 & 120 & 280 & 60 & 210 & 100 & 260 & 50 & 200 & 110 & 290 & 50 & 225 & 77 & 285 & 30 & 180 & 60 & 260 \\
\hline & Care for others & 10 & 60 & 20 & 70 & 20 & 100 & 10 & 80 & 20 & 80 & 20 & 70 & 30 & 150 & 40 & 180 & 15 & 105 & 16 & 123 \\
\hline & Active leisure & 50 & 140 & 50 & 120 & 50 & 150 & 50 & 130 & 40 & 130 & 40 & 120 & 45 & 150 & 40 & 120 & 30 & 180 & 25 & 105 \\
\hline & Screen-based leisure & 80 & 230 & 70 & 200 & 110 & 290 & 70 & 210 & 110 & 310 & 90 & 230 & 95 & 270 & 75 & 240 & 115 & 350 & 90 & 280 \\
\hline & Other leisure & 100 & 230 & 80 & 220 & 70 & 250 & 80 & 270 & 60 & 230 & 60 & 230 & 61 & 276 & 80 & 303 & 60 & 240 & 73 & 270 \\
\hline & $65+$ Sleeping & 440 & 560 & 450 & 570 & 470 & 590 & 490 & 590 & 450 & 560 & 450 & 570 & 450 & 570 & 470 & 590 & 475 & 600 & 475 & 620 \\
\hline & Personal care & 50 & 90 & 40 & 90 & 30 & 80 & 30 & 80 & 30 & 80 & 40 & 90 & 20 & 60 & 30 & 70 & 30 & 60 & 30 & 90 \\
\hline & Meals & 60 & 110 & 60 & 100 & 70 & 120 & 60 & 120 & 70 & 150 & 70 & 150 & 45 & 120 & 45 & 110 & 30 & 95 & 30 & 90 \\
\hline & Paid work & 130 & 460 & 70 & 410 & 80 & 360 & 105 & 340 & 110 & 450 & 80 & 320 & 184 & 510 & 165 & 468 & 180 & 508 & 165 & 505 \\
\hline & Study & 60 & 160 & 60 & 150 & 40 & 220 & 90 & 140 & 50 & 160 & 30 & 130 & 60 & 187 & 90 & 140 & 45 & 248 & 60 & 95 \\
\hline & Housework & 30 & 120 & 120 & 260 & 70 & 230 & 130 & 300 & 80 & 220 & 140 & 300 & 60 & 265 & 95 & 290 & 33 & 180 & 65 & 260 \\
\hline & Care for others & 20 & 90 & 20 & 100 & 10 & 60 & 20 & 120 & 10 & 70 & 20 & 70 & 45 & 230 & 30 & 147 & 10 & 105 & 10 & 108 \\
\hline & Active leisure & 60 & 160 & 50 & 120 & 50 & 150 & 30 & 110 & 40 & 150 & 40 & 110 & 45 & 165 & 30 & 120 & 30 & 150 & 20 & 96 \\
\hline & Screen-based leisure & 130 & 330 & 110 & 280 & 130 & 300 & 110 & 250 & 140 & 350 & 120 & 270 & 140 & 360 & 120 & 320 & 165 & 470 & 130 & 375 \\
\hline & Other leisure & 100 & 270 & 100 & 270 & 120 & 340 & 140 & 340 & 90 & 270 & 110 & 290 & 120 & 390 & 155 & 410 & 119 & 353 & 120 & 360 \\
\hline
\end{tabular}

Source: Multinational Time Use Study [32]. 
Figure A1. Gender Differences in Time Use by employment status type: employed, unemployed, retired
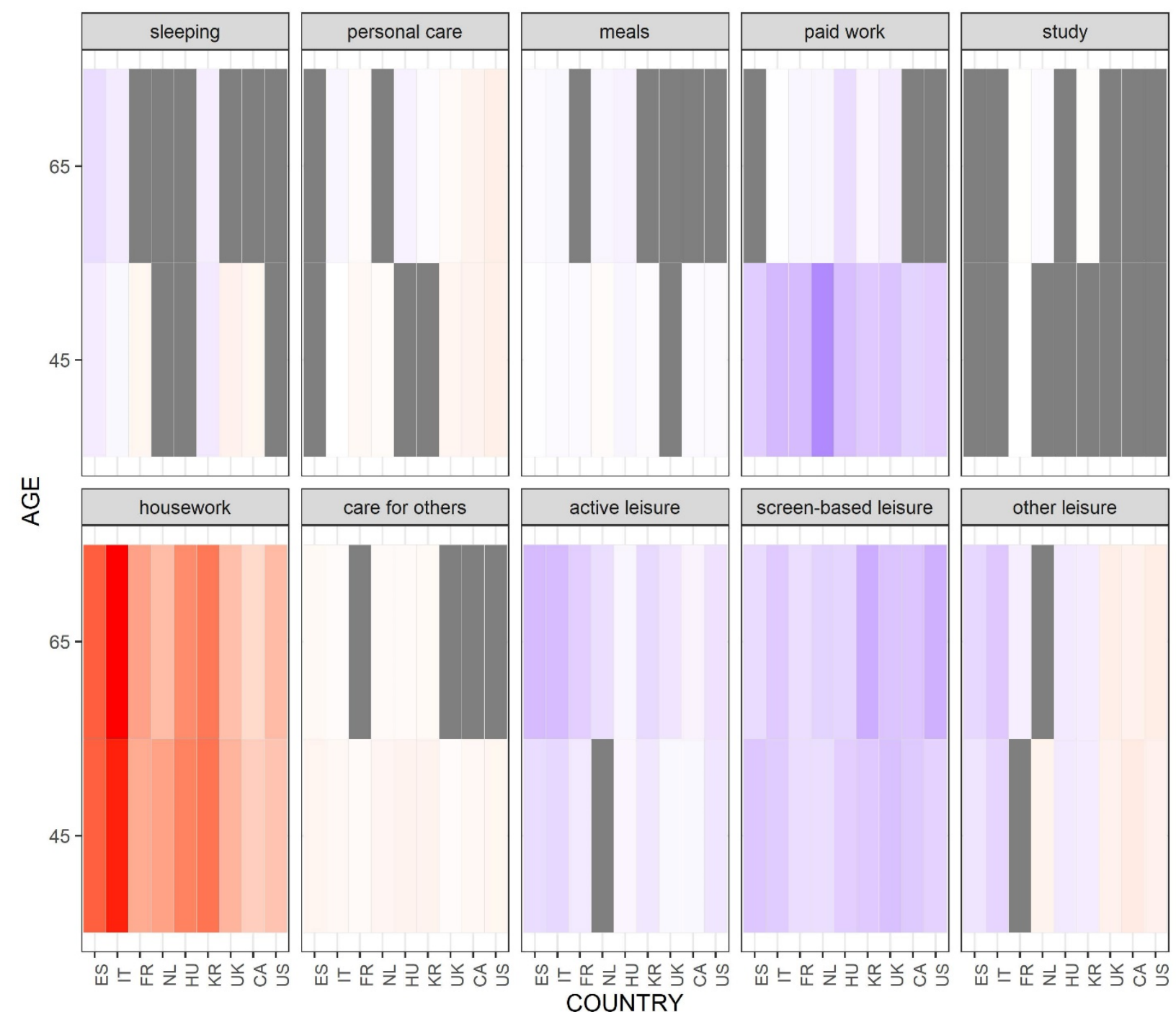

COUNTRY

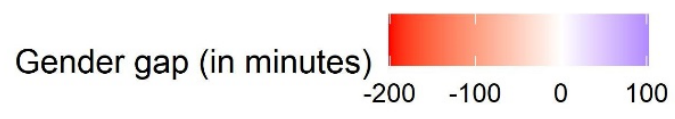

Coefficients not significant at $p$-value $<0.05$

Source: Own calculations from the Multinational Time Use Study [32].

Notes: Estimates correspond to the coefficient for Category Men (ref=Women) from the OLS regressions by country and age groups, including the groups 45-64 and 65 and older. All regressions control by day of the week, educational attainment, employment status in 3 categories, children in the household, and union status. For Finland it is not possible to separate retired and not employed with the data. 